\title{
Predictors of Self-Control During Emerging Adulthood: The Roles of Implicit Beliefs and Early Risk
}

\author{
Katy L. DeLong \\ West Virginia University, kldelong@mix.wvu.edu
}

Follow this and additional works at: https://researchrepository.wvu.edu/etd

Part of the Developmental Psychology Commons, and the Development Studies Commons

\section{Recommended Citation}

DeLong, Katy L., "Predictors of Self-Control During Emerging Adulthood: The Roles of Implicit Beliefs and Early Risk" (2020). Graduate Theses, Dissertations, and Problem Reports. 7572.

https://researchrepository.wvu.edu/etd/7572

This Dissertation is protected by copyright and/or related rights. It has been brought to you by the The Research Repository @ WVU with permission from the rights-holder(s). You are free to use this Dissertation in any way that is permitted by the copyright and related rights legislation that applies to your use. For other uses you must obtain permission from the rights-holder(s) directly, unless additional rights are indicated by a Creative Commons license in the record and/ or on the work itself. This Dissertation has been accepted for inclusion in WVU Graduate Theses, Dissertations, and Problem Reports collection by an authorized administrator of The Research Repository @ WVU.

For more information, please contact researchrepository@mail.wvu.edu. 
Predictors of Self-Control During Emerging Adulthood: The Roles of

Implicit Beliefs and Early Risk

Katy L. DeLong, M. S.

Dissertation submitted to the Eberly College of Arts and Sciences

at West Virginia University

in partial fulfillment of the requirements

for the degree of

Doctor of Philosophy

in Psychology

Amy Gentzler, Ph.D., Chair

Nick Turiano, Ph.D.

Natalie Shook, Ph.D.

Kristin L. Moilanen, Ph.D.

Department of Psychology

Morgantown, West Virginia

2020

Keywords: self-control, emerging adulthood, temptations, implicit beliefs, early risk

Copyright 2020 Katy L. DeLong 


\begin{abstract}
Predictors of Self-Control During Emerging Adulthood: The Roles of Implicit Beliefs and Early Risk
\end{abstract}

Katy L. DeLong

This study explored how early adverse experiences (i.e., low socioeconomic status, household chaos, attachment insecurity) and implicit beliefs about self-control (i.e., whether self-control is a limited or nonlimited resource) were associated with trait and momentary self-control in a sample of college students. As the first study to explore these factors together, individuals' implicit beliefs were tested as a moderator and meditator of the association between early risk and self-control. Participants $(N=214)$ first completed a baseline survey with the main predictors and trait self-control, followed by one week of experience sampling to assess momentary self-control, or success resisting desires. SPSS was used to conduct analyses with data collected at baseline, and HLM version 8 and Mplus version 8 were used for analyses with data collected via experience sampling. Higher levels of early risks predicted lower levels of trait self-control and less successful resistance against desires. Individuals who believed self-control was nonlimited reported higher trait self-control and marginally better success at resisting desires. Individuals' beliefs did not moderate the association between early risks and trait or momentary self-control. There was an indirect effect of early risk on trait self-control through individuals' implicit beliefs. However, this pattern was not found for momentary self-control. Together, these results indicated that implicit beliefs may partially explain the link between accumulated early risks and self-control, but that other contextual factors may play a large role for momentary self-control. This study offers a possible explanation for how early risk is associated with self-control, and a promising target for future interventions for individuals who have low self-control.

Keywords: self-control, emerging adulthood, temptations, implicit beliefs, early risk 


\section{TABLE OF CONTENTS}

I. Abstract (ppii)

II. Introduction (pp1-19)

III. Method (pp19-28)

1. Participants (pp19-20)

2. Procedure (pp20-22)

3. Measures (pp22-26)

4. Data Analysis Plan (pp26-28

IV. Results (pp28-36)

1. Preliminary analyses (pp28-30)

2. Primary analyses (pp30-36)

V. Discussion (pp36-50)

VI. References (pp51-66)

VII. Table 1: Number of Each Type of Caregiver Reported by Participants (pp67)

VIII. Table 2: Descriptive Statistics of Variables of Interest at Baseline Assessment (pp68)

IX. Table 3: Descriptive Statistics of Variables of Interest Measured with Experience Sampling (pp69)

X. Table 4: Bivariate Correlations Among Baseline Risk Composite Score, Separate Risk Indices, and Trait and Momentary Self-control (pp70)

XI. Table 5: Regression Associations Among Each Main Baseline Variables and Momentary Self-Control, Without Any Level 1 Variables (pp71)

XII. Table 6: Unstandardized Coefficients and Standard Errors for Regression Models Predicting Baseline Trait Self-Control (pp72) 
XIII. Table 7: Unstandardized Coefficients and Standard Errors for Regression Models of Level 1 and Level 2 Predictors on Momentary Self-Control (pp 73)

XIV. Figure 1: Conceptual model of motivated behavior as presented by Hofmann, Baumeister, Forster, and Vohs (2012a) (pp74)

XV. Figure 2: Conceptual model of early risk and self-control beliefs as individual difference factors that impact self-control (pp75)

XVI. Figure 3: Conceptual model of early risk predicting self-control ability through selfcontrol beliefs (pp76)

XVII. Figure 4: Graph of the frequency of participants by total accumulated early risks (pp77)

XVIII. Figure 5: Mediation model with total early risks, implicit beliefs, and trait self-control $(\mathrm{pp} 78)$

XIX. Figure 6: Mediation model with total early risks, implicit beliefs, and resistance success (pp79)

XX. Appendices (pp80-121)

XXI. Appendix A: Baseline Survey Measures (pp80-87)

XXII. Appendix B: Experience Sampling Measures- Desire and Resistance Success (pp88-90)

XXIII. Appendix C: Follow-up Measures (pp91-94)

XXIV. Appendix D: Additional Baseline Descriptive Analyses (pp95-103)

XXV. Appendix E: Additional Experience Sampling Descriptive Analyses (pp104-105)

XXVI. Appendix F: Analyses with Follow-up Assessment (pp106-115)

XXVII. Appendix G: Exploratory Comparisons Among Final Sample and Sub-samples (pp116119)

XXVIII. Appendix H: Primary Analyses with Original Resistance Success Measure (pp120-121) 
Predictors of Self-Control During Emerging Adulthood: The Roles of Implicit Beliefs and Early Risk

Learning to manage one's thoughts, emotions, and behaviors is a necessary part of development. This ability, well known as self-control (Moilanen, 2007; Tangney, Baumeister, \& Boone, 2004), has important implications for a multitude of life outcomes such as physical health, wealth, and wellbeing (Moffitt et al., 2011; Moilanen, 2007; Tangney et al., 2004). Although developing adequate self-control is essential for outcomes across the lifespan, it is especially important for emerging adults (i.e., 18-25 year-olds). Proposed as a new stage of the lifespan, emerging adulthood is the developmental period tasked with gradually making the transition to adulthood (Arnett, 2000; Arnett, 2007). Emerging adults have mostly left home, started higher education, and begun working, making them less dependent on caregivers than their adolescent selves, but they have not taken on the full responsibilities of young adulthood (Arnett, 2000; Arnett, 2007). As such, this is a time of experimentation with adult roles and responsibilities (e.g., exploring career options, romantic relationships), in which they begin to act more autonomously and make important life decisions for themselves (Arnett, 2000). Emerging adults with more self-control may be better able to make good decisions. Among emerging adults in college, more self-control is related to fewer problematic outcomes, such as fewer internalizing symptoms (Park, Edmondson, \& Lee, 2012), less substance use (Ford \& Blumenstein, 2013; Gibson, Schreck, \& Miller, 2004; Piquero, Gibson, \& Tibbetts, 2002; Tangney et al., 2004), and low grade point average (Kirby, Winston, \& Santiesteban, 2005; Tangney et al., 2004). Overall, self-control is a key component for successful adjustment in emerging adulthood and beyond. 
The use of self-control emerges out of the interaction between desires and personal goals. Hofmann, Baumeister, Forster, and Vohs (2012a) describe how self-control is an act of resisting the urge to satisfy desires or temptations, which ultimately allow individuals to pursue goals (see Figure 1 for conceptual model). In this model, individuals are motivated to satisfy desires, but it may also conflict with other goals. The conflict between the desire and personal goals gives reason to enact resistance over the desire. However, not all individuals experience temptations in the same way or are able to use the same degree of resistance when experiencing them, even when the desire conflicts with goals. For example, adults experience desires across a varied set of domains (e.g., bodily desires like food and drink, social contact, social media use), and the strength of those desires vary (Hofmann, Vohs, \& Baumeister, 2012b). Importantly, one study identified some contextual and individual difference factors that can affect success at resisting desires (e.g., alcohol consumption, narcissistic entitlement; Hofmann et al., 2012a). Further research is needed to identify the factors that influence the use of self-control.

Individual difference factors that are of special interest in the present study are implicit beliefs about self-control and early adverse life experiences (i.e., low socioeconomic status, chaos in the home, and attachment insecurity). Implicit beliefs about self-control and early risks had not previously been investigated together for their combined effects on self-control, but doing so could offer promising new avenues for research and interventions. Many adverse experiences are beyond the ability of youth to change (e.g., low socioeconomic status, confusion and noise in the home environment). This may make designing interventions aimed to promote youth development within these circumstances challenging. However, there is evidence that implicit beliefs are modifiable through intervention (e.g., beliefs about intelligence; Blackwell, Trzesniewski, \& Dweck, 2007; Paunesku et al., 2015; Yeager et al., 2016), and there is evidence 
that self-control implicit beliefs can be manipulated in the lab (Vohs, Baumeister, \& Schmeichel, 2012). Thus, the present study investigated how implicit beliefs might qualify or explain selfcontrol deficits among those exposed to early adverse experiences. Investigating the combined effects could offer a promising target for intervention among individuals with adverse circumstances outside of their control.

The present study began to extend the literature by examining how early risk factors and beliefs about self-control were associated with and operate together to predict self-control. Namely, the beliefs that individuals hold about self-control were explored as a moderator on the way early risk associated with self-control (e.g., a limited resource belief may exacerbate the adverse effects of early risk factors). In contrast, early risk factors were examined for their association on the beliefs individuals hold (e.g., if more early risks related to a limited resource belief), and if that associated with subsequent self-control (e.g., if a limited resource belief associated with lower self-control).

Additionally, another goal of the study was to investigate self-control in a comprehensive way by using two forms of measurement: a global measure and an experience sampled measure of self-control. There are several benefits to using global and momentary measures of selfcontrol in the present study. The use of momentary assessments of self-control enabled the measurement of relevant situational factors. Only measuring self-control globally ignores the rich context about when people are successful at resisting desires, and the reasons they enact resistance at all. A nuanced examination of self-control that compares global and momentary measures of self-control allows for critical examination of why some individuals appear to be consistently successful at resisting their desires, while others appear to perpetually 'give in' to temptation. Some previous research has found that self-control shows instability across daily 
measures (e.g., differences in self-control across a day; Hofmann et al., 2012b), but others have found it remains relatively stable (e.g., little variability day-to-day; Zhang, Smolders, Lakens, \& IJsselsteijn, 2018). The potential individual variability of self-control in daily life may be lost with only a global measure of self-control. Moreover, multiple measures of self-control are needed as they may capture different aspects of the process of motivated behavior (e.g., desire strength, conflict with goals; see Figure 1; Hofmann et al., 2012a), which may subsequently relate to predictors of self-control differently. For example, Hofmann et al., (2012a) found that the presence of others was likely to affect an individual's ability to successfully resist a desire, but did not affect the strength of that desire. Even trait self-control was differentially associated with fewer attempts to resist desires (an index of momentary self-control) and experiencing weaker desires, but was not associated with whether or not the resistance attempt was effective (i.e., if the desire was satisfied or inhibited; Hofmann et al., 2012a). Overall, increasing understanding of how self-control operates in day-to-day life and how it differs from global assessments could improve the design of interventions for people with self-control deficits.

Additionally, most studies of self-control find consistent patterns of associations between self-control and self-reported outcomes (e.g., self-reported school performance) and observed behaviors (e.g., time spent working on a challenging task; de Ridder, Lensvelt-Mulders, Finkenauer, Stok, \& Baumeister, 2012). However, there is evidence that the strength of the associations between self-control and self-reported outcomes differs from that of self-reported self-control and observed behaviors. A meta-analysis found that studies measuring self-reported global self-control tend to find stronger associations between it and self-reported outcomes than studies using observed outcome behaviors (de Ridder et al., 2012). This work further suggests that the context and specificity of self-control acts are not well understood. Taken together, it is 
clear there is a need to further investigate if daily self-control success remains consistent at each use. If measurements of self-control are discrepant, it could imply that people are less accurate in recognizing their self-control abilities, or that their global self-reported self-control is subject to social desirability or recall bias (Schwarz, 1999). Alternatively, it might indicate global assessments of self-control are not capturing a potentially context-dependent process of using self-control in daily life, which may indicate predictors and outcomes of self-control may be differentially associated as well.

The possibility of discrepancies highlights the need to understand what factors (e.g., implicit beliefs and early risk) may impact daily self-control success variability. Previous research has not examined if predictors similarly associate with self-control when measured multiple ways (e.g., a one-time assessment of trait self-control and self-control use throughout a day). Thus, the present investigation examined how early risk and implicit beliefs about selfcontrol were associated with both trait (self-report scale) and momentary (experience sampling method or ESM) self-control.

\section{Predictors of Self-Control}

Self-control is posited to be part of a larger process of motivated behavior, as outlined by Hofmann, Baumeister, Forster, and Vohs (2012a). Figure 1 shows their model of motivated behavior as a process of experiencing a desire, the presence of conflict between desire and other personal goals, attempting to resist the desire (act of self-control), and then the outcome of whether or not the desire was ultimately satisfied despite attempts to resist it (self-control success). One reason there are individual differences in self-control may be due to the various factors that may affect different steps of this process (Hofmann et al., 2012a). Beliefs about selfcontrol affect performance on self-control tasks, in that believing self-control is a limited 
resource (compared to nonlimited) results in lessened self-control use (Job et al., 2010).

Additionally, early adverse experiences have been identified as contributors to individual differences in self-control. For example, risk factors like low socioeconomic status and worse parent-child relationships were associated with lower self-control in children and adolescents (e.g., Bernier, Carlson, Whipple, 2010; Brown, 2009; Fuller-Rowell, Evans, Paul, \& Curtis, 2015; Kahn, Holmes, Farley, \& Kim-Spoon, 2015). Overall, self-control appears to be systematically related to early life risks and beliefs about self-control, however the present study is among the first to investigate if these factors operate together, and if these factors similarly associate with trait and momentary self-control.

\section{Early Risk}

Early adversity goes by a few names (e.g., childhood misfortune, cumulative risk), but generally refers to exposure to any nonnormative situation or event experienced as a youth that can compromise individual's healthy development in the future (Felitti et al., 1998; Turiano, Silva, McDonald, \& Hill, 2017). The experience of adversity in early life is of prime importance for the development of self-control. The consequences of adversity are well established across development generally (e.g., academic achievement, internalizing symptoms, physical health; Brooks-Gunn \& Duncan, 1997; Felitti et al., 1998; Letourneau, Duffett-Leger, Levac, Watson, \& Young-Morris, 2011), many of which coincide with the outcomes related to self-control. Understanding the role of adversity on self-control may ultimately elucidate how early risk factors contribute to so many negative outcomes across development.

Investigations on the effects of early adversity in relation to self-control are substantial and growing. Separately, socioeconomic status, chaos in the home, and insecure attachment with caregivers are three important early risk factors that may have lasting effects on self-control. For 
each of these, much of this research has concentrated on youth, with less extension into the emerging adulthood period (see Blair \& Raver, 2012 for review of self-regulation and adversity in children; see Pallini et al., 2018 for meta-analysis of parental attachment and effortful control in children under 18 years old). However, a primary interest of the present study was how accumulated adverse experiences (e.g., a combination of living in low socioeconomic status, high levels of chaos in the home, and insecure attachment to caregivers) related to the use of selfcontrol. The extensiveness of risks an individual is exposed to can result in a negatively incremental effect on child development (Brooks-Gunn \& Duncan, 1997). As such, individuals with more risk exposure may have greater deficits in self-control. Cumulative risk has been shown to negatively affect outcomes related to self-control in childhood (Brown, 2009; Evans, 2003; Evans, Li, \& Whipple, 2013; Trentacosta et al., 2008), which could extend into emerging adulthood. By emerging adulthood, individuals have had more time to accumulate exposure to potentially adverse experiences. Therefore, the present study assessed early risk factors that were present before emerging adulthood.

The link between cumulative early risks and self-control might be explained in various ways. One possibility is that exposure to adversity may associate with low self-control through facilitating distrust in others. Trust in others emerges out of increasing interactions with others including promises to work together to achieve a positive outcome (Rotenberg, 1995; Sutter \& Kocher 2006). Social distrust in adults has been found to diminish children's ability to delay gratification for larger later rewards (Michaelson \& Munakata, 2016). If distrust in others emerges out of adverse experiences, emerging adults may similarly demonstrate low self-control. But the role of other people in an individual's experience of adversity is likely complex. For instance, caregivers are heavily responsible for a youth's socioeconomic status and home 
conditions, and play a large role in the attachment style the individual develops toward that caregiver. Also, there are many other adults (e.g., teachers, police officers, neighbors) and peers that would interact with an individual throughout exposures to adversity. Perhaps adversity may pose unique challenges to individuals to keep promises with one another, resulting in trust violations when promises are broken, which may increase with added exposures to adversity. Violations of trust may lead to a preference to satisfy desires because it is rewarding, unlike waiting for an untrustworthy other person who may not 'deliver' on the promised rewards (Michaelson \& Munakata, 2016). In this way, accumulated early risks may promote greater social distrust in emerging adults, which associates with a preference for satisfying desires in the moment instead of resisting them.

However, the leading theorized mechanism for the relation between early adversity and regulatory capacity is through chronic stress (Blair \& Raver, 2012). Simply, early adversity affects the stress response system at multiple levels (e.g., stress hormones, caregiving quality), which alters self-regulatory ability (Blair \& Raver, 2012). More specifically, early adversity alters the functioning of our stress response system by elevating glucocorticoid levels over extended periods of time (e.g., cortisol; Blair, 2010; Meaney, 2001). Outwardly, the altered stress response manifests as increases in stress reactivity and hypervigilance (Blair, 2010; Meaney, 2001). The increase in glucocorticoids is particularly problematic in the prefrontal cortex, which undergoes synaptic changes due to the rise in glucocorticoids (Blair, 2010). This localized change can result in the changed reactions to experience (e.g., heightened stress reactivity), and is posited to be responsible for decrements in self-control. The stress response changes are associated with changes in memory functioning, diversion of attention to the environment (e.g., scanning for threats instead of on efforts toward goal-related processes), and feeling tired and 
apprehensive (Meaney, 2001). The connection between adversity, neuroendocrine changes, and regulatory ability is supported by empirical investigations with animal models and youth (Blair, 2010; Blair et al., 2011; Blair \& Raver, 2012; Meaney, 2001). The present study will extend the literature by investigating if the link between early adversity and self-control extends into emerging adulthood, which may suggest that the neurological changes persist beyond childhood. In the following paragraphs, each of the previously named early risk factors (socioeconomic status, home environment, and attachment with caregivers) will be reviewed for their separate associations with self-control to demonstrate the importance of their inclusion in a cumulative risk model of adversity.

Socioeconomic status. Socioeconomic status (SES) generally represents economic or social status, and can be comprised of several components (e.g., education, household income; Bradley \& Corwyn, 2002). Although little research has examined past SES in relation to emerging adult self-control, low SES is associated with less self-control in youth and adults. Children from low SES backgrounds tend to display less ability to wait for rewards (e.g., delay gratification; Evans \& English, 2002; Evans \& Rosenbaum, 2008). Children and adolescents from low SES backgrounds tend to persist less on a challenging task compared to their more affluent peers (Brown, 2009; Fuller-Rowell et al., 2015). Additionally, infants from low SES backgrounds, at one and two years old, displayed low executive functions two years later compared to their high SES peers (Blair et al., 2011; Raver, Blair, \& Willoughby, 2013).

Limited research with adults has also found that low SES is associated with reduced selfcontrol (Hostinar et al., 2015; Lui et al., 2012; Mani, Mullainathan, Shafir, \& Zhao, 2013). Additionally, low SES in adults has been related to several outcomes that are known to relate to self-control (e.g., worse parenting behaviors, more crime, worse mental and physical health, 
higher mortality risk, less educational attainment; Galobardes, Shaw, Lawlor, Lynch, \& Smith, 2006; Glymour, Ertel, \& Berkman, 2009; Nikulina, Widom, \& Czaja, 2011; Poulton et al., 2002; Walpole, 2003). For example, low SES predicted less positive parenting behaviors through low self-control (measured through executive functions; Deater-Deckard, Chen, Wang, \& Bell, 2012). Taken together, low SES relates to less self-control in youth and adults through direct and indirect findings (e.g., SES linked to outcomes likely through low self-control).

Chaos in the home. Chaotic living conditions refers to a home environment that has substantial noise, a high density of people for the living area, and few routines (Evans, Gonnella, Marcynyszyn, Gentile, \& Salpekar, 2005). Although low SES homes are more likely to be chaotic compared to wealthier homes, families of diverse SES backgrounds have reported varied living conditions (Evans, 2004; Evans et al., 2005; Evans \& Marcynyszyn, 2004; Fuller-Rowell et al., 2015; Hughes \& Ensor 2009). Living in unpredictability may interfere with self-control processes through alterations or disruption of interactions in the immediate environment (e.g., interactions with parents; Bronfenbrenner \& Evans, 2000; Evans et al., 2005) that would ordinarily promote regulation. Moreover, unpredictable homes may add stress to the environment, thus taxing regulatory systems to cope with environmental demands (Evans \& Kim, 2013).

A growing literature indicates that more chaotic living conditions relate directly to less regulatory ability in children and adolescents via teacher ratings, cognitive control, persistence, and delay of gratification tasks (Evans, 2003; Evans et al., 2005; Fuller-Rowell et al., 2015; Hughes \& Ensor, 2009; Vernon-Feagans, Willoughby, \& Garrett-Peters, 2016). Overall, youth living in homes characterized by unpredictability and noise are more likely to have self-control 
difficulties. The effects from early environmental conditions are also expected to remain for emerging adults; though this has not been previously examined.

Attachment. The attachment system is a security regulation system, which encourages closeness with others (Ainsworth \& Bowlby, 1991; Bretherton, 1992). Attachment security emerges in infancy during interactions between the infant and caregiver. Infants with a secure attachment form internal working models between themselves and others in which they learn to depend on caregivers to soothe them when upset (Ainsworth, 1979). Through this process, securely attached infants learn strategies that effectively manage emotional upsets without becoming overwhelmed, allowing infants to engage in other forms of behavior such as exploration of their environment. When infants cannot rely on caregivers, an insecure attachment (anxious or avoidant) is formed, resulting in the development of strategies to manage distress that are less effective (compared to those used by securely attached peers). Avoidantly attached infants attempt to manage distress alone by downregulating their distress. Anxiously attached infants attempt to keep attachment figures close by to help manage their near chronic feelings of distress (Cassidy, 1994; Mikulincer, Shaver, \& Pereg, 2003). These forms of self-soothing and emotion regulation are learned patterns of responses that continue throughout one's life with the potential to continually affect one's ability to manage behaviors (e.g., pursue goals).

Empirical evidence supports the positive association between secure attachment and selfcontrol from infancy to adulthood (Drake, Belsky, \& Fearon, 2014; Kochanska, Philibert, \& Barry, 2009; Orehek, Vazeou-Nieuwenhuis, Quick, \& Weaverling, 2017; Pallini et al., 2018). Insecure avoidantly attached emerging adults developed strategies relevant to avoiding distress (Maier et al., 2005), but which interfered with other attempts to self-regulate or cope (Gentzler, Kerns, \& Keener, 2010; Pallini et al., 2018; Zimmermann \& Iwanski, 2015). Insecure anxiously 
attached emerging adults also exhibited less adaptive self-control as evidenced by coping (Gentzler et al., 2010; Mikulincer, Florian, \& Weller, 1993). In contrast, emerging adults with secure attachment (compared to insecure attachment) were better able to control their attention to balance attachment-related and task-relevant stimuli as indexed by neural activity (Warren et al., 2010). Individuals with insecure attachments (with peers and romantic partners) also exhibited interference with initiating a goal and continuing goal pursuit (Orehek et al., 2017). Thus, the less effective management of arousal and stress associated with insecure attachments may undercut overall self-control abilities in emerging adults.

\section{Implicit Theories}

Implicit beliefs are assumptions held about how the world works (Dweck, 1996). For instance, Dweck and colleagues have found that the belief that intelligence can grow (growth mindset) can improve performance or effort on challenging academic tasks, whereas believing intelligence is innate or fix is linked to less effort (Blackwell et al., 2007; Dweck, 1999; Molden \& Dweck, 2006). Because other implicit theories relate to their respective outcomes, beliefs about self-control may similarly relate to self-control use.

Implicit theories of self-control. Individual differences in self-control performance have been found when individuals have differing implicit beliefs about self-control (Job, 2016). Individuals with a limited resource theory (i.e., belief that using self-control drains the resource) typically show worsened self-control performance following a demanding task compared to individuals with a nonlimited resource theory (i.e., belief that using self-control energizes the resource for the next time; Job, Dweck, \& Walton, 2010; Job, Walton, Bernecker, Dweck, \& 2015). The implicit theories of self-control stem from the strength model of self-control, which suggests that self-control deteriorates with repeated use (Baumeister, Vohs, \& Tice, 2007; 
Muraven \& Slessareva, 2003). It should be noted that it is unknown if self-control is truly drawn from a limited or nonlimited resource, which highlights a need to consider other models of selfcontrol (e.g., executive function model of self-control, Barkley, 2001; Hofmann, Schmiechel, \& Baddeley, 2012c). Although there are some distinctions among self-control theories, there is also considerable overlap. For instance, the executive function model and the strength model both emphasize that self-control involves inhibiting a dominant response, but there are differences on where that ability originates. The strength model suggests self-control stems from an unknown resource that diminishes with use (Baumeister et al., 2007). The executive function model suggests that self-control originates in the prefrontal cortex through the use of executive functions which enable individuals to work toward goals (Barkley, 2001). For example, working memory can enable monitoring of an individual's situation or progress in reaching a goal (Hofmann et al., 2012c).

Whether or not self-control truly draws from a limited or nonlimited resource, individuals' beliefs about self-control appear to predict their actual self-control attempts. The nonlimited believers (compared to limited believers) can generally continue to use self-control even after demanding tasks (Job et al., 2010). A series of studies found that individuals' implicit beliefs of self-control moderated the effects of ego depletion (i.e., state of lessened self-control following a demanding task) on subsequent self-control performance (Job et al., 2010). Specifically, among individuals who completed demanding tasks, those with a limited resource belief performed worse on subsequent self-control tasks than those with a nonlimited belief. In addition, there were no differences among participants that had completed demanding tasks or not, if they held a nonlimited belief. 
Studies often use an experimental paradigm asking participants to use self-control in multiple tasks such as completing a stimulus detection task (e.g., cross out all instances of a specified letter on a page of text), and measuring participant success to continue using selfcontrol on the next task (e.g., Stroop task; Job, Dweck, \& Walton, 2010). However, these assessments generally occur in isolation, without other temptations particularly relevant to the participant. Less understood is how self-control outside a laboratory relates to the limited or nonlimited resource belief. Some research has found that a limited resource belief predicted worse self-regulation over several weeks when self-control demands were high (Job et al., 2010; Klinger, Scholer, Hui, \& Molden, 2018). For example, participants with a nonlimited theory exhibited better self-control over a college semester as evidenced by less unhealthy eating and drinking, less procrastination, fewer impromptu purchases, better emotion regulation, and better time management, when life demands were high (e.g., heavy course load, anticipated academic stressors; Job et al., 2015). Conversely, this effect was not significant when demands were low. When demands were low, few self-regulation failures occurred and there was not a significant difference in number of regulation failures between individuals that held a limited vs. nonlimited resource belief. Overall, individual differences of implicit beliefs about self-control seem to associate with later acts of self-control.

Only a few investigations of self-control have focused on the use of self-control in 'real time' using experience sampling methodology. These studies found that there are antecedent factors that affect subsequent self-control in a given moment (e.g., conflict between desire and goals, location at time of desire, motivation for goals; Hofmann et al., 2012a; Milyavskaya, Inzlicht, Hope, \& Koestner, 2015). For instance, Hofmann et al. (2012a) found in a sample of adults that when participants reported strong desires, they were more likely to satisfy them rather 
than resist them (use self-control). Additionally, the more strongly the reported desires conflicted with personal goals, the better participants were able to resist the desire. However, many possible antecedents of self-control still need to be addressed, particularly the effect of the nonlimited versus limited resource belief on momentary self-control. However, only one study is known to have investigated the impact of implicit beliefs on self-control use through momentary assessments. Using daily diaries to investigate resource beliefs and daily self-control, Bernecker and Job (2015) found that despite experiencing a demanding day, having a nonlimited belief of self-control predicted significantly more effective goal striving, less exhaustion, and fewer demanding tasks on the next day. This study suggests a nonlimited belief is protective against factors that may diminish self-control (Bernecker \& Job, 2015). The finding that believing selfcontrol is drawn from a nonlimited resource provides a promising direction for research on implicit beliefs and momentary use of self-control, such that implicit beliefs may associate with success resisting momentary despite the presence of influences that may make that difficult.

\section{Considering Both Early Risk and Implicit Beliefs}

Both early risk factors and implicit beliefs about self-control appear to impact the ability to use self-control effectively (e.g., successfully ignoring temptations). The present study was the first to investigate their combined effects on self-control, so both moderation (see Figure 2) and mediation (see Figure 3) were explored.

Implicit beliefs as a moderator. The factors that influence self-control do not operate in isolation. It is unrealistic to study the impact of many factors independent of one another as these associations may hinge on the presence of other factors. For instance, risk factors are associated with low self-control. However, not all individuals who have been exposed to risks will exhibit less self-control. Emergent research suggests that implicit beliefs may explain for whom or when 
risk factors associate with outcomes. Claro, Paunesku, and Dweck (2016) found that implicit theories about intelligence (i.e., that intelligence is malleable or fixed) determine whether SES is linked to academic achievement. Specifically, the belief that intelligence is malleable buffered against the link between low SES and low academic achievement. This study is the only known investigation of the moderating effect of implicit beliefs on the SES and achievement link (Claro et al., 2016). Because implicit beliefs are domain specific (e.g., beliefs about intelligence affect intelligence and academic achievement specifically; Dweck, 1996), the association between early risk and self-control may be similarly contingent on self-control implicit beliefs. Accordingly, the present study explored under which conditions (participants reporting greater nonlimited or limited beliefs) the link between early risk and self-control is most apparent (see Figure 2). Specifically, more early risk factors were expected to relate to low self-control for those with a limited resource belief.

Implicit beliefs as a mediator. Exposure to risks may also influence the beliefs individuals hold, which may in turn influence overall self-control (see Figure 3). Claro et al. (2016) found initial evidence that lower SES predicted a greater likelihood of holding a fixed mindset about intelligence in children. Although Claro et al. (2016) did not offer a possible explanation, one stems from the cumulative risk models. Early adversity may chronically heighten individuals' stress response systems, altering how an individual reacts to future experiences (Blair \& Raver, 2012). These individuals may perceive demanding situations as more threatening, resulting in highly stressed reactions to even small stressors. Highly stressed reactions could result in feeling fatigued and less able to work toward any task, including using self-control. Regarding Claro et al.'s (2016) study, children with financial risk (i.e., low SES) may have developed a fixed mindset of intelligence through a similar process. Chronic stress 
may have fatigued the children, resulting in beliefs that they only have so much effort or ability to use their intelligence. This could then lead to less effort on academic tasks. The present study will explore if more early risk factors are associated with a limited resource self-control belief, which may subsequently predict lower self-control.

\section{Present Study}

The present study had several aims. The first was to replicate the associations between self-control and established predictors in a sample of emerging adults. Namely, cumulative early risk (insecure attachment with caregivers, home chaos, SES) and the belief that self-control uses a limited resource were expected to be associated with lower self-control. Second, the present study investigated how implicit beliefs of self-control moderated the association between early risk factors and self-control. Finally, the present study explored if implicit beliefs of self-control mediated the association between early risk factors and self-control. These predictors of selfcontrol largely have not been explored during emerging adulthood, nor have these factors been examined together. The current study provided much needed findings on these predictors and how they contribute to self-control without manipulation or intervention. These associations were explored with two measures of self-control: trait self-control by self-report survey and resistance to desires by experience sampling. The use of multiple measures of self-control will better elucidate any unique effects of these factors on trait-like self-control compared with deployment of resistance of desires in the moment. Previous research has not examined predictors of both measures of self-control in the same study, which made the present study novel in this regard.

\section{Research Questions and Hypotheses}

\section{Research Question 1}


Does early risk relate to self-control?

Hypothesis 1a. Individuals who report higher risk (i.e., lower SES, more home chaos, more insecure attachment) will report lower trait self-control at baseline.

Hypothesis 1b. Individuals who report higher risk (i.e., lower SES, more chaos, more insecure attachment) will report less self-control (i.e., "How successful were you at resisting the desire?") via experience sampling.

\section{Research Question 2}

Do implicit beliefs about self-control relate to self-control?

Hypothesis 2a. Individuals who report greater belief that self-control is drawn from a nonlimited resource will report higher trait self-control at baseline.

Hypothesis 2b. Individuals who report greater belief that self-control is drawn from a nonlimited resource will report higher self-control (i.e., "How successful were you at resisting the desire?") via experience sampling.

\section{Research Question 3 (exploratory)}

Do beliefs about self-control moderate the association between early risk and selfcontrol?

Hypothesis 3a. The negative association between early risk and trait self-control will be stronger for those with the belief that self-control uses a limited resource. Thus, individuals with more risk factors and a limited belief, will have lower trait self-control at baseline.

Hypothesis 3b. The negative association between early risk (i.e., lower SES, more chaos, more insecure attachment) and resistance to desires will be stronger for those with the belief that self-control uses a limited resource. Thus, individuals reporting more risk factors and a limited 
belief, will have less self-control (i.e., "How successful were you at resisting the desire?’) via experience sampling.

\section{Research Question 4 (exploratory)}

Does early risk relate to self-control beliefs?

Hypothesis 4. Individuals who report higher risk (i.e., lower SES, more chaos, more insecure attachment) will report less nonlimited (more limited) resource beliefs.

\section{Research Question 5 (exploratory)}

Do self-control beliefs mediate the association between early risk and self-control?

Hypothesis 5a. Individuals who report higher risk (i.e., lower SES, more chaos, more insecure attachment) will predict less nonlimited (more limited) resource beliefs, which will predict low trait self-control at baseline.

Hypothesis 5b. Individuals who report higher risk (i.e., lower SES, more chaos, more insecure attachment) will predict less nonlimited (more limited) resource beliefs, which will predict low self-control (i.e., "How successful were you at resisting the desire?") via experience sampling.

\section{Method}

\section{Participants}

The final sample analyzed for the present study includes 214 emerging adults $(M=19.11$, $S D=1.17)$, who are predominantly White $(87.90 \%)$, early in their college education $(79.00 \%$ in first or second year of college), and most were women (79.80\%). Up to 400 participants could sign up to participate in the study on SONA, of which 368 completed the initial survey. Of them, $253(68.75 \%$ of the 368$)$ properly enrolled to receive text messages for the experience sampled portion of the study, of which 244 (96.44\% of the 253$)$ passed two of three validity checks in the 
baseline survey. Additionally, because there were five participants that completed zero texted questionnaires and 25 participants who reported experiencing zero desires during ESM period (resulting in no experience sampling data to analyze), these participants were dropped from analyzes. Thus, the final sample included 214 participants with baseline and experience sampled data.

There are no uniformly agreed upon standards for estimating power and sample size within hierarchical linear modeling (HLM; Castelloe \& O’Brien, 2000; Hox, Moerbeek, \& van de Schoot, 2010). This is especially true with experience sampling data, in which only a few guidelines exist (e.g., Monte Carlo simulations; Bolger \& Laurenceau, 2013; Hox et al., 2010). A large sample size is identified as the best way to reach adequate power for intensive longitudinal designs (Bolger et al., 2013; Hox et al., 2010; Maas \& Hox, 2005). One Monte Carlo simulation provided by Bolger and Laurenceau (2013) found that to reach $80 \%$ power to detect one between-subjects effect at $p<.05,125$ participants providing only 16 time points would be sufficient. Prior studies with experience sampling including a minimum five reports per day for seven days have successfully detected significant effects with roughly 200 participants (i.e., four between-subjects effects; Hofmann et al., 2012a; two between-subjects effects; Milyavskaya et al., 2015). The current study had three between-subjects effects (total early risks, implicit belief, and their interaction) and each participant provided a maximum of 35 reports. Based on the above examples, a final sample size of 214 participants should have been sufficient to detect significant effects.

\section{Procedure}

Eligible participants were college students between ages of 18 and 25 years who were enrolled in psychology courses at a large mid-Atlantic university. These participants were 
recruited through advertisements in psychology courses and the study was available through the university's SONA system. Interested participants signed up for the study on SONA. Students gave informed consent after reading an explanation of the study, which consented for participation in all parts of the study (baseline survey, ESM for one week, and a follow-up survey). The baseline survey took participants about 45 minutes. Participants were also asked to give their cell phone provider and phone number to receive texts with survey links, and confirmed they could access an internet browser through their phone. Their cell phone numbers and email addresses were used to link their responses when data collection was complete and to contact them during the duration of the study (if needed), but were then deleted from the dataset. Three validity check questions (e.g., "Answer '1 strongly disagree for this question”) were incorporated throughout the baseline survey to verify participants are reading the questions fully. After completing the baseline survey, ESM data were collected over seven days via SurveySignal (Hofmann \& Patel, 2015) which sent text messages with a Qualtrics survey link for participants to answer a few short questions. Based on recommendations by Hektner, Schmidt, and Csikszentmihalyi (2007) to reduce participant burden and to facilitate more responses, surveys in each text were kept to an average of two to three minutes, with a few signals each day (Hektner et al., 2007). Thus, 5 signals were sent each day within 150-minute blocks (2.5 hours). These blocks were at 9:30-11:59am, 12-2:29pm, 2:30-4:59pm, 5-7:29pm, 7:30-10pm. A text message was sent at random within each block, and was at least 30 minutes later than the previous signal (Hektner et al., 2007). For example, if the first signal was sent at 11:45am, the next signal would be sent no earlier than 12:15am. Each survey was open for 2 hours that participants could respond. 
Although the present study only analyzed data from baseline and ESM surveys, participants that completed at least $25 \%$ of ESM surveys were invited to complete a follow-up survey. The survey link was emailed to the participant one week after their final ESM survey was sent. This follow-up survey included a short battery of questionnaires, and inquired about their experience during the ESM portion of the study.

Participants were compensated with psychology course extra credit for each part of the study. Completing the baseline survey earned one hour credit. Up to seven hours could be earned for completing at least $75 \%$ of the experience sampling portion, with fewer responses earning less course credit (i.e., at least $25 \%$ earned 1.5 hours, at least $50 \%$ earned 3 hours). An additional two hours of credit was earned for completing the follow-up survey.

\section{Measures}

Demographics. Participants answered a set of demographic questions, including age, gender, race, ethnicity, year in school, where students go "home" to during school breaks, and the roles of their caregivers (e.g., biological mother, step-mother, custodial grandparent, etc.). All baseline questionnaires are presented in Appendix A.

Self-control. Participants reported on their trait-level self-control using the Brief SelfControl Scale (Tangney et al., 2004), which was designed to capture general self-control ability. This scale averaged 13 items that were rated on a 5-point rating scale $(1=$ Not at all like me to 5 =Very much like me; $\alpha=.86)$. One example item read, "I am good at resisting temptation." Higher scores indicated more self-control. In the creation of this scale, Tangney et al. (2004) found the full scale demonstrated adequate internal reliability (two studies: $\alpha=.84$ ) and testretest reliability $(\alpha=.87)$. Tangney et al. (2004) also demonstrated predictive validity through the scale's associations with established outcomes of self-control (e.g., academic performance, 
psychopathology). Although it was designed as a unidimensional structure, other researchers have proposed a multidimensional nature (de Ridder, De Boer, Lugtig, Bakker, \& Van Hooft, 2011; Ferrari, Stevens, \& Jason, 2009; Maloney, Grawitch, \& Barber, 2012). However, Lindner, Nagy and Retelsdorf (2015) recently found that in comparing the multidimensional models to the original unidimensional structure, the unidimensional structure maintained reliable model fit unbiased by the wording of items and had better predictive associations on related outcomes.

Beliefs about self-control. The belief that self-control draws on a limited or nonlimited resource was measured with the Implicit Theories about Willpower scale (Job, Dweck, \& Walton, 2010). This scale averaged 12 items that were rated on a 6-point Likert scale $(1=$ strongly disagree to $6=$ strongly agree; $\alpha=.83$ ). Questions focused on strenuous mental activity (e.g., "After a strenuous mental activity, your energy is depleted and you must rest to get it refueled again") and resisting temptations (e.g., "Resisting temptations makes you feel more vulnerable to the next temptations that come along"). Higher values indicated a greater belief that self-control uses a nonlimited resource model.

Early Risk. All early risk factor measures (i.e., caregivers' 1 and 2 educational level, difficulty paying bills, SES ladder, home chaos, attachment to caregivers 1 and 2) were prefaced with instructions to answer about "While growing up" or "Before starting college." This decision was made to keep the focus on risks of early life factors that have accumulated before the participant entered emerging adulthood.

SES was measured using a set of single questions that asked about family or household's SES while the participant was growing up, including difficulty paying bills $(1=$ None/not at all to $4=$ A great deal), caregiver(s)' education, and perceived social status. To report on perceived social status, participants used a ladder to represent the social hierarchy $(1=$ worst off with the 
least money, little or no education, no jobs or jobs that no one wants or respects to $10=$ best off with the most money, the highest amount of schooling, and the jobs that bring the most respect; Goodman et al., 2001).

Home conditions were assessed with the Confusion, Hubbub, and Order Scale (CHAOS; Matheny, Wachs, Ludwig, \& Phillips, 1995). Fifteen items captured the noise, traffic and disorganization in the home while growing up, and were rated on a forced choice true or false rating scale that has previously had good reliability (Dumas et al., 2005; Matheny et al., 1995; Valiente, Lemery-Chalfant, \& Reiser, 2007). A sum of the 15 responses was taken for indicators of 'true', with higher values representing greater confusion, noise, and unpredictability in the home (Guttman split-half $\alpha=.85$ ).

Insecure attachment with caregivers will be assessed with the Experiences in Close Relationships- Relationship Structures (ECR-RS; Fraley, Heffernan, Vicary, \& Brumbaugh, 2011). With nine items per caregiver, two subscales captured attachment avoidance (e.g., "I prefer not to show this person how I feel deep down"; seven items) and anxiety (e.g., "I'm afraid this person may abandon me"; three items). All items were rated on a 7-point Likert scale ( $1=$ strongly disagree to $7=$ strongly agree) and averaged for each subscale. This resulted in separate average scores for each caregiver (avoidance for caregiver $1 \alpha=.90$ and caregiver $2 \alpha=.91$; anxious for caregiver $1 \alpha=.91$ and caregiver $2 \alpha=.94)$. On each scale, higher values indicate more attachment avoidance or anxiety to the particular person. Of the 214 participants, 188 $(87.38 \%)$ reported a second primary caregiver. Most participants reported caregiver 1 as a biological mother and caregiver 2 as a biological father (see Table 1).

Similar to previous research (Brown, 2009; Evans, 2003; Evans, Li, \& Sepanski Whipple, 2013; Trentacosta et al., 2008), the presence of any of the factors earned a score of $1(1=$ risk 
present, $0=$ risk absent) and scores were summed to create a risk index that ranges from no risk

(0) to all risks (7). Participants who reported any difficulty paying bills, each caregiver who does not have any college degree, and a four or below on perceived family social status (lower scores indicate lower perceived social status) earned a risk score of 1 for each. In line with prior research using questionnaires without readily available risk cutoffs (Evans et al., 2013; Trentacosta et al., 2008), one standard deviation above the mean of the sample reached criteria for risk on home chaos and insecure attachment to each caregiver (either avoidant or anxious attachment earned a risk score).

Experience sampling. The experience sampling questions were based on previously successful ESM data collection involving temptations and regulatory function (see Appendix B; Hofmann et al., 2012a; Hofmann et al., 2012b). Participants were signaled five times a day for one week. Each signal included questions about temptations/desires and self-control. ESM questions are based on the model of motivated behavior presented by Hofmann et al. (2012a), where questions focus on desires, conflict, and attempts to enact self-control or avoid satisfying the desire.

At the start of each signal, participants were asked "Are you experiencing OR have you experienced a desire in the last 30 minutes?" to which participants could respond "Yes" or "No". If the participant responds negatively, other questions unrelated to desires and self-control (e.g., affect) were presented; if the participants responded affirmatively, the next questions about desires and self-control were presented. Participants answered questions about the desire, including what type, how long it was experienced, and the subjective strength of the desire. The self-control questions were then presented which included, "Have you tried to resist the desire?" with answer choices "Yes" or "No". If the participants answered affirmatively, they were asked 
"How successful were you at resisting the desire?" with answer options "Not at all successful - I fully gave in to the desire", "Slightly successful", "Moderately successful - I gave in to the desire somewhat", "Very successful", and "Entirely successful- did NOT give in to the desire." The times that participants answered "No" to using resistance, those responses were recoded as the lowest degree of resistance success. Lastly, participants will be asked about why they used selfcontrol, "Briefly, why did you try to resist the desire? (What goal do you have that conflicts with the desire?" and then asked to rate how important this goal is to them on a 4-point rating scale (Not at all important to Extremely important). A few other questions remained after completing the portion about self-control and desires (e.g., affect, stress), but these were unexamined in the current study.

Follow-up. The follow-up questionnaire included a short battery of questionnaires which included completing the Brief Self-Control Scale $(\alpha=.85)$ and the Implicit Theories about Willpower Scale $(\alpha=.80)$ again (Job et al., 2010; Tangney et al., 2004). The follow-assessment also inquired about their experience during the ESM portion of the study. Participants were asked to report on how many surveys they estimated they missed, for what reasons, the most common reason they missed surveys, and how disruptive they found the text messages (see Appendix C).

\section{Data Analysis Plan}

Preliminary analyses. Data was cleaned based on analyses for response patterns, unlikely responses, and missingness. Assumption of normality was be checked for key variables and transformations were computed if violations were found. Univariate and multivariate outliers were also examined. Analyses were conducted with and without the multivariate outliers included to determine their effect on the results. 
Gender, age, college class rank, and race were examined as potential covariates through correlations, $t$-tests, and previous research in relation to the outcomes of interest, self-control. Correlations among all study variables were also examined. Intraclass correlations (ICC) were analyzed to determine if there was significant clustering by person on momentary self-control (success at resisting desires; Garson, 2014). Finding a significant effect, hierarchical linear modeling was employed to analyze hypotheses involving momentary self-control.

\section{Primary Analyses}

Primary analyses for each research question were completed first on trait self-control, then on momentary self-control. All analyses with trait self-control were computed using SPSS. Linear regression models using SPSS was computed to investigate the associations between predictors (i.e., risk index, implicit belief, the interaction of risk index and belief, and possible covariates) and trait self-control. The SPSS PROCESS macro (Hayes, 2013) was used to test mediation and moderation models by entering all predictors and covariates of interest for a research questions three and five in one step. Continuous variables were mean centered to reduce collinearity (Enders \& Tofighi, 2007).

Hierarchical linear modeling (HLM) was employed through HLM version 8 (Raudenbush, Bryk, Cheong, \& Congdon, 2019) software to address hypotheses when the outcome is momentary self-control (i.e., How successful were you at resisting the desire?" from the experience sampling signals). Resistance to desire was in each of the ESM surveys that participants answered, and was thus a repeated measure. HLM is well suited to address these hypotheses as ESM data are nested among individuals, in which observations are not independent (Garson, 2014). HLM also handles time unstructured data (Garson, 2014), in which data collection schedules may vary across participants (e.g., missed surveys). Mediation analyses 
on momentary self-control will be assessed with MPlus, which is well suited to handle the nested data of momentary self-control at the 'lower level' and a predictor and mediator variable at an 'upper level' resulting in a 2-2-1 mediation (Bolger, \& Laurenceau, 2013; Muthén \& Muthén, 1998-2017; Preacher, Zyphur, \& Zhang, 2010).

\section{Results}

\section{Preliminary Analysis}

Univariate, bivariate, and multivariate statistics were used to assess normality on key baseline variables including trait self-control, implicit belief, and the total early risk score. Baseline and experience sample descriptives are presented in Tables 2 and 3, including the variables that comprise the total early risk score (i.e., home chaos score, insecure attachment with caregiver 1 , insecure attachment with caregiver 2 ). The total early risk score was skewed, as indicated by a z-score skew value of 4.82 , which exceeded the recommend \pm 3.29 at which a zscore is significant at $p<.001$. As a result, a log transformation was applied which normalized its distribution (Field, 2009). This transformation is used in subsequent analyses, but the number of participants with their summed total risk is presented in its original scale in Figure 4.

Additionally, boxplots were examined for univariate outliers. A few possible outliers were identified on trait self-control $(n=2)$ and implicit belief $(n=10)$, but they were retained since these variables are otherwise normally distributed. No univariate outliers were identified for total early risk score following the transformation that normalized the data. Associations between main study variables and trait self-control and momentary self-control are presented in Tables 4 and 5.

Possible demographic covariates (e.g., age, college year, gender, race or ethnicity) were examined in relation to the outcomes of interest, trait and momentary self-control. Participant 
age and college year were not significantly correlated with trait self-control at baseline, and race/ethnicity and gender yielded non-significant differences $(p s=.73-.81)$. Age, college year, race/ethnicity, and gender were also tested for significant associations on momentary self-control assessed through experience sampling across one week. None of these analyses yielded significant effects. Because the potential covariates were unrelated to the outcome variables of interest, they were not included in subsequent models. Also, a correlation was conducted for the association between trait and total momentary self-control, and a regression in HLM examined the effect of trait self-control on momentary self-control, which also revealed no significant associations (see Tables 4 and 5).

Multivariate outliers were assessed with the Mahalanobis distance including the main variables of implicit belief, early risk, and trait self-control. Using a chi-square distribution accounting for 3 variables $(d f=3)$, one multivariate outlier was identified. One participant had a Mahalanobis distance value of 18.63 which exceeded the critical value of $16.27(p=.001)$. This participant reported a strong belief that self-control is nonlimited (i.e., not limited by mental resources), but has below average self-control. This is a multivariate outlier as it contradicts the positive correlation between these variables, such that more self-control is associated with a greater belief in a nonlimited resource theory $(r=.57, p<.001)$. Multivariate outliers were assessed among desire strength, goal importance, and momentary self-control (level 1 variables for hierarchical linear models). No multivariate outliers were identified.

Also, multicollinearity was assessed between main study variables. Tolerance values were above .2, and VIF values were below 10, and the average of the VIF values was not substantially greater than 1 for any variables. Therefore, no multicollinearity problems are apparent in the baseline data. Using Little's MCAR test to analyze missingness within the two 
baseline predictors (implicit belief and early risk index) and main baseline outcome (trait selfcontrol) was missing completely at random, $\chi^{2}(2)=1.72, p=.42$. All baseline variables had less than $1 \%$ missingness.

Among the text messaged data, there were potentially a total of 7,490 responses (i.e., reports sent 5 times a day for 7 days from 214 individuals). Together, participants averaged 77\% response to text messaged signals $(N=5597$ total signals answered $)$. After removing data points from participants who failed baseline validity checks, did not have baseline data to match, or had zero momentary self-control data points, 5609 responses remained. Of those responses, participants reported experiencing a current desire $39.7 \%$ of the time $(N=2223)$. Participants reported attempting to resist nearly half of those desires, $44.60 \%(N=990)$.

\section{Primary Analyses}

All primary analyses were conducted with and without outliers, and results did not change appreciably, including no changes to significant tests. All values presented in text and tables are analyses with outliers included.

Trait self-control. To test hypothesis $1 \mathrm{a}$, which was that more early risk should be associated with lower trait self-control, a linear regression was conducted in SPSS. The model was significant, $F(1,212)=23.92, p<.001, R^{2}=.10$, but explained only $10 \%$ of the variance in trait self-control. Early risk was significantly negatively related to trait self-control, such that a high number of early risk factors associated with low trait self-control, $b=-.80$, se $=.16, p<$ .001. A second model tested hypothesis $2 \mathrm{a}$, that more nonlimited implicit beliefs would be associated with high trait self-control. This analysis yielded a significant model with $32 \%$ variance accounted for in trait self-control, $F(1,211)=100.99, p<.001, R^{2}=.32$. A strong belief 
that self-control is a nonlimited resource was associated with more trait self-control, $b=.47$, se $=$ $.05, p<.001$. Results are presented in Table 6.

Implicit beliefs as a moderator. The results of analyses for hypothesis 3a, that implicit beliefs would moderate between the negative association of early risk and trait self-control, are presented in Table 6. Hayes PROCESS was used which entered early risk, self-control beliefs, and the interaction term simultaneously into the model. The overall model was significant and explained $36 \%$ of the variance in self-control, $F(3,209)=39.44, p<.001, R^{2}=.36$. Main effects emerged with early risk significantly related to trait self-control, $b=-.49$, se $=.14, p<.001$, and implicit beliefs significantly related to trait self-control, $b=.42$, se $=.05, p<.001$. The interaction term was not significant, $b=.21, s e=.20, p=.30$.

Implicit beliefs as a mediator. In hypothesis 5a, implicit beliefs were expected to be a mechanism for the association of early risk and trait self-control. Specifically, more early risk was expected to associate with lower implicit beliefs (limited resource theory), which was expected to associate with lower trait self-control. In preparation for this test, hypothesis 4 (i.e., more early risk would associate with a limited resource belief) was also tested. A significant correlation between early risk and implicit beliefs was found in the expected direction; low implicit beliefs (limited belief) was associated with more accumulated early risks. Additionally, early risk was negatively associated with trait self-control. The significant correlations support the exploration of indirect effects between these variables. Hayes PROCESS was used to test hypothesis 5a which entered trait self-control as the outcome, early risk as the predictor, and beliefs as the mediator (see Figure 5). Total risk was significantly associated with implicit beliefs, $b=-.73$, se $=.20, p<.001$. Implicit beliefs were significantly associated with trait selfcontrol, $b=.43$, se $=.05, p<.001$. The direct path of total early risks on trait self-control was 
significant, $b=-.48$, se $=.14, p<.001$. The indirect effect of total early risk with trait selfcontrol through implicit beliefs was also significant, $b=-.32$, se $=.09,95 \%$ CI [-.51, -..14], indicating that individuals with more early risks reported believing self-control was limited, which subsequently associated with low trait self-control.

Momentary self-control. HLM version 8 (Raudenbush et al., 2019) software was used to test linear regressions on momentary self-control success assessed through a week of text message collected data. The unconditional model including only the outcome variable of momentary self-control success tested if there was appropriate variance to use HLM analyses. Within-subject level variance was estimated at 3.79 , and between-subject variation was estimated as .45. Together, an intraclass correlation (ICC) assessing between-subjects variability was calculated at .1061, or $10.61 \%$ of variability in self-control success is found between subjects. Additionally, the chi-square test on the between-subjects variance components was significant, $\chi^{2}(213)=479.19, p<.001$. Thus, there is significant variability among individuals' self-control success over daily desires, which was evidence for interdependence of data, and necessitated the need to use HLM analyses (Woltman, Feldstain, MacKay, \& Rocchi, 2012). Because there is much variance unexplained, level one and level two predictors were added in subsequent models in attempt to explain the variability (Maas \& Hox, 2005; Woltman et al., 2012).

Hofmann et al.'s (2012a) theory on motivated behavior regarding desires and self-control posits other level 1 variables (i.e., stronger desires and desires that conflict with other goals) should decrease desire resistance success (i.e., increase the likelihood of giving in to the temptation). Desire strength has been found to make acting on the desire more likely (worse selfcontrol success), but greater conflict (i.e., the importance of goals) has been found to improve 
likelihood of successfully resisting the desire (Hofmann et al., 2012a). Thus, the present study considered desire strength and conflict between current desires and goals for inclusion in subsequent hierarchical models.

In the present study, desire strength had a significant negative effect on self-control success, $b=-.32$, se $=.04, p<.001$ (see Table 7), such that with strong desires, participants reported less success resisting them (enacting self-control). Goal importance also had a significant positive effect on self-control success, $b=.22$, se $=.06, p<.005$. In other words, when a desire conflicted with an important goal, the individual was more successful resisting that desire. These level one predictors were checked for variance component significance to determine if they should be treated as fixed (the effect of the predictor is the same across people) or random (the effect of the predictor is different across people) in subsequent analyses. Because the variance components for desire strength, $\chi^{2}(122)=110.80, p=.50$, and goal importance, $\chi^{2}$ $(122)=133.31, p=.23$, were found to be non-significant, they were treated as fixed effects in subsequent models including Level 2 predictors (Hofmann et al., 2012a; Hox et al., 2010).

To address hypotheses $1 \mathrm{~b}$ (more early risk would associate with low momentary selfcontrol) and $2 \mathrm{~b}$ (a nonlimited belief would associate with more momentary self-control), early risk and an individuals' beliefs about self-control were tested in separate models for associations with momentary self-control. In each case, the full model tested included level 1 predictors (desire strength and goal importance). The level 2 predictors early risk and implicit beliefs were regressed onto the intercept of self-control success. A person's implicit beliefs and accumulated early risk were expected to associate with momentary self-control, but were not hypothesized to moderate the strength of associations of desires strength and goal importance with self-control 
success. Therefore, early risk and implicit beliefs were tested for effects on the intercept of selfcontrol success, and not for their effects on the level 1 variables.

A test of hypothesis $1 \mathrm{~b}$ found early risk index was associated with momentary selfcontrol success, $b=-.54$, se $=.22, p=.015$. Desire strength and goal importance remained significantly associated with self-control success when early risk was included in the model ( $p s<$ .001 ; see Table 7). A test of hypothesis $2 \mathrm{~b}$ found implicit beliefs had a marginally significant positive effect on self-control success, $b=.13$, se $=.07, p=.06$. A stronger belief that selfcontrol resources are nonlimited predicted more desire resistance success. Desire strength and goal importance remained significantly associated with self-control success with implicit beliefs in the model ( $p s<.001$; see Table 7).

Implicit beliefs as a moderator. Hypothesis $3 \mathrm{~b}$ stated that implicit beliefs would to moderate the association between early risk and momentary self-control. Interactions within levels in HLM can take the same for as ordinary least squares regression using centered predictor variables and a multiplicative term (Curran, Bauer, Willoughby, 2005; Enders \& Tofighi, 2007; Garson, 2014; Hofmann et al., 2012a). As such, this model included level 1 covariates of desire strength and goal importance, and level 2 predictors of early risk, implicit beliefs, and the interaction term (implicit beliefs X early risk). Early risk predicted self-control success, $b=-.45$, $s e=.30, p=.049$. However, self-control beliefs were not significantly associated with selfcontrol success, $b=.11$, se $=.07, p=.14$. The interaction term was also not significant, $b=-.25$, $s e=.30, p=.40$, such that a person's beliefs about self-control did not qualify the association between risk and self-control success.

Implicit beliefs as a mediator. Implicit beliefs were considered to be a potential mediator between the association of early risk and in-the-moment self-control. Specifically, hypothesis $5 \mathrm{~b}$ 
was that more early risk should be associated with lower implicit beliefs (limited resource theory), which should predict lower momentary self-control. A significant correlation between early risk and implicit beliefs at baseline, and significant associations between early risk and implicit beliefs on momentary self-control support the exploration of mediation analyses. An upper level (2-2-1) mediation model was tested using Mplus version 8 (see Figure 6). Total risk was significantly associated with implicit beliefs, $b=-.75$, se $=.21, p<.001$. However, implicit beliefs were not significantly associated with momentary self-control, $b=.01$, se $=.07, p=.17$. The direct path of total early risks on momentary self-control was significant, $b=-.46$, se $=.21$, $p=.028$, but the indirect effect between total early risk on momentary self-control through implicit beliefs was not, $b=.07$, se $=.06, p=.21$. Level one variables of desire strength and goal importance were also included in the model predicting resistance success, which were both significant $(p s<.001$, see Figure 6).

Analyses with follow-up assessments. Exploratory analyses were conducted with assessments collected during the follow-up questionnaire (see the tables and figures in Appendix G). These analyses include examining participant experiences during the week of text messaged data (e.g., reasons for not responding to surveys), analyzing associations among the completion rate with baseline variables of interest, and comparing trait self-control and implicit beliefs from baseline to follow-up. Most participants reported that the week of texted surveys were not at all or only slightly annoying, and that the most common reason for missing a texted survey was that they were "unable to respond at time it was sent".

Of note, there were significant positive correlations between baseline and follow-up trait self-control and implicit beliefs. Entering baseline trait self-control and implicit beliefs into linear regression models, both positively significantly predicted trait self-control at follow-up but 
only implicit beliefs significantly predicted implicit beliefs at follow-up. Additionally, dependent samples $t$-tests were used to examine differences in average responses of trait self-control and implicit beliefs between baseline and follow-up assessments. There was no significant difference for means of implicit beliefs, but there was a small but significant increase in mean trait selfcontrol. This result may suggest that asking individuals to document their daily self-control successes may make them more likely to recall it during a self-report survey due to the availability heuristic (Tversky \& Kahneman, 1973), or that there is an effect of attrition in who responded to the follow-up survey (i.e., individuals with higher self-control completed the follow-up survey raising the average score).

\section{Discussion}

Because self-control is a key component of adjustment during emerging adulthood and beyond (Arnett, 2000; Ford \& Blumenstein, 2013; Park et al., 2012; Tangney et al., 2004), identifying predictors of effective self-control is valuable for developing interventions that can be used to benefit individuals with less self-control. The present study was the first to examine the combination of early risks and implicit beliefs about self-control as possible predictors of self-control in a sample of emerging adults. Early risk comprised several types of potentially adverse experiences including social bonds, socioeconomic, and environmental factors. Additionally, self-control was assessed two ways: trait self-control was assessed at the same time point as the predictors, whereas momentary self-control (i.e., success resisting desires) was measured five times a day for one week as success resisting desires. These measures of selfcontrol are not statistically related in a correlation or HLM analysis, which is similar to prior work (Hofmann et al., 2012a). Hofmann et al., (2012a) had found trait self-control was not associated with the success of desire resistance attempts (but was associated with the number of 
times attempts were made). Also, the specificity of momentary SC in context (e.g., desire strength, location, presence of others) may be lost in a global measure based on the participant's perception and memory of their typical self-control ability, which may explain why the measures of self-control in the current study are unrelated.

Despite the distinctiveness of the self-control measures, the overall results of the hypothesis tests indicated that early risk associated with low trait and momentary self-control. Next, holding implicit beliefs that self-control resources are more nonlimited, meaning that selfcontrol does not need to be replenished after using it, was significantly associated with higher trait self-control and marginally associated with better momentary self-control. Implicit beliefs did not moderate the association between early risk and self-control for either measurement. Lastly, implicit beliefs were explored as a mechanism between early risk and self-control, finding support at the trait level but not the momentary level. This finding suggests that there may be contextual factors related to momentary self-control qualifying associations between early risk, implicit beliefs, and success resisting desires. Overall, there is clear support that accumulated risk factors and personal beliefs about how self-control operates have consequences for individuals' ability to use self-control.

\section{Early Risk}

The present study hypothesized that individuals who experienced more early risk factors before emerging adulthood would subsequently have low trait and momentary self-control. In line with expectations, a high number of early risks was found to predict lower trait self-control. Early risk also significantly predicted less success resisting desires experienced throughout the day even when accounting for other factors associated with the attempt to resist (i.e., desire strength and goal importance). In other words, the accumulated experiences of living with 
socioeconomic disadvantage, less routine in the home, and poor relationships with caregivers contribute to worse self-control in emerging adulthood. The findings are in line with publications which found worse self-control was associated with separate risk factors, namely socioeconomic status (i.e., difficulty paying bills, subjective social status, and education level of caregivers; Blair et al., 2011; Brown, 2009; Fuller-Rowell et al., 2015; Hostinar et al., 2015; Lui et al., 2012; Mani et al., 2013; Raver et al., 2013), chaotic living conditions (i.e., confusion and noise in the home; Evans, 2003; Evans et al., 2005; Fuller-Rowell et al., 2015; Hughes \& Ensor, 2009; Vernon-Feagans et al., 2016), and social bonds with caregivers (i.e., attachment insecurity; Gentzler et al., 2010; Mikulincer et al., 1993; Pallini et al., 2018). This was the first known study to assess the impact of accumulated risks as a youth, with lasting consequences on self-control into emerging adulthood. Additionally, this study demonstrated that accumulated risks account for a significant portion of variability in momentary self-control success and failures.

Accumulated adversity may be associated with low self-control through social distrust or chronic stress (Felitti et al., 1998). Chronic adversity elevates stress reactivity, resulting in localized changes in the brain structure and functions known for self-control (e.g., prefrontal cortex, executive attention, working memory; Blair, 2010; Meaney, 2001). Additionally, the elevated stress reactivity draw attention to threats instead of on goals processes (Meaney, 2001). For example, Blair et al. (2011) found that poverty, housing quality, and little positive caregiving were found to be important risk factors that culminated in individuals having elevated stress (e.g., cortisol levels) and worse self-regulation (e.g., executive functions) in children through three years old. The present study used a similar set of early risk factors (i.e., bonds with caregivers, socioeconomic status, and home environment), and similarly found it predicted worse self-control. An alternative interpretation is that early risk relates to self-control through social 
distrust (Rotenberg, 1995; Sutter \& Kocher 2006). Distrust may emerge in exposure to adversity in which individuals may have more difficulty following through on promised positive outcomes. Youth who are sensitive to these trust violations may develop a preference toward satisfying desires for which the reward is clear, rather than waiting for a later reward which may or may not come (Michaelson \& Munakata, 2016). Overall, the present study demonstrates that accumulated risk factors were associated with worse trait and momentary self-control in emerging adults.

The present study extends prior research in several ways. First, substantial prior research had focused on children and adolescents, but the present study demonstrates that the effects of early risks on self-control extend into emerging adulthood. Specifically, several studies found that accumulated risks were associated with worse self-regulatory behaviors and outcomes in children and toddlers (Blair et al., 2011; Brown, 2009; Evans, 2003; Evans, Li, \& Whipple, 2013; Trentacosta et al., 2008), and in adolescents (Evans \& Rosenbaum, 2008; Holmes, Brieant, Kahn, Deater-Deckard, \& Kim-Spoon, 2019). The present study was the first to examine the occurrence of risks before emerging adulthood, which then associated with self-control in emerging adulthood. The link between early risks and self-control provides evidence that the impact of early risks on self-control extends past childhood and adolescence. Additionally, published studies tend to focus on abuse and neglect by caregivers (e.g., Felitti et al., 1998; Turiano et al., 2017) instead of relationship quality. The present study included a measure of relationship quality with caregivers in the form of attachment insecurity, which has been uniquely associated with detrimental effects on self-regulatory development in infancy through adulthood (Gentzler et al., 2010; Mikulincer et al., 1993; Pallini et al., 2018). 
Also, the present study was the first to provide evidence that the link between early risk and self-control is present in a global measure and a moment-to-moment assessment of selfcontrol. Individuals with more accumulated early risks seem to be less successful at resisting desires in daily life and when participants are asked to recall their typical self-control behavior. Of note, this pattern for momentary self-control remains even when accounting for other contextual factors that give rise to an act of self-control- namely, the strength of a particular desire to be overridden and the degree of conflict between that desire and other personal goals. Given that the associations are similar across measurement, this may suggest that the global measure is able to capture an aggregate of a context-dependent process, or that individuals are relatively accurate in assessing their own regulatory abilities unaltered by social desirability or recall bias (Schwarz, 1999). The significance of early risk across multiple methods of assessment also suggests that accumulated risks can help explain general patterns of behavior, and alter moment to moment experiences (e.g., management of conflict between current desires and longterm goals). Finding that accumulated adverse experience can put individuals at risk for lower self-control on a momentary basis suggests new avenues for prevention and intervention efforts. Interventions designed to improve self-control by managing temptations could be implemented among people who are likely to experience self-control difficulties, like emerging adults with known exposure to early risk factors (e.g., socioeconomic disadvantage, strained relationships with caregivers). For instance, interventions have been designed that enable adults to suppress dominant responses toward desirable but unhealthy food with refocusing attention on goals and through training to avoid dominant responses to tempting stimuli (van Koningsbruggen, Veling, Stroebe, \& Aarts, 2014).

\section{Implicit Beliefs}


The hypothesis regarding implicit beliefs and reported self-control ability was partially supported. A stronger belief that self-control is drawn from a nonlimited resource was associated with more trait self-control. This belief was also marginally associated with greater self-control success over daily desires, even when including desire strength and goal importance in the model. In other words, believing that self-control can be used without taking breaks may enable individuals to continue resisting daily desires with somewhat greater success than individuals who believe self-control is limited. This finding is in line with prior work, such as beliefs about self-control have been found to predict the continued use of self-control in the face of challenges and fatigue (Job et al., 2010; Job et al., 2015).

The present study extends this literature in several ways. Believing self-control is drawn from a nonlimited resource marginally predicted individuals' greater success at resistance over any reported daily desire. This finding extends the literature as several prior studies focus on the impact of beliefs on self-control as observed in a laboratory with performance on specific demanding tasks, instead of situated in real-time and context (e.g., Job et al., 2010; Job et al., 2015). Additionally, only one prior study found that among college students, a limited implicit belief of self-control was associated with worse self-regulation over several weeks when the participants experienced high demands (e.g., heavy course load; Job et al., 2015). However, selfregulation was assessed in the form of performance a specific set of domains (e.g., procrastination of completing tasks, healthy eating behaviors) rather than self-reported success over any temptations. The present study extended prior work by expanding the range of selfregulatory acts to match any desire participants are experiencing in real time, in conjunction with overarching implicit beliefs. The current findings partially matched prior work, in that a nonlimited belief marginally associated with more resistance success when accounting for other 
situational factors of desire strength and goal importance which were both significant predictors of resistance success. Together, this suggests that overarching beliefs about how self-control operates have some impact how individuals resist any desire in context.

However, the results for implicit beliefs and self-control should be qualified by a few considerations. One is that stronger effects are more common with a short time of assessment between variables (e.g., cross-sectional) versus a delay between assessments (e.g., longitudinal; de Ridder et al., 2012). But in most cases, the direction and significance of the effect remains (de Ridder et al., 2012). Partially in line with these expectations, the present study found the association between implicit beliefs and momentary self-control to be weaker but in the expected direction. Although it is likely that the delay between assessments can contribute to the discrepancy, another possible explanation exists. Momentary self-control may be strongly dependent on contextual factors related to the act of self-control (e.g., strength of desire trying to resist) rather than overarching beliefs, but beliefs may become more important when examined in the context of the act of self-control. Hofmann et al. (2012a) note in their model of motivated behavior that the process of resisting a desire is predicated on contextual factors about the desire (e.g., desire strength, presence of a goal in conflict with desire), other situational factors (e.g., alcohol consumption, presence of others satisfying the desire another individual is experiencing), and some trait-level individual differences (e.g., behavioral inhibition, perfectionism, trait selfcontrol). Although some individual difference factors have been found to impact success resisting desires in prior work, it is possible that implicit beliefs about self-control are too general in the present study to have an association with resistance success. It is more likely that the effect of implicit beliefs about self-control associates with other components of the model (e.g., simply attempting to resist regardless of success), or that implicit beliefs may need to be specific to the 
moment of self-control. Noting how individuals think about their self-control resources when being asked to use them may better capture the effect beliefs have on momentary self-control. Taken together, the present study was the first to find that overarching beliefs about self-control are strongly associated with global self-control, but less strongly moment-to-moment, such that beliefs in the moment may be necessary when considering the impact on momentary self-control.

\section{Considering Both: Implicit Beliefs as a Moderator}

Contrary to hypotheses, the association between early risk and self-control was not moderated by one's implicit beliefs about self-control. This association was posited because emerging evidence suggested that there is heterogeneity among individuals who experienced adversity and their subsequent outcomes. For instance, individuals between 14-92 years who retrospectively reported more adverse childhood experiences and more trait resilience exhibited less distress than those with low trait resilience (Beutel et al., 2017). Related to implicit beliefs, children from low SES who believed intelligence was malleable had higher academic achievement than children who believed that intelligence was fixed (Claro et al., 2016). However, the present study did not support this pattern for trait or momentary self-control. It is possible that the current model does not fully capture the complex ways that accumulated risk and implicit beliefs explain self-control acts. For instance, implicit beliefs may only moderate the association between risk and self-control under specific conditions (e.g., when individuals experience high levels of self-regulatory demands; Job et al., 2010; Klinger et al., 2018).

\section{Considering Both: Implicit Beliefs as a Mediator}

Implicit beliefs were also hypothesized to be a mechanism explaining the association between cumulative early risk and self-control ability. The present study was the only known study to examine a possible pathway through which accumulated risks as a youth predict later 
emerging adult self-control. Individuals who endured adversity as youth may be more likely to hold similar beliefs (i.e., that self-control is drawn from a limited resource), resulting in similarly low trait and momentary self-control. The present study found a significant indirect effect to partially support the hypothesis. Emerging adults with more risk factors reported a belief that self-control is drawn from a limited resource, which in turn was associated with low trait selfcontrol. However, this indirect association was not found for momentary self-control.

Cumulative adverse experiences may result in worse self-control through implicit beliefs about self-control. One similar finding was found among adolescents and implicit beliefs about intelligence. Claro et al., (2016) found that adolescents from low income families were more likely to believe that intelligence was fixed or unchangeable. The authors also found that a fixed mindset was associated with worse academic performance. The associations between financial risk, beliefs, and academic performance may fit into an extended process involving the proposed mechanism of chronic stress. Risk factors in childhood and adolescence, including financial disadvantage, are known to contribute to individuals developing a chronically elevated stress response (Blair, 2010; Blair et al. 2011; Evans, 2003). The feeling of heightened stress and apprehension that accompanies a hypervigilant stress response may also affect how individuals experience and perceive situations (Meaney, 2001). For instance, extremely stressful experiences (e.g., abuse) have been documented to alter individual's perceptions of control over and helplessness in life events (Irving \& Ferraro, 2006; Kendall-Tackett, 2002). Additionally, the experience of chronic stress could result in feeling tired or fatigued (Meaney, 2001), but there is new evidence that perceiving recent experiences as tiring or draining diminishes individuals' self-control through altering implicit beliefs. For example, Sieber, Flückiger, Mata, Bernecker, and Job (2019) found that if adults reported a recent event as draining or demanding (versus 
energizing), they were more likely to report believing their self-control was limited. Those individuals who felt generally fatigued believed they had a limited amount of self-control to use (Seiber et al., 2019). Taken together, accumulated risk factors may chronically heighten stress responses into emerging adulthood; an elevated stress response may lead to feeling drained or fatigued in subsequent demanding situations and a perception of inability to use self-control, ultimately resulting in low self-control. The present study began to address this possibility by finding support for the indirect path between early risk, implicit beliefs, and self-control. Future research should explore the role of stress (e.g., current stress, allostatic load) in relation to early risk, implicit beliefs, and self-control.

The present study was also the only known study to investigate this proposed pathway on momentary self-control. However, this indirect path was not supported for momentary selfcontrol. Accumulated risks continued to have a direct effect on resistance success, but it did not operate through individuals' beliefs about self-control. Perhaps success resisting momentary desires is more dependent on other context specific factors related to the act of self-control (e.g., desire strength). For instance, the indirect effect was tested in a model that included the other contextual factors of desire strength and goal importance, which remained significant predictors. There may be other contextual factors that also matter, such as the presence of other people satisfying the same desire, where a person experiences a desire, and their emotional state. Regarding implicit beliefs, perhaps resistance success would be more strongly influenced by beliefs at the time of enacting resistance. Seiber et al. (2019) found that experiencing recent demanding events shifted individuals' beliefs about self-control to be more limited. As such, subjective feelings of fatigue or stress while trying to resist desires could alter individuals' implicit beliefs about self-control at that time. Additionally, it is possible that cumulative early 
risk, implicit beliefs, and related mechanisms alter how situational factors, like desire strength, affect success resisting desires. Future work should examine these possibilities to better understand how self-control success is situated in context which could elucidate why individuals' self-control fails.

Identifying effective avenues to improve self-control is of great importance. Self-control is a key factor predicting many of life's important outcomes, such as better health, greater wealth, academic achievement and more (Moffitt et al., 2011; Moilanen, 2007; Tangney et al., 2004). Thus, finding ways to improve self-control could have beneficial consequences across domains of life, especially for groups likely to be disadvantaged such as those with several accumulated risks. There is substantial evidence that implicit beliefs are malleable. Beliefs about self-control have been successfully manipulated in the laboratory (Job et al., 2010). Interventions to promote growth mindsets about intelligence have been found to improve academic performance (Blackwell et al., 2007; Paunesku et al., 2015; Yeager et al., 2016). For instance, Andersen and Nielsen (2016) designed an intervention to change how parents view their child's reading ability and how to interact with their child while reading. Parents in the intervention group were given information that their child's reading ability can be improved (promoting a growth mindset instead of fixed), which resulted in improvements in the children's reading ability and language skills up to seven months later. Other interventions aimed at promoting a growth mindset for improving academic performance have also been successful in adolescents and college students (Aronson, Fried, \& Good, 2002; Blackwell et al., 2007). Interventions could be designed to promote a nonlimited view of self-control resources, which may improve trait and potentially momentary self-control. One recent study found that training individuals across several weeks to have a growth mindset about self-regulation (i.e., that self-regulation can be 
improved with effort) was related to better self-control in daily life and more perseverance on laboratory tasks (Mrazek et al., 2018). Thus, interventions aimed at implicit beliefs about selfcontrol hold great promise as they could help individuals persevere in their pursuit of goals despite other temptations or prior adverse experiences.

There is also evidence that other situational factors that coincide with attempts to use self-control in any moment (e.g., strength of desires, importance of other goals) may also be ideal targets for interventions. In models of momentary self-control, these factors remained consistently important in predicting resistance success. With increasing strength of desires and less importance of competing goals, individuals were less successful resisting their desires. Thus, intervention efforts targeting a reduction of desire strength or an increase in a conflicting goal's importance, may be effective for improving self-control at each desire resistance attempt.

\section{Limitations and Future Directions}

The present study adds to the literature about the importance of accumulated risk factors and current implicit beliefs for self-control, but the findings should be interpreted in light of some limitations. Although the current sample of college students are within the emerging adulthood period, they may not represent all emerging adults that did not attend college. Also, a large majority of the sample was female. Some studies of youth find girls demonstrate more selfcontrol than boys (e.g., Duckworth \& Seligman, 2006; Matthews, Ponitz, \& Morrison, 2009). Although the present study did not find any gender differences among key variables, there may not be enough power to detect differences with so few males in the sample. Additionally, there may be some selection bias among participants in the final sample, such that the final sample may be more self-controlled than those who were screened out. The final sample included individuals who passed validity check questions, signed up for the text-messaged service by 
following directions at the end of the survey, and attend college, all of which may associate with higher self-control compared to individuals that were screened out. Future work would benefit from a more diverse sample (e.g., gender, college and non-college students). For instance, studies should include emerging adults in various stages of career development, such as those attending college, those in a technical or trade school, or already having entered the workforce. Also, more than one set of accessible directions about signing-up for the ESM portion would be valuable so that participants who clicked out of the survey without reading all directions (e.g., those with low self-control or high impulsivity) may be more likely to complete the sign-up process and be included in the final sample.

Self-reported responses about the experience of risk factors while growing up could have been inaccurately reported by participants. Inaccurate reporting may be due to recall bias in retrospectively reporting some aspects of their family history (Hardt \& Rutter, 2004; Turiano et al., 2017). For instance, emerging adults' perception or memory of their families' financial status or difficulty paying bills while growing up may not coincide with actual family income or net wealth. However, there is evidence that participants can accurately recall if an event occurred into adulthood (Turiano et al., 2017; Hardt \& Rutter, 2004), suggesting that emerging adults in the present study are likely accurately reporting the presence of the assessed risk factors while growing up (e.g., caregiver education, difficulty paying bills, chaos in home, attachments to caregivers). Prospective designs with multiple informants, such as caregiver reports, would be beneficial to gain accuracy in reporting of risk factors as a youth.

Also, there is missing data for experience sampled questionnaires. For instance, if individuals reported experiencing a recent desire, the participants were then asked if they attempted to resist it. Those who indicated "No", had missing data on subsequent questions of 
self-control success. Although the "No" response was treated as "entirely unsuccessful" 1, the participant may have had specific reasons for 'giving in' to the desire without resisting. Thus, future research should investigate self-control success with the inclusion of an option to provide an explanation to understand the circumstances behind choosing not to use self-control. Some recent theorists argue that individuals with the greatest self-control are not inherently better at resisting desires, but are better at selecting situations that avoid temptations so they do not have to enact resistance (Hofmann et al. 2012a). Allowing participants to explain why they did and did not resist a desire would greatly enhance our understanding of the use of self-control in the moment.

The present study cannot address how the timing of the risk factors matters in its association with self-control. It is possible that self-control could decrease close in time to the events indicating risk (e.g., financial strain may only be problematic on self-control during the time of strain). However, it is possible that it is a gradual or additive process, as would be suggested by the accumulated stress models of adverse experience. For instance, between seven months to four years of age, children's cortisol elevated more each passing year with increasing number caregiver changes (Blair et al., 2011), suggesting that the effect of adversity may be observable after years of exposure in childhood. Prospective designs with assessments every few years with additional experience sampling bursts should be employed in future work to determine when adverse events begin and end, and how the timing of such events associate with self-control at the trait and momentary level over time, including in emerging adulthood. A prospective design would also help identify how nuanced exposure to many different risks across

\footnotetext{
${ }^{1}$ Primary analyses reported in text include the participants who reported not resisting a desire as the lowest success resisting (0), and were also conducted with the original resist metric (1=not at all successful, I gave in to the desire fully to 5 = entirely successful, I did not give in to the desire) which does not include those who reported "No" to having a desire. The main findings were the same for both codings of resistance success (see Appendix I).
} 
time (e.g., the onset of caregiver unemployment, when they moved residences), uniquely associate with self-control. Future work would also benefit from including measurements of selfreported chronic stress and biological assessments of stress reactivity (e.g., allostatic load, daily cortisol reactivity) to examine as a mechanism between accumulated risk, implicit beliefs, and trait and momentary self-control.

\section{Conclusions}

Despite the limitations, there is clear evidence that experiencing fewer risk factors before emerging adulthood and holding the belief that self-control is drawn from a nonlimited resource are predictors of greater self-control success. These associations were found cross-sectionally in association with trait self-control, and with an intensive longitudinal design assessing self-control success with multiple responses over a week. Exploratory work also identified that the association of early risk on self-control may be taking place through development of implicit beliefs about self-control. This provides a target for intervention and prevention efforts to improve low self-control, which has lasting implications for several life outcomes. Finding that implicit beliefs may be a mechanism for connecting accumulated risks to self-control suggests individuals with risks are vulnerable to developing a limited belief about self-control, and could benefit greatly from an intervention targeting self-control beliefs. 


\section{References}

Ainsworth, M. S. (1979). Infant-mother attachment. American Psychologist, 34, 932-937. doi:10.1037/0003-066X.34.10.932

Ainsworth, M. S., \& Bowlby, J. (1991). An ethological approach to personality development. American Psychologist, 46, 333-341.

Andersen, S. C., \& Nielsen, H. S. (2016). Reading intervention with a growth mindset approach improves children's skills. Proceedings of the National Academy of Sciences, 113, 12111-12113. doi: 10.1073/pnas. 1607946113

Aronson, J., Fried, C. B., \& Good, C. (2002). Reducing the effects of stereotype threat on African American college students by shaping theories of intelligence. Journal of Experimental Social Psychology, 38, 113-125. doi: 10.1006/jesp.2001.1491

Arnett, J. J. (2000). Emerging adulthood: A theory of development from the late teens through the twenties. American Psychologist, 55, 469-480. doi:10.1037//0003-066X.55.5.469

Arnett, J. J. (2007). Emerging adulthood: What is it, and what is it good for?. Child Development Perspectives, 1, 68-73. doi: 10.1111/j.1750-8606.2007.00016.x

Barkley, R. A. (2001). The executive functions and self-regulation: An evolutionary neuropsychological perspective. Neuropsychology Review, 11, 1-29. doi:10.1023/A:1009085417776

Baumeister, R. F., Vohs, K. D., \& Tice, D. M. (2007). The strength model of selfcontrol. Current Directions in Psychological Science, 16, 351-355.

Bernecker, K., \& Job, V. (2015). Beliefs about willpower moderate the effect of previous day demands on next day's expectations and effective goal striving. Frontiers in Psychology, 6, 1-10. doi:10.3389/fpsyg.2015.01496 
Bernier, A., Carlson, S. M., \& Whipple, N. (2010). From external regulation to self-regulation: Early parenting precursors of young children's executive functioning. Child Development, 81, 326-339. http://www.jstor.org/stable/40598981

Beutel, M. E., Tibubos, A. N., Klein, E. M., Schmutzer, G., Reiner, I., Kocalevent, R. D., \& Brähler, E. (2017). Childhood adversities and distress: The role of resilience in a representative sample. PLoS One, 12, e0173826. doi: 10.1371/ journal.pone.0173826

Blackwell, L. S., Trzesniewski, K. H., \& Dweck, C. S. (2007). Implicit theories of intelligence predict achievement across an adolescent transition: A longitudinal study and an intervention. Child Development, 78, 246-263. doi:10.1111/j.1467-8624.2007.00995.x

Blair, C. (2010). Stress and the development of self-regulation in context. Child Development Perspectives, 4, 181-188. doi:10.1111/j.1750-8606.2010.00145.x

Blair, C., \& Raver, C. C. (2012). Child development in the context of adversity: Experiential canalization of brain and behavior. American Psychologist, 67, 309-318. doi: $10.1037 / \mathrm{a} 0027493$

Blair, C., Granger, D. A., Willoughby, M., Mills-Koonce, R., Cox, M., Greenberg, M. T., ... \& FLP Investigators. (2011). Salivary cortisol mediates effects of poverty and parenting on executive functions in early childhood. Child Development, 82, 1970-1984. doi:10.1111/j.1467-8624.2011.01643.x

Bolger, N. \& Laurenceau, J. (2013). Statistical power for intensive longitudinal designs. In N. Bolger \& J. Laurenceau (Eds.), Intensive longitudinal methods: An Introduction to diary and experience sampling research (pp. 197-228). New York, NY: Guilford Press.

Bradley, R. H., \& Corwyn, R. F. (2002). Socioeconomic status and child development. Annual Review of Psychology, 53, 371-399. doi:10.1146/annurev.psych.53.100901.135233 
Bretherton, I. (1992). The origins of attachment theory: John Bowlby and Mary Ainsworth. Developmental Psychology, 28, 759-775.

Brooks-Gunn, J., \& Duncan, G. J. (1997). The effects of poverty on children. The Future of Children, 7, 55-71.

Bronfenbrenner, U., \& Evans, G. W. (2000). Developmental science in the 21 st century: Emerging questions, theoretical models, research designs and empirical findings. Social Development, 9, 115-125. doi:10.1111/1467-9507.00114

Brown, E. D. (2009). Persistence in the face of academic challenge for economically disadvantaged children. Journal of Early Childhood Research, 7, 173-184. doi:10.1177/1476718X09102650

Cassidy, J. (1994). Emotion regulation: Influences of attachment relationships. Monographs of the Society for Research in Child Development, 59, 228-249. doi:10.1111/j.1540-5834.1994.tb01287.x

Castelloe, J. M., \& O'Brien, R. G. (2001). Power and sample size determination for linear models. Proceedings of the Twenty-Sixth Annual SAS Users Group International Conference, 240-26.

Claro, S., Paunesku, D., \& Dweck, C. S. (2016). Growth mindset tempers the effects of poverty on academic achievement. Proceedings of the National Academy of Sciences, 113, 86648668. doi:10.1073/pnas.1608207113

Curran, P. J., Bauer, D. J., \& Willoughby, M. T. (2006). Testing and probing interactions in hierarchical linear growth models. In C. Bergeman \& S. Boker (Eds.), Methodological issues in aging research. New York, NY: Psychology Press. 
Deater-Deckard, K., Chen, N., Wang, Z., \& Bell, M. A. (2012). Socioeconomic risk moderates the link between household chaos and maternal executive function. Journal of Family Psychology, 26, 391. doi:10.1037/a0028331.

De Ridder, D. T. D., De Boer, B. J., Lugtig, P., Bakker, A. B., \& Van Hooft, E. A. J. (2011). Not doing bad things is not equivalent to doing the right thing: Distinguishing between inhibitory and initiatory self-control. Personality and Individual Differences, 50, 10061011. http://dx.doi.org/10.1016/j.paid.2011.01.015.

De Ridder, D. T., Lensvelt-Mulders, G., Finkenauer, C., Stok, F. M., \& Baumeister, R. F. (2012). Taking stock of self-control: A meta-analysis of how trait self-control relates to a wide range of behaviors. Personality and Social Psychology Review, 16, 76-99. doi: $10.1177 / 1088868311418749$

Drake, K., Belsky, J., \& Fearon, R. M. (2014). From early attachment to engagement with learning in school: The role of self-regulation and persistence. Developmental Psychology, 50, 1350-1362. doi: 10.1037/a0032779

Duckworth, A. L., \& Seligman, M. E. (2006). Self-discipline gives girls the edge: Gender in selfdiscipline, grades, and achievement test scores. Journal of Educational Psychology, 98, 198-208. doi: 10.1037/0022-0663.98.1.198

Dumas, J. E., Nissley, J., Nordstrom, A., Smith, E. P., Prinz, R. J., \& Levine, D. W. (2005). Home chaos: Sociodemographic, parenting, interactional, and child correlates. Journal of Clinical Child and Adolescent Psychology, 34, 93-104.

doi:10.1207/s15374424jccp3401_9 
Dweck, C. S. (1996). Implicit theories as organizers of goals and behavior. In P. M. Gollwitzer \& J. A. Bargh (Eds.), The psychology of action: Linking cognition and motivation to behavior. New York, NY: Guilford Press.

Enders, C. K., \& Tofighi, D. (2007). Centering predictor variables in cross-sectional multilevel models: A new look at an old issue. Psychological Methods, 12, 121-138. doi:10.1037/1082-989X.12.2.121

Evans, G. W. (2003). A multimethodological analysis of cumulative risk and allostatic load among rural children. Developmental Psychology, 39, 924-933. doi:10.1037/0012-1649.39.5.924

Evans, G. W. (2004). The environment of childhood poverty. American Psychologist, 59, 77-92. doi:10.1037/0003-066X.59.2.77

Evans, G. W., \& English, K. (2002). The environment of poverty: Multiple stressor exposure, psychophysiological stress, and socioemotional adjustment. Child Development, 73, 1238-1248.

Evans, G. W., \& Kim, P. (2013). Childhood poverty, chronic stress, self-regulation, and coping. Child Development Perspectives, 7, 43-48. doi:10.1111/cdep.12013

Evans, G. W., \& Marcynyszyn, L. A. (2004). Environmental justice, cumulative environmental risk, and health among low-and middle-income children in upstate New York. American Journal of Public Health, 94, 1942-1944. doi:10.2105/AJPH.94.11.1942

Evans, G. W., Gonnella, C., Marcynyszyn, L. A., Gentile, L., \& Salpekar, N. (2005). The role of chaos in poverty and children's socioemotional adjustment. Psychological Science, 16, 560-565. doi:10.1111/j.0956-7976.2005.01575.x 
Evans, G. W., Li, D., \& Whipple, S. S. (2013). Cumulative risk and child development. Psychological Bulletin, 139, 1342-1396. doi:10.1037/a0031808

Evans, G. W., \& Rosenbaum, J. (2008). Self-regulation and the income-achievement gap. Early Childhood Research Quarterly, 23, 504-514. doi:10.1016/j.ecresq.2008.07.002

Felitti, V. J., Anda, R. F., Nordenberg, D., Williamson, D. F., Spitz, A. M., Edwards, V., \& Marks, J. S. (1998). Relationship of childhood abuse and household dysfunction to many of the leading causes of death in adults: The Adverse Childhood Experiences (ACE) Study. American Journal of Preventive Medicine, 14, 245-258,

Ferrari, J.R., Stevens, E.B., \& Jason, L.A. (2009). The relationship of self-control and abstinence maintenance: An exploratory analysis of self-regulation. Journal of Groups in Addiction and Recovery, 4, 32-41. http://dx.doi.org/10.1080/15560350802712371.

Ford, J. A., \& Blumenstein, L. (2013). Self-control and substance use among college students. Journal of Drug Issues, 43, 56-68. doi:10.1177/0022042612462216

Fraley, R. C., Heffernan, M. E., Vicary, A. M., \& Brumbaugh, C. C. (2011). The experiences in close relationships—-Relationship Structures Questionnaire: A Method for assessing attachment orientations across relationships. Psychological Assessment, 23, 615-625. doi: $10.1037 / \mathrm{a} 0022898$

Field, A. (2009). Discovering statistics using SPSS. New York, NY: Sage Publications.

Fuller-Rowell, T. E., Evans, G. W., Paul, E., \& Curtis, D. S. (2015). The role of poverty and chaos in the development of task persistence among adolescents. Journal of Research on Adolescence, 25, 606-613. doi:10.1111/jora.12157 
Galobardes, B., Shaw, M., Lawlor, D. A., Lynch, J. W., \& Smith, G. D. (2006). Indicators of socioeconomic position (part 1). Journal of Epidemiology \& Community Health, 60, 712. doi:10.1016/j.annepidem.2005.06.053

Garson, G. D. (2013). Hierarchical linear modeling: Guide and applications. Thousand Oaks, CA: SAGE Publications, Inc.

Gentzler, A. L., Kerns, K. A., \& Keener, E. (2010). Emotional reactions and regulatory responses to negative and positive events: Associations with attachment and gender. Motivation and Emotion, 34, 78-92. doi:10.1007/s11031-009-9149-x

Gibson, C., Schreck, C. J., \& Miller, J. M. (2004). Binge drinking and negative alcohol-related behaviors: A test of self-control theory. Journal of Criminal Justice, 32, 411-420. doi:10.1016/j.jcrimjus.2004.06.003

Glymour, M. M., Ertel, K. A., \& Berkman, L. F. (2009). What can life-course epidemiology tell us about health inequalities in old age. In T. Antonucci and J. Jackson (Eds.), Annual review of gerontology and geriatrics. New York, NY: Springer Publishing Company.

Goodman, E., Adler, N. E., Kawachi, I., Frazier, L. A., Huang, B., \& Colditz, G. A. (2001). Adolescents' perceptions of social status: Development and evaluation of a new indicator. Pediatrics, 108, 1-8. doi:10.1542/peds.108.2.e31

Hardt, J., \& Rutter, M. (2004). Validity of adult retrospective reports of adverse child- hood experiences: Review of the evidence. Journal of Child Psychology and Psychiatry, 45, $260-273$.

Hayes, A. F. (2013). Introduction to mediation, moderation, and conditional process analysis: A Regression-based approach. New York, NY: Guilford Press. 
Hektner, J. M., Schmidt, J. A., \& Csikszentmihalyi, M. (2007). Experience sampling method: Measuring the quality of everyday life. Thousand Oaks, CA: Sage.

Hofmann, W., Baumeister, R. F., Förster, G., \& Vohs, K. D. (2012a). Everyday temptations: An experience sampling study of desire, conflict, and self-control. Journal of Personality and Social Psychology, 102, 1318-1335. doi:10.1037/a0026545

Hofmann, W., \& Patel, P. V. (2015). SurveySignal: A convenient solution for experience sampling research using participants' own smartphones. Social Science Computer Review, 33, 235-253. doi:10.1177/0894439314525117

Hofmann, W., Schmiechel, B. J., \& Baddeley, A. D. (2012c). Executive functions and selfregulation. Trends in Cognitive Science, 16, 174-180. doi:10.1016/j.tics. 2012.01.006.

Hofmann, W., Vohs, K. D., \& Baumeister, R. F. (2012b). What people desire, feel conflicted about, and try to resist in everyday life. Psychological Science, 23, 582-588. doi:10.1177/0956797612437426

Holmes, C., Brieant, A., Kahn, R., Deater-Deckard, K., \& Kim-Spoon, J. (2019). Structural home environment effects on developmental trajectories of self-control and adolescent risk taking. Journal of Youth and Adolescence, 48, 43-55. doi:10.1007/s10964-018-0921-7

Hostinar, C. E., Ross, K. M., Chen, E., \& Miller, G. E. (2015). Modeling the association between lifecourse socioeconomic disadvantage and systemic inflammation in healthy adults: The role of self-control. Health Psychology, 34, 580-590. doi:10.1037/hea0000130

Hox, J. J., Moerbeek, M., \& Van de Schoot, R. (2010). Sample sizes and power analysis in multilevel regression. In J. Hox, M. Moerbeek, \& R. Van de Schoot (Eds.). Multilevel analysis: Techniques and applications. New York: Routledge. 
Hughes, C., Ensor, R., Wilson, A., \& Graham, A. (2009). Tracking executive function across the transition to school: A latent variable approach. Developmental Neuropsychology, 35, 2036. doi:10.1080/87565640903325691

Irving, S. M., \& Ferraro, K. F. (2006). Reports of abusive experiences during childhood and adult health ratings: personal control as a pathway?. Journal of Aging and Health, 18, 458-485. doi:10.1177/0898264305280994

Job, V. (2016). Implicit Theories About Willpower. In E. R. Hirt, J. J. Clarkson, \& L. Jia (Eds.), Self-Regulation and Ego Control. Academic Press.

Job, V., Dweck, C. S., \& Walton, G. M. (2010). Ego depletion-Is it all in your head? Implicit theories about willpower affect self-regulation. Psychological Science, 21, 1686-1693. doi:10.1177/0956797610384745

Job, V., Walton, G. M., Bernecker, K., \& Dweck, C. S. (2015). Implicit theories about willpower predict self-regulation and grades in everyday life. Journal of Personality and Social Psychology, 108, 637-647. doi:10.1037/pspp0000014

Kahn, R. E., Holmes, C., Farley, J. P., \& Kim-Spoon, J. (2015). Delay discounting mediates parent-adolescent relationship quality and risky sexual behavior for low self-control adolescents. Journal of Youth and Adolescence, 44, 1674-1687. doi: 10.1007/s10964-015-0332-y

Kendall-Tackett, K. (2002). The health effects of childhood abuse: Four pathways by which abuse can influence health. Child Abuse \& Neglect, 26, 715-729.

Kirby, K. N., Winston, G. C., \& Santiesteban, M. (2005). Impatience and grades: Delay-discount rates correlate negatively with college GPA. Learning and Individual Differences, 15, 213-222. doi:10.1016/j.lindif.2005.01.003 
Klinger, J. A., Scholer, A. A., Hui, C. M., \& Molden, D. C. (2018). Effortful experiences of selfcontrol foster lay theories that self-control is limited. Journal of Experimental Social Psychology, 78, 1-13. doi:10.1016/j.jesp.2018.04.006

Kochanska, G., Philibert, R. A., \& Barry, R. A. (2009). Interplay of genes and early motherchild relationship in the development of self-regulation from toddler to preschool age. Journal of Child Psychology and Psychiatry, 50, 1331-1338.

doi: $10.1111 / \mathrm{j} .1469-7610.2008 .02050 . \mathrm{x}$

Letourneau, N. L., Duffett-Leger, L., Levac, L., Watson, B., \& Young-Morris, C. (2011). Socioeconomic status and child development: A meta-analysis. Journal of Emotional and Behavioral Disorders, 21, 1-14. doi: 10.1177/1063426611421007

Liu, L., Feng, T., Suo, T., Lee, K., \& Li, H. (2012). Adapting to the destitute situations: Poverty cues lead to short-term choice. PloS one, 7, e33950. doi:10.1371/journal.pone.0033950

Maas, C. J., \& Hox, J. J. (2005). Sufficient sample sizes for multilevel modeling. Methodology, 1, 86-92. doi:10.1027/1614-1881.1.3.86

Maier, M. A., Bernier, A., Pekrun, R., Zimmermann, P., Strasser, K., \& Grossmann, K. E. (2005). Attachment state of mind and perceptual processing of emotional stimuli. Attachment \& Human Development, 7, 67-81. doi:10.1080/14616730500039606

Maloney, P.M., Grawitch, M.J., \& Barber, L.K. (2012). The multi-factor structure of the brief self-control scale: Discriminant validity of restraint and impulsivity. Journal of Research in Personality, 46, 111-115. doi: 10.1016/j.jrp.2011.10. 001.

Mani, A., Mullainathan, S., Shafir, E., \& Zhao, J. (2013). Poverty impedes cognitive function. Science, 341, 976-980. doi:10.1126/science.1238041 
Matheny Jr, A. P., Wachs, T. D., Ludwig, J. L., \& Phillips, K. (1995). Bringing order out of chaos: Psychometric characteristics of the confusion, hubbub, and order scale. Journal of Applied Developmental Psychology, 16, 429-444.

Matthews, J. S., Ponitz, C. C., \& Morrison, F. J. (2009). Early gender differences in selfregulation and academic achievement. Journal of Educational Psychology, 101, 689-704. doi: $10.1037 / \mathrm{a} 0014240$

Meaney, M. J. (2001). Maternal care, gene expression, and the transmission of individual differences in stress reactivity across generations. Annual Review of Neuroscience, 24, 1161-1192. doi: 0147-006X/01/0621-1161

Michaelson, L. E., \& Munakata, Y. (2016). Trust matters: Seeing how an adult treats another person influences preschoolers' willingness to delay gratification. Developmental Science, 19, 1011-1019. doi: 10.1111/desc. 12388

Mikulincer, M., Florian, V., \& Weller, A. (1993). Attachment styles, coping strategies, and posttraumatic psychological distress: The impact of the Gulf War in Israel. Journal of Personality and Social Psychology, 64, 817-826.

Mikulincer, M., Shaver, P. R., \& Pereg, D. (2003). Attachment theory and affect regulation: The dynamics, development, and cognitive consequences of attachment-related strategies. Motivation and Emotion, 27, 77-102. doi: 0146-7239/03/0600-0077/0

Milyavskaya, M., Inzlicht, M., Hope, N., \& Koestner, R. (2015). Saying "no" to temptation: Want-to motivation improves self-regulation by reducing temptation rather than by increasing self-control. Journal of Personality and Social Psychology, 109, 677-693. doi:10.1037/pspp0000045 
Moffitt, T. E., Arseneault, L., Belsky, D., Dickson, N., Hancox, R. J., Harrington, H., ... Caspi, A. (2011). A gradient of childhood self-control predicts health, wealth, and public safety. PNAS Proceedings of the National Academy of Sciences of the United States of America, 108, 2693-2698. doi:10.1073/pnas.1010076108

Moilanen, K. L. (2007). The adolescent self-regulatory inventory: The development and validation of a questionnaire of short-term and long-term self-regulation. Journal of Youth and Adolescence, 36, 835-848. doi:10.1007/s10964-018-0825-6

Molden, D. C., \& Dweck, C. S. (2006). Finding "meaning" in psychology: A lay theories approach to self-regulation, social perception, and social development. American Psychologist, 61, 192-203. doi:10.1037/0003-066X.61.3.192

Mrazek, A. J., Ihm, E. D., Molden, D. C., Mrazek, M. D., Zedelius, C. M., \& Schooler, J. W. (2018). Expanding minds: Growth mindsets of self-regulation and the influences on effort and perseverance. Journal of Experimental Social Psychology, 79, 164-180. doi:10.1016/j.jesp.2018.07.003

Muraven, M., \& Slessareva, E. (2003). Mechanisms of self-control failure: Motivation and limited resources. Personality and Social Psychology Bulletin, 29, 894-906.

Muthén, L. K., \& Muthén, B. O. (1998-2017). Mplus User's Guide. Eighth Edition. Los Angeles, CA: Muthén \& Muthén.

Nikulina, V., Widom, C. S., \& Czaja, S. (2011). The role of childhood neglect and childhood poverty in predicting mental health, academic achievement and crime in adulthood. American Journal of Community Psychology, 48, 309-321. doi:10.1007/s10464-010-9385-y 
Orehek, E., Vazeou-Nieuwenhuis, A., Quick, E., \& Weaverling, G. C. (2017). Attachment and self-regulation. Personality and Social Psychology Bulletin, 43, 365-380. doi:10.1177/0146167216685292

Pallini, S., Chirumbolo, A., Morelli, M., Baiocco, R., Laghi, F., \& Eisenberg, N. (2018). The relation of attachment security status to effortful self-regulation: A meta-analysis. Psychological Bulletin, 144, 501-531. doi:10.1037/bul0000134

Park, C. L., Edmondson, D., \& Lee, J. (2012). Development of self-regulation abilities as predictors of psychological adjustment across the first year of college. Journal of Adult Development, 19, 40-49. doi:10.1007/s10804-011-9133-z

Paunesku, D., Walton, G. M., Romero, C., Smith, E. N., Yeager, D. S., \& Dweck, C. S. (2015). Mind-set interventions are a scalable treatment for academic underachievement. Psychological Science, 26, 784-793. doi: 10.1177/0956797615571017

Piquero, A. R., Gibson, C. L., \& Tibbetts, S. G. (2002). Does self-control account for the relationship between binge drinking and alcohol-related behaviors? Criminal Behavior and Mental Health, 12, 135-154. doi:10.1002/cbm.492

Poulton, R., Caspi, A., Milne, B. J., Thomson, W. M., Taylor, A., Sears, M. R., \& Moffitt, T. E. (2002). Association between children's experience of socioeconomic disadvantage and adult health: A life-course study. The Lancet, 360, 1640-1645. doi:10.1016/S0140-6736(02)11602-3

Preacher, K. J., Zyphur, M. J., \& Zhang, Z. (2010). A general multilevel SEM framework for assessing multilevel mediation. Psychological Methods, 15, 209-233. doi: $10.1037 / \mathrm{a} 0020141$ 
Raudenbush, S.W., Bryk, A.S, Cheong, Y.F. \& Congdon, R. (2019). HLM 8 for Windows [Computer software]. Skokie, IL: Scientific Software International, Inc.

Raver, C. C., Blair, C., \& Willoughby, M. (2013). Poverty as a predictor of 4-year-olds' executive function: New perspectives on models of differential susceptibility. Developmental Psychology, 49, 292-304. doi:10.1037/a0028343.

Rotenberg, K. J. (1995). The socialisation of trust: Parents' and children's interpersonal trust. International Journal of Behavioral Development, 18, 713-726.

Schwarz, N. (1999.) Self-reports: How the questions shape the answers. American Psychologist, 54, 93-105.

Sieber, V., Flückiger, L., Mata, J., Bernecker, K., \& Job, V. (2019). Autonomous goal striving promotes a nonlimited theory about willpower. Personality and Social Psychology Bulletin, 45, 1295-1307. doi: 10.1177/0146167218820921

Sutter, M., \& Kocher, M. G. (2007). Trust and trustworthiness across different age groups. Games and Economic Behavior, 59, 364-382. doi:10.1016/j.geb.2006.07.006

Tangney, J. P., Baumeister, R. F., \& Boone, A. L. (2004). High self-control predicts good adjustment, less pathology, better grades, and interpersonal success. Journal of Personality, 72, 271-322. doi:10.1111/j.0022-3506.2004.00263.x

Trentacosta, C. J., Hyde, L. W., Shaw, D. S., Dishion, T. J., Gardner, F., \& Wilson, M. (2008). The relations among cumulative risk, parenting, and behavior problems during early childhood. Journal of Child Psychology and Psychiatry, 49, 1211-1219. doi:10.1111/j.1469-7610.2008.01941.x

Turiano, N. A., Silva, N. M., McDonald, C., \& Hill, P. L. (2017). Retrospective reports of childhood misfortune are associated with positive and negative affect in adulthood: 
Exploring the moderating role of control beliefs. The International Journal of Aging and Human Development, 84, 276-293.

Tversky, A., \& Kahneman, D. (1973). Availability: A heuristic for judging frequency and probability. Cognitive Psychology, 5, 207-232.

Valiente, C., Lemery-Chalfant, K., \& Reiser, M. (2007). Pathways to problem behaviors: Chaotic homes, parent and child effortful control, and parenting. Social Development, 16, 249267. doi:10.1111/j.1467-9507.2007.00383.x

van Koningsbruggen, G. M., Veling, H., Stroebe, W., \& Aarts, H. (2017). Comparing two psychological interventions in reducing impulsive processes of eating behavior: Effects on self-selected portion size. British Journal of Health Psychology, 19, 767-782. doi:10.1111/bjhp. 12075

Vernon-Feagans, L., Willoughby, M., \& Garrett-Peters, P. (2016). Predictors of behavioral regulation in kindergarten: Household chaos, parenting, and early executive functions. Developmental Psychology, 52, 430-441. doi:10.1037/dev0000087

Walpole, M. (2003). Socioeconomic status and college: How SES affects college experiences and outcomes. The Review of Higher Education, 27, 45-73. doi:10.1353/rhe.2003.0044

Warren, S. L., Bost, K. K., Roisman, G. I., Silton, R. L., Spielberg, J. M., Engels, A. S., ... \& Heller, W. (2010). Effects of adult attachment and emotional distractors on brain mechanisms of cognitive control. Psychological Science, 21, 1818-1826. doi:10.11770956797610388809

Woltman, H., Feldstain, A., MacKay, J. C., \& Rocchi, M. (2012). An introduction to hierarchical linear modeling. Tutorials in Quantitative Methods for Psychology, 8, 52-69. doi:10.20982/tqmp.08.1.p052 
Yeager, D. S., Romero, C., Paunesku, D., Hulleman, C. S., Schneider, B., Hinojosa, C., ... \& Trott, J. (2016). Using design thinking to improve psychological interventions: The case of the growth mindset during the transition to high school. Journal of Educational Psychology, 108(3), 374-411. doi:10.1037/edu0000098.

Zhang, C., Smolders, K. C., Lakens, D., \& IJsselsteijn, W. A. (2018). Two experience sampling studies examining the variation of self-control capacity and its relationship with core affect in daily life. Journal of Research in Personality, 74, 102-113. doi:10.1016/j.jrp.2018.03.001

Zimmermann, P., \& Iwanski, A. (2015). Attachment in middle childhood: Associations with information processing. New Directions for Child and Adolescent Development, 148, 4761. doi:10.1002/cad.20099 
Table 1

Number of Each Type of Caregiver Reported by Participants

\begin{tabular}{lcc}
\hline & $\begin{array}{c}\text { Caregiver 1 } \\
\text { Total } N \text { reported a } \\
\text { caregiver } 1=213\end{array}$ & $\begin{array}{c}\text { Caregiver 2 } \\
\text { Total } N \text { reported a } \\
\text { caregiver } 2=188\end{array}$ \\
\hline Biological mother & $176(82.2 \%)$ & $22(11.7 \%)$ \\
Biological father & $28(13.1 \%)$ & $146(77.6 \%)$ \\
Step-Mother & $0(0 \%)$ & $2(1.1 \%)$ \\
Step-Father & $0(0 \%)$ & $9(4.8 \%)$ \\
Mother-Figure/Guardian & $0(0 \%)$ & $0(0 \%)$ \\
Father-Figure/Guardian & $1(.5 \%)$ & $0(0 \%)$ \\
Custodial Grandparents & $3(1.4 \%)$ & $4(2.1 \%)$ \\
Other & $5(2.3 \%)$ & $2(2.7 \%)$ \\
\hline
\end{tabular}

Note. One person seems to have skipped a page of questions on Qualtrics which happened to include reporting the $1^{\text {st }}$ caregiver's role and their attachment. The other caregiver 1 questions unrelated to attachment were answered, and so was this person's caregiver 2 questions. 
Table 2

Descriptive Statistics of Variables of Interest at Baseline Assessment

\begin{tabular}{|c|c|c|c|c|c|}
\hline Variables & $\frac{\text { Mean }(\mathrm{SD}) \text { or }}{\underline{\mathbf{0}}}$ & $\begin{array}{c}\text { Min } \\
\text { Possible } \\
\end{array}$ & $\begin{array}{c}\text { Max } \\
\text { Possible } \\
\end{array}$ & Skew (SE) & $\underline{\text { Kurtosis (SE) }}$ \\
\hline \multicolumn{6}{|l|}{ Potential Covariates } \\
\hline Age & $19.11(1.2)$ & 18 & 25 & $1.33(.17)$ & $2.76(.33)$ \\
\hline College Year & $1.79(.93)$ & 1 & 4 & $.95(.17)$ & $-.10(.33)$ \\
\hline Gender & $79.4 \%$ female & 0 & 1 & -- & -- \\
\hline Race/ Ethnicity & $87.9 \%$ White & 0 & 1 & -- & -- \\
\hline Willpower Beliefs & $3.51(.74)$ & 1 & 6 & $.15(.17)$ & $.61(.33)$ \\
\hline \multicolumn{6}{|l|}{ Early Risk Variables } \\
\hline Total Early Risk & $1.77(1.46)$ & 0 & 7 & $.82(.17)$ & $-.60(.33)$ \\
\hline $\begin{array}{l}\text { Education } \\
\text { Caregiver } 1\end{array}$ & $7.79(1.73)$ & 1 & 9 & $-1.23(.17)$ & $.45(.33)$ \\
\hline $\begin{array}{l}\text { Education } \\
\text { Caregiver } 2\end{array}$ & $7.74(1.69)$ & 3 & 9 & $-.89(.18)$ & $-.86(.36)$ \\
\hline SES Ladder & $6.79(1.47)$ & 2 & 10 & $-.48(.17)$ & $-.05(.33)$ \\
\hline $\begin{array}{l}\text { Difficulty } \\
\text { Paying Bills }\end{array}$ & $1.87(.92)$ & 1 & 4 & $.63(.17)$ & $-.76(.33)$ \\
\hline Home Chaos & $4.55(4.02)$ & 0 & 15 & $-.78(.17)$ & $-.36(.33)$ \\
\hline $\begin{array}{l}\text { Caregiver } 1 \\
\text { avoidance }\end{array}$ & $2.47(1.29)$ & 1 & 7 & $1.08(.17)$ & $.90(.33)$ \\
\hline $\begin{array}{l}\text { Caregiver } 1 \\
\text { anxious }\end{array}$ & $1.49(1.05)$ & 1 & 7 & $2.93(.17)$ & $9.46(.33)$ \\
\hline $\begin{array}{l}\text { Caregiver } 2 \\
\text { avoidance }\end{array}$ & $3.31(1.59)$ & 1 & 7 & $.45(.17)$ & $-.52(.35)$ \\
\hline $\begin{array}{l}\text { Caregiver } 2 \\
\text { anxious }\end{array}$ & $1.77(1.41)$ & 1 & 7 & $2.08(.17)$ & $3.56(.35)$ \\
\hline \multicolumn{6}{|l|}{ Self-control } \\
\hline Trait & $3.12(.61)$ & 1 & 5 & $-.08(.17)$ & $.07(.33)$ \\
\hline Momentary & $1.67(2.06)$ & 0 & 5 & $.63(.05)$ & $-1.34(.10)$ \\
\hline
\end{tabular}

Note. All values listed are prior to any transformations. $\mathrm{SES}=$ socioeconomic status. Race / Ethnicity coded $0=$ White and $1=$ non-White. Gender coded $0=$ male and $1=$ female. 
Table 3

Descriptive Statistics of Variables of Interest Measured with Experience Sampling

\begin{tabular}{|c|c|c|c|c|c|}
\hline Variables & $\frac{\text { Mean (SD) or }}{\frac{\text { Number of }}{\text { reports }}}$ & $\underline{\underline{\text { Min }}} \underline{\underline{\text { Possible }}}$ & $\underline{\underline{\text { Max }}} \underline{\text { Possible }}$ & $\frac{\text { Skew }}{(\mathrm{SE})}$ & $\frac{\text { Kurtosis }}{(\mathrm{SE})}$ \\
\hline $\begin{array}{l}\text { Number of desires } \\
\text { reported }\end{array}$ & $\begin{array}{l}2223 \text { desires } \\
\text { reported }\end{array}$ & 0 & 1 & $.42(.03)$ & $-1.8(.07)$ \\
\hline Desire strength & $4.74(1.2)$ & 1 & 7 & $.03(.05)$ & $-.26(.10)$ \\
\hline $\begin{array}{l}\text { Number of resistance } \\
\text { attempts }\end{array}$ & $\begin{array}{l}990 \text { self-control } \\
\text { attempts reported }\end{array}$ & 0 & 1 & $.22(.05)$ & $-2.0(.10)$ \\
\hline Momentary SC & $1.67(2.06)$ & 0 & 5 & $.63(.05)$ & $-1.3(.10)$ \\
\hline Goal importance & $2.8(.10)$ & 1 & 4 & $-.23(.08)$ & $-1.0(.16)$ \\
\hline
\end{tabular}

Note. Momentary $\mathrm{SC}=$ desire resistance success. 
Table 4

Bivariate Correlations Among Baseline Risk Composite Score, Separate Risk Indices, and Trait and Momentary Self-control

\begin{tabular}{|c|c|c|c|c|c|c|c|c|c|c|c|c|}
\hline & 1 & 2 & 3 & 4 & 5 & 6 & 7 & 8 & 9 & 10 & 11 & 12 \\
\hline $\begin{array}{l}\text { 1. Implicit } \\
\text { Beliefs }\end{array}$ & -- & & & & & & & & & & & \\
\hline 2. Trait SC & $.57 * * *$ & --- & & & & & & & & & & \\
\hline $\begin{array}{l}\text { 3. Momentary } \\
\text { SC }\end{array}$ & .03 & -.05 & -- & & & & & & & & & \\
\hline $\begin{array}{l}\text { 4. Total Early } \\
\text { Risk }\end{array}$ & $-.24 * * *$ & $-.32 * * *$ & -.11 & -- & & & & & & & & \\
\hline $\begin{array}{l}\text { 5. Caregiver } 1 \\
\text { education }\end{array}$ & .01 & -.01 & .01 & $-.49 * * *$ & -- & & & & & & & \\
\hline $\begin{array}{l}\text { 6. Caregiver } 2 \\
\text { education }\end{array}$ & .01 & .08 & $.16^{*}$ & $-.51 * * *$ & $.37 * * *$ & -- & & & & & & \\
\hline 7. SES ladder & $.15^{*}$ & $.18 * *$ & .02 & $-.57 * * *$ & $.36 * * *$ & $.30 * * *$ & -- & & & & & \\
\hline $\begin{array}{l}\text { 8. Difficulty } \\
\text { paying bills }\end{array}$ & -.11 & $-.16^{*}$ & -.06 & $.60 * * *$ & $-.19 * *$ & $-.22 * *$ & $-.57 * * *$ & -- & & & & \\
\hline $\begin{array}{l}\text { 9. Chaos in the } \\
\text { home }\end{array}$ & $-.28 * * *$ & $-.33 * * *$ & -.04 & $.60 * * *$ & -.12 & -.03 & $-.41 * * *$ & $.42 * * *$ & -- & & & \\
\hline $\begin{array}{l}\text { 10. Caregiver } 1 \\
\text { avoidance }\end{array}$ & $-.28 * * *$ & $-.31 * * *$ & .06 & $.36^{* * *}$ & -.11 & .12 & $-.21 * *$ & .09 & $.45 * * *$ & -- & & \\
\hline $\begin{array}{l}\text { 11. Caregiver } 1 \\
\text { anxious }\end{array}$ & $-.18 * *$ & -.11 & -.04 & $.31 * * *$ & .01 & .07 & $-.28 * * *$ & $.17 *$ & $.35 * * *$ & $.56 * * *$ & -- & \\
\hline $\begin{array}{l}\text { 12. Caregiver } 2 \\
\text { avoidance }\end{array}$ & $-.24 * *$ & $-.31 * * *$ & .04 & $.43 * * *$ & -.09 & -.02 & $-.18^{*}$ & .11 & $.41 * * *$ & $.30 * * *$ & .10 & -- \\
\hline $\begin{array}{l}\text { 13. Caregiver } 2 \\
\text { anxious }\end{array}$ & $-.15 *$ & $-.22 * *$ & -.05 & $.37 * * *$ & .08 & .05 & -.11 & .13 & $.46 * * *$ & $.21 * *$ & $.26^{* * *}$ & $.59 * * *$ \\
\hline
\end{tabular}

Note. ${ }^{*} p<.05 . * * p<.01 . * * * p<.001$. Total early risk $=\log$ transformed composite of caregivers' education, SES ladder, difficulty paying bills, chaos, insecure attachment to both caregivers. SC $=$ self-control. Momentary SC = average of each time participants reported desire resistance success. 
Table 5

Regression Associations Among Each Main Baseline Variables and Momentary Self-Control, Without Any Level 1 Variables

Random Intercept Models Including Level 2 Baseline Variable Only

\begin{tabular}{lccccccccccccc}
\hline & $\begin{array}{c}\text { Trait } \\
\text { SC }\end{array}$ & Beliefs & $\begin{array}{c}\text { Total } \\
\text { risk }\end{array}$ & Edu 1 & Edu 2 & $\begin{array}{c}\text { SES } \\
\text { ladder }\end{array}$ & Bills & $\begin{array}{c}\text { Home } \\
\text { Chaos }\end{array}$ & Avd. 1 & Anx. 1 & Avd. 2 & Anx. 2 \\
\hline & $\begin{array}{c}\text { beta } \\
(\mathrm{se})\end{array}$ & $\begin{array}{c}\text { beta } \\
(\mathrm{se})\end{array}$ & $\begin{array}{c}\text { beta } \\
(\mathrm{se})\end{array}$ & $\begin{array}{c}\text { beta } \\
(\mathrm{se})\end{array}$ & $\begin{array}{c}\text { beta } \\
(\mathrm{se})\end{array}$ & $\begin{array}{c}\text { beta } \\
(\mathrm{se})\end{array}$ & $\begin{array}{c}\text { beta } \\
(\mathrm{se})\end{array}$ & $\begin{array}{c}\text { beta } \\
(\mathrm{se})\end{array}$ & $\begin{array}{c}\text { beta } \\
(\mathrm{se})\end{array}$ & $\begin{array}{c}\text { beta } \\
(\mathrm{se})\end{array}$ & $\begin{array}{c}\text { beta } \\
(\mathrm{se})\end{array}$ & $\begin{array}{c}\text { beta } \\
(\mathrm{se})\end{array}$ \\
\hline $\begin{array}{l}\text { Level 2 } \\
\text { variable }\end{array}$ & -.02 & .01 & -.30 & .02 & $.09 *$ & -.003 & -.02 & -.002 & .05 & .02 & .01 & -.03 \\
$(.11)$ & $(.07)$ & $(.25)$ & $(.04)$ & $(.04)$ & $(.04)$ & $(.07)$ & $(.02)$ & $(.05)$ & $(.05)$ & $(.05)$ & $(.05)$ \\
\hline $\begin{array}{l}\text { Residual } \\
\text { variance }\end{array}$ & $89.44 \%$ & $89.39 \%$ & $89.50 \%$ & $89.49 \%$ & $88.98 \%$ & $89.46 \%$ & $89.44 \%$ & $89.46 \%$ & $89.53 \%$ & $88.57 \%$ & $89.47 \%$ & $88.60 \%$ \\
\hline
\end{tabular}

Note. $* p<.05 . * * p<.01 . * * * p<.001$. Trait SC $=$ trait self-control. Implicit belief $=$ higher belief indicates stronger belief that selfcontrol is nonlimited. Total early risk = composite of caregivers' education, SES ladder, difficulty paying bills, chaos, insecure attachment to both caregivers $\log$ transformed. $\mathrm{Edu}=$ caregiver education. Bills $=$ difficulty paying bills. Avd. $=$ attachment avoidance. Anx. = attachment anxiety 
Table 6

Unstandardized Coefficients and Standard Errors for Regression Models Predicting Baseline Trait Self-Control

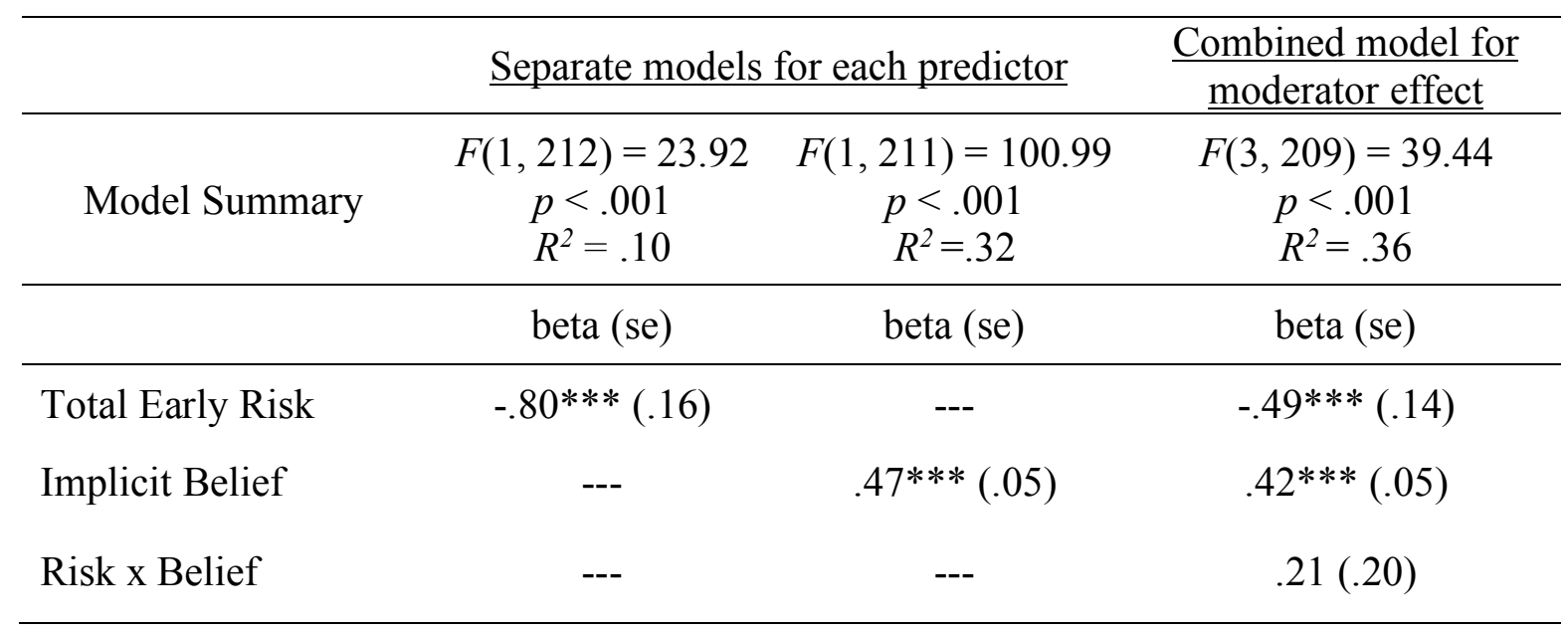

Note. Linear regressions computed using SPSS. Model with interaction was computed using Hayes PROCESS. Total early risk is summed number of risks including education level of two caregivers, difficulty paying bills, SES ladder, chaos in the home, attachment insecurity of two caregivers. $* p<.05$. $* * p<.01 . * * * p<.001$. 
Table 7

Unstandardized Coefficients and Standard Errors for Regression Models of Level 1 and Level 2 Predictors on Momentary Self-Control

\begin{tabular}{|c|c|c|c|c|c|}
\hline \multirow[t]{2}{*}{$\underline{\text { Variables }}$} & \multirow[t]{2}{*}{$\underline{\text { Null }}$} & $\frac{\frac{\text { Random }}{\text { Intercept }}}{\frac{\text { Model with }}{\text { Level 1 }}}$ & \multicolumn{3}{|c|}{$\frac{\text { Random Intercept Models Including Level } 1}{\underline{\text { and Level } 2 \text { Predictors }}}$} \\
\hline & & beta $(\mathrm{se})$ & beta $(\mathrm{se})$ & beta (se) & beta (se) \\
\hline Desire strength & -- & $-.32 * * *(.04)$ & $-.32 * * *(.04)$ & $-.32 * * *(.04)$ & $-.32 * * *(.04)$ \\
\hline $\begin{array}{l}\text { Goal } \\
\text { importance }\end{array}$ & -- & $.22 * * *(.06)$ & $.22 * * *(.06)$ & $.22 * * *(.06)$ & $.22 * * *(.06)$ \\
\hline Early risk & -- & -- & $-.54 *(.22)$ & -- & $-.45 *(.23)$ \\
\hline Implicit Belief & -- & -- & -- & $.13^{+}(.07)$ & $.11(.07)$ \\
\hline Risk x Belief & -- & - & -- & -- & $-.25(.30)$ \\
\hline $\begin{array}{c}\text { Residual } \\
\text { variance } \\
\text { (unexplained) }\end{array}$ & $88.47 \%$ & $83.40 \%$ & $83.82 \%$ & $83.95 \%$ & $83.81 \%$ \\
\hline
\end{tabular}

Note. ${ }^{+} p=.06 .{ }^{*} p<.05 . * * p<.01 . * * * p<.001$. 


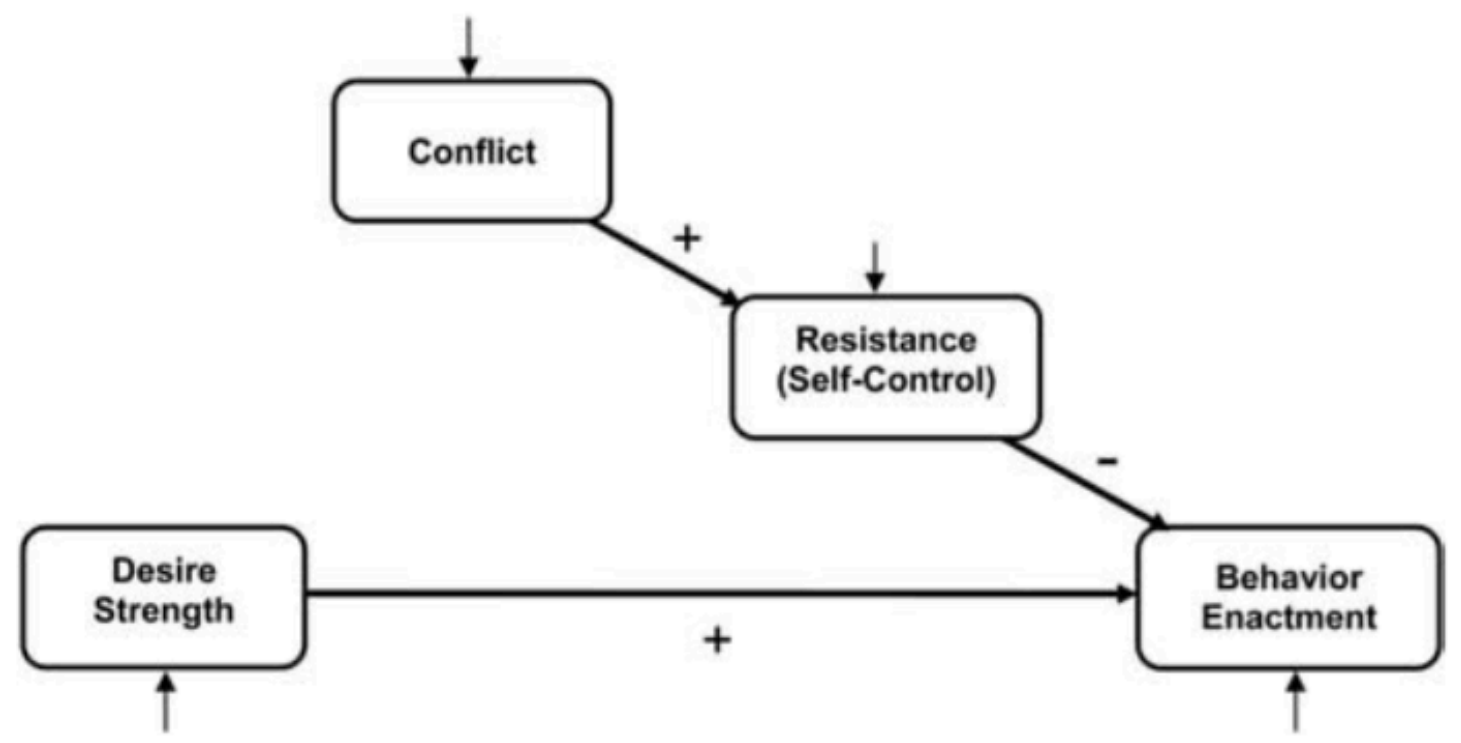

Figure 1. Conceptual model of motivated behavior as presented by Hofmann, Baumeister, Forster, and Vohs (2012a). The bottom path denotes how the strength of a desire sets the process in motion, leading to enacting behaviors to satisfy the desire. The upper path shows the factors that impede satisfying the desire. Experiencing greater conflict between the desire and another goal leads to greater self-control or resistance over the desire, preventing behaviors that satisfy the desire. The outside arrows show that at all parts of the process individual difference characteristics can affect the flow of this process 


\section{Implicit Self-control}

\section{Beliefs}

Limited Resource vs

Nonlimited Resource

Risk Index

- Socioeconomic Status

- Chaos in the Home

- Insecure Attachment

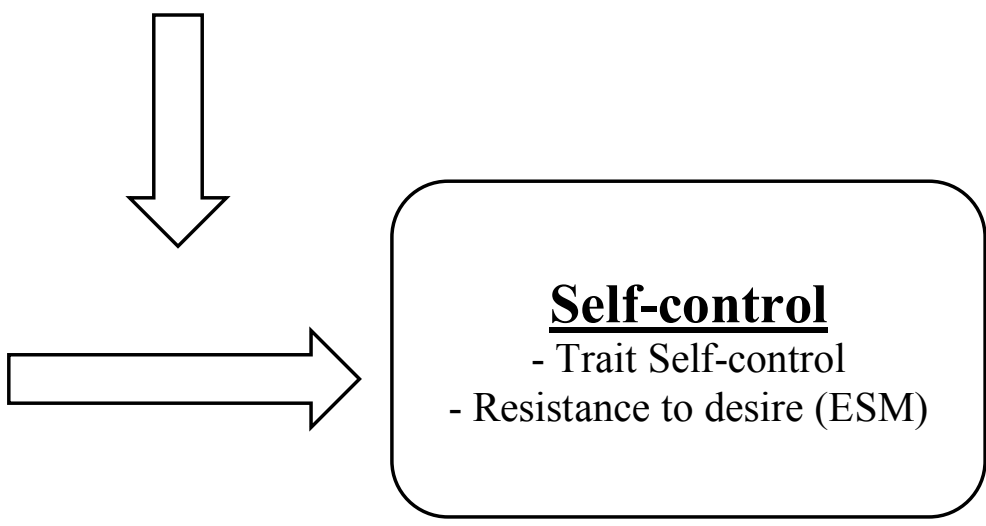

Figure 2. Conceptual model of early risk and self-control beliefs as individual difference factors that impact self-control. More early risks relate to low self-control for individuals with a limited resource belief. Trait self-control = self-report scale. ESM = experience sampling methodology. Socioeconomic status $=$ family difficulty paying bills, caregiver education, perceived social status. 

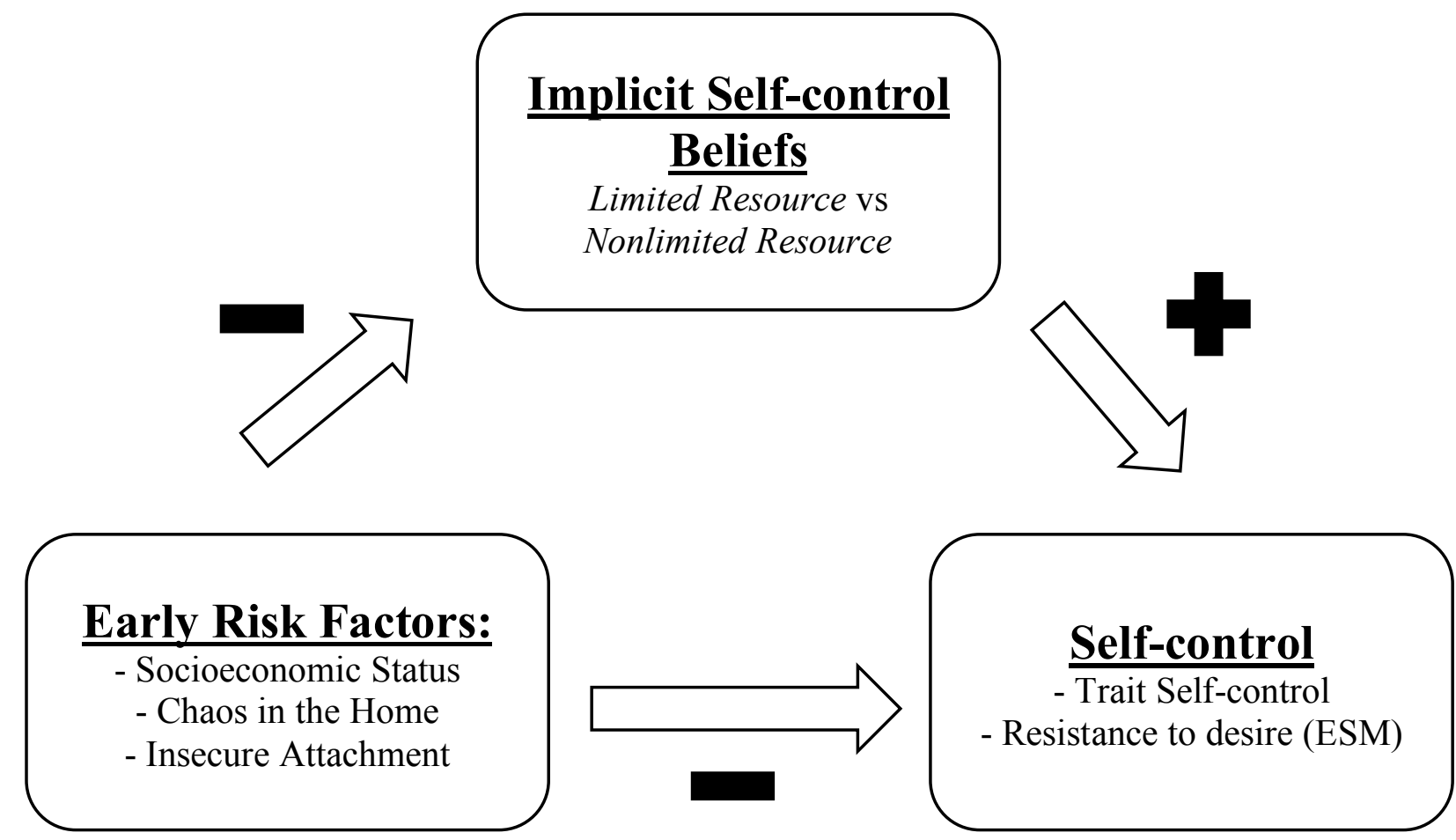

Figure 3. Conceptual model of early risk predicting self-control ability through self-control beliefs. More early risk factors associate with a low belief in nonlimited resources (or a more limited belief), which associates with a high self-control. Trait self-control = self-report scale at baseline. ESM = experience sampling methodology. Socioeconomic status = family difficulty paying bills, caregiver education, perceived social status. 


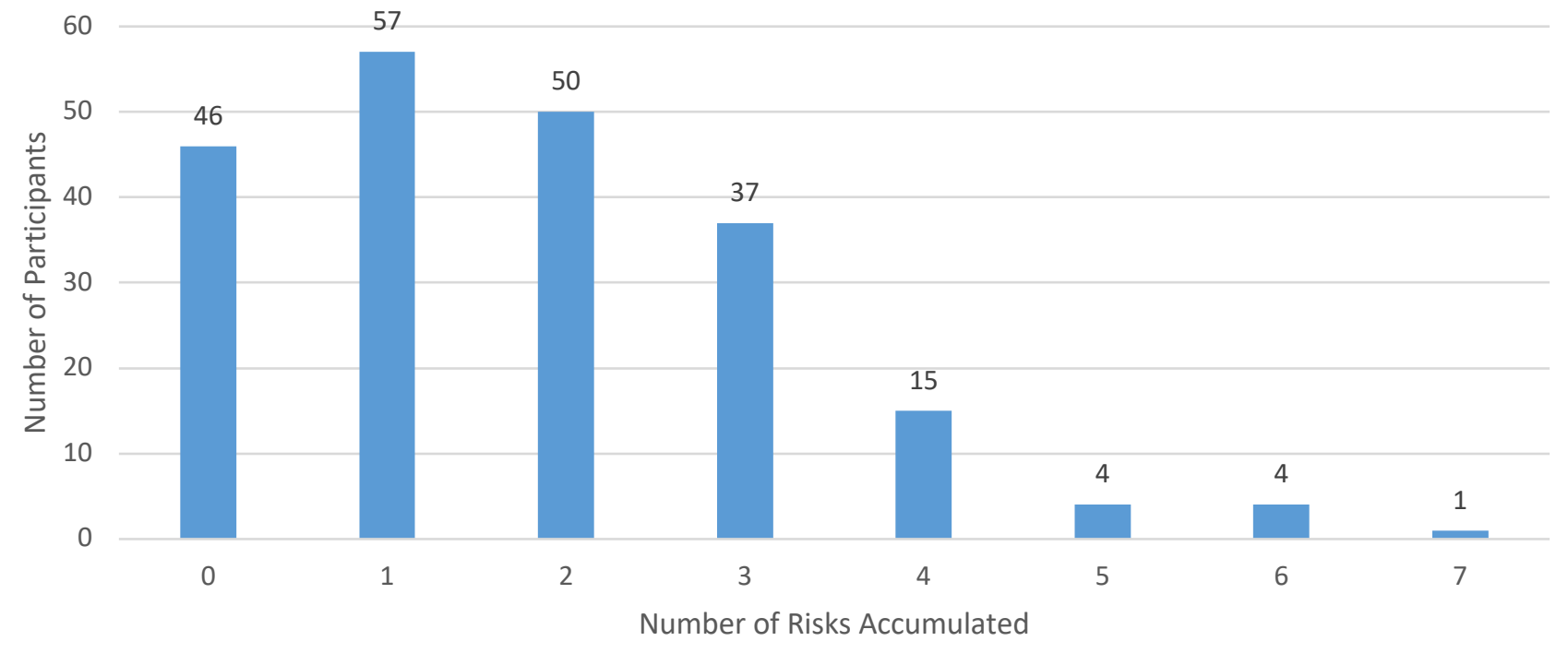

Figure 4. The number of participants reporting total accumulated early risks. Data labels represent exact number of participants with that number of accumulated risks out of a total $N=$ 214 (missing $n=30$, for not answering at least five of seven factors that comprise the risk score). 


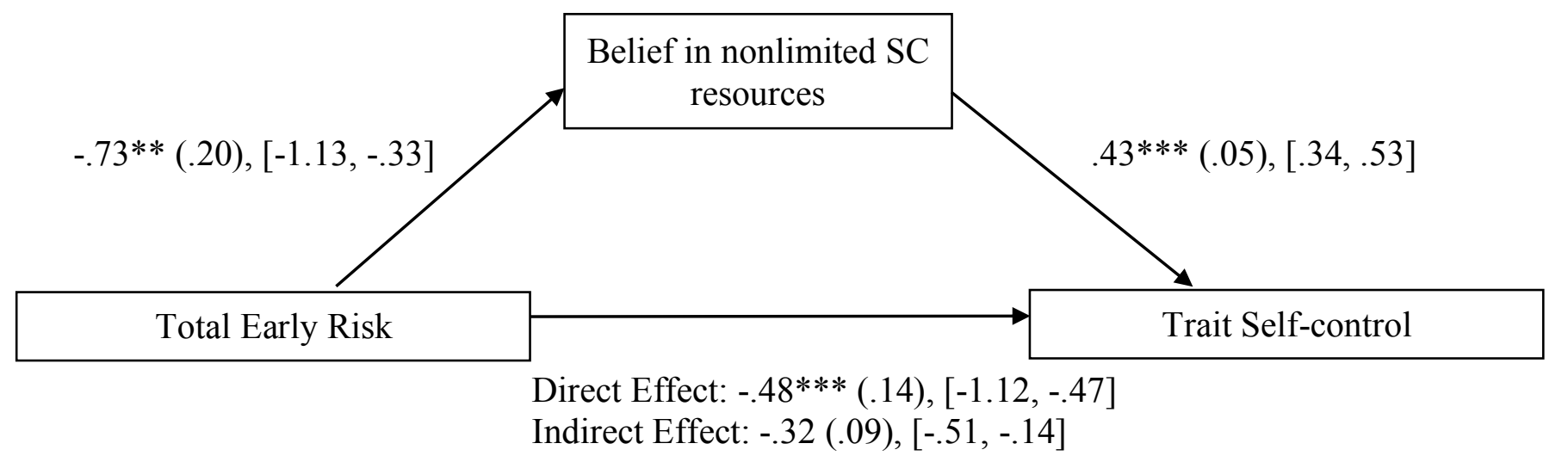

Figure 5. Mediation model with total early risks, implicit belief about SC (higher values indicate stronger nonlimited belief), and trait self-control. The confidence interval values of the indirect effect do not include zero, indicating that the indirect effect is significant.

Note. ${ }^{*} p<.05 . * * p<.01$. 


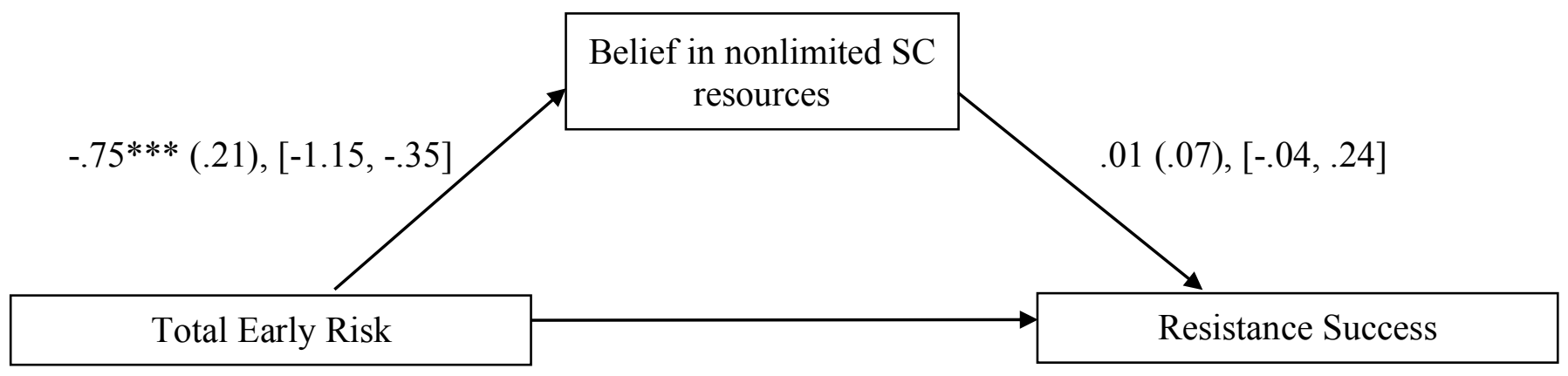

Direct Effect: $-.46^{*}(.21),[-.87,-.05]$

Indirect Effect: .07 (.06), [-.10,.11]

Figure 6. Mediational model with total early risks, implicit belief about SC (higher values indicate stronger nonlimited belief), and resistance success (higher values indicate greater success resisting desires). Model includes level one variables predicting resistance success (desire strength, $b=-.30$, se $=.04, p<.001$, CI [-0.38, -0.22], and goal importance, $b=.20$, se $=$ $.06, p<.001, \mathrm{CI}[0.10,0.31])$. The confidence interval values of the indirect effect include zero, indicating that the indirect effect is non-significant.

Note. $* p<.05 . * * p<.01$. 
Appendices 
Appendix A

Baseline Survey Measures

\section{Demographics}

1. Are you 18 years old or older?

Yes

No

2. Do you have a smart phone that can access the internet?

Yes

No

3. Does your phone have access to data and wifi?

Yes

No

4. What cell phone company is your service provider?

Verizon

AT\&T

T-Mobile

Sprint

US Cellular

Cricket Wireless

Other

5. What is the phone number for your smart phone?

6. What is your current age in years?

7. What is your race or ethnicity?

$\square$ White or Caucasian

Black or African-American

$\square$ Pacific Islander or Native Hawaiian

$\square$ Asian or Asian-American

Native American

Hispanic or Latino-American

$\square$ Other (please specify)

8. What is your gender?

$\square$ Male

$\square$ Female

$\square$ Other (please specify) 
9. What type of high school did you attend?

$\square$ Home-schooled

$\square$ Public

$\square$ Private

$\square$ Military

$\square$ Other (please specify)

10. What was your final high school cumulative school grade point average (GPA)?

11. What is your current year in college?

$$
\begin{aligned}
& 1^{\text {st }} \mathrm{yr} \\
& 2^{\text {nd }} \\
& 3^{\text {rd }} \\
& 4^{\text {th }} \\
& 5^{\text {th }} \text { or more }
\end{aligned}
$$

12. Are you a psychology major?

Yes

No

13. What is your major?

14. What is your current GPA in college?

15. Please provide your legal name. Your name is only going to be used to connect your responses across this survey and the future smart phone signals, and to give credit for completing the survey.

What is your legal first name?

What is your legal last name? 


\section{Early Risk Questionnaires}

\section{SES Ladder}

16. Imagine that this ladder shows how your society is set up. At the top of the ladder are the people who are the best off - they have the most money, the highest amount of schooling, and the jobs that bring the most respect. At the bottom are people who are the worst off - they have the least money, little or no education, no jobs or jobs that no one wants or respects.

Now think about your living with your primary parent/guardian before coming to college. Please tell us where you think your family would be on this ladder. Select the number of the rung that best represents where your family would be on this ladder.

10

9

8

7

6

5

4

3

2

1

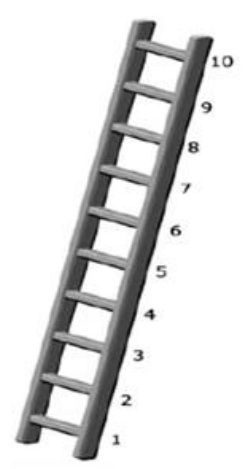

\section{Difficulty Paying Bills}

17. Before coming to college, how much difficulty did your family have paying bills?

A great deal

Some

A little

None/not at all

\section{Parent Education}

18. What is the highest level of education your Mother has earned?

No school/ some grad school (1-6)

Eighth grade/ junior high school (7-8)

Some high school (9-12; no diploma GED)

GED

Graduated from high school

1-2 years of college, no degree yet

3 or more years of college, no degree yet

Graduated from a two year college or vocational school, or Associate's degree

Graduated from a four or five- year college, Bachelor's degree

Not applicable 
19. What is the highest level of education your Father has earned?

No school/ some grad school (1-6)

Eighth grade/ junior high school (7-8)

Some high school (9-12; no diploma GED)

GED

Graduated from high school

1-2 years of college, no degree yet

3 or more years of college, no degree yet

Graduated from a two year college or vocational school, or Associate's degree

Graduated from a four or five- year college, Bachelor's degree

Not applicable 


\section{Confusion, Hubbub, and Order Scale (CHAOS)}

This questionnaire interested in what living in your primary home growing up, or before coming to college, was like. There are no right or wrong answers. Using the scale below, please indicate if the statement is true or false of your home while growing up.

While growing up...

1 There is very little commotion in our home.

2 We can usually find things when we need them.

3 We almost always seem to be rushed.

$4 \quad$ We are usually able to stay on top of things.

5 No matter how hard we try, we always seem to be running late.

6 It's a real zoo in our home.

$7 \quad$ At home we can talk to each other without being interrupted.

8 There is often a fuss going on at our home.

9 No matter what our family plans, it usually doesn't seem to work out.

10 You can't hear yourself think in our home.

11 I often get drawn into other people's arguments at home.

12 Our home is a good place to relax.

13 The telephone takes up a lot of our time at home.

14 The atmosphere in our home is calm.

15 First thing in the day, we have a regular routine at home. 


\section{Experiences in Close Relationships- Revised Scale (ECR-RS)}

Using the scale below, please indicate how much you agree or disagree with each statement about your relationship with your mother/ father while growing up (before college).

\begin{tabular}{|c|c|c|c|c|c|c|c|c|c|c|}
\hline \multicolumn{2}{|c|}{$\begin{array}{c}\text { Strongly } \\
\text { Disagree } \\
1\end{array}$} & $\begin{array}{c}\text { Disagree } \\
2 \\
\end{array}$ & $\begin{array}{c}\text { Slightly } \\
\text { Disagree } \\
3 \\
\end{array}$ & & $\begin{array}{l}\text { shtly } \\
\text { sree } \\
5 \\
\end{array}$ & & \multicolumn{2}{|c|}{$\begin{array}{l}\text { Agree } \\
6\end{array}$} & \multicolumn{2}{|r|}{$\begin{array}{c}\text { Strongly } \\
\text { Agree } \\
7 \\
\end{array}$} \\
\hline & & & & $\begin{array}{c}\text { Strongly } \\
\text { Disagree } \\
1 \\
\end{array}$ & 2 & 3 & 4 & 5 & 6 & $\begin{array}{c}\text { Strongly } \\
\text { Agree } \\
7\end{array}$ \\
\hline \multicolumn{11}{|c|}{ Avoidant Attachment } \\
\hline 1 & \multicolumn{3}{|c|}{$\begin{array}{l}\text { I usually discuss my problems and } \\
\text { concerns with this person. }\end{array}$} & $\square$ & $\square$ & $\square$ & $\square$ & $\square$ & $\square$ & $\square$ \\
\hline 2 & \multicolumn{3}{|c|}{ I talk things over with this person. } & $\square$ & $\square$ & $\square$ & $\square$ & $\square$ & $\square$ & $\square$ \\
\hline 3 & \multicolumn{3}{|c|}{$\begin{array}{l}\text { It helps to turn to this person in times of } \\
\text { need. }\end{array}$} & $\square$ & $\square$ & $\square$ & $\square$ & $\square$ & $\square$ & $\square$ \\
\hline 4 & \multicolumn{3}{|c|}{ I find it easy to depend on this person. } & $\square$ & $\square$ & $\square$ & $\square$ & $\square$ & $\square$ & $\square$ \\
\hline 5 & \multicolumn{3}{|c|}{$\begin{array}{l}\text { I prefer not to show this person how I feel } \\
\text { deep down. }\end{array}$} & $\square$ & $\square$ & $\square$ & $\square$ & $\square$ & $\square$ & $\square$ \\
\hline 6 & \multicolumn{3}{|c|}{$\begin{array}{l}\text { I don't feel comfortable opening up to this } \\
\text { person. }\end{array}$} & $\square$ & $\square$ & $\square$ & $\square$ & $\square$ & $\square$ & $\square$ \\
\hline & \multicolumn{10}{|c|}{ Anxious Attachment } \\
\hline 7 & \multicolumn{3}{|c|}{ I'm afraid this person may abandon me. } & $\square$ & $\square$ & $\square$ & $\square$ & $\square$ & $\square$ & $\square$ \\
\hline 8 & \multicolumn{3}{|c|}{$\begin{array}{l}\text { I worry that this person won't care about } \\
\text { me as much as I care about him or her. }\end{array}$} & $\square$ & $\square$ & $\square$ & $\square$ & $\square$ & $\square$ & $\square$ \\
\hline 9 & \multicolumn{3}{|c|}{$\begin{array}{l}\text { I often worry that this person doesn't really } \\
\text { care for me. }\end{array}$} & $\square$ & $\square$ & $\square$ & $\square$ & $\square$ & $\square$ & $\square$ \\
\hline
\end{tabular}




\section{Implicit Theories of Self-control Questionnaire}

This questionnaire has been designed to investigate your ideas about willpower. Willpower is what you use to resist temptations, to stick to your intentions, and to remain in strenuous mental activity.

There are no right or wrong answers. We are interested in your ideas. Using the scale below, please indicate how much you agree or disagree with each of the following statements.

\begin{tabular}{cccccc}
\hline Strongly & Moderately & Slightly & Slightly & Moderately & Strongly \\
Disagree & Disagree & Disagree & Agree & Agree & Agree \\
1 & 2 & 3 & 4 & 5 & 6 \\
\hline
\end{tabular}

$\begin{array}{lllllll}\text { Strenuous mental activity } & 1 & 2 & 3 & 4 & 5 & 6\end{array}$

1 Strenuous mental activity exhausts your resources, which you need to refuel afterwards

(e.g. through taking breaks, doing nothing, watching television, eating snacks).

2 After a strenuous mental activity, your energy is depleted and you must rest to get it refueled again.

3 When you have been working on a strenuous mental task, you feel energized and you are able to immediately start with another demanding activity.

4 Your mental stamina fuels itself. Even after strenuous mental exertion, you can continue doing more of it.

5 When you have completed a strenuous mental activity, you cannot start another activity

immediately with the same concentration because you have to recover your mental energy again

6 After a strenuous mental activity, you feel energized for further challenging activities.

\section{Resisting Temptations}

7 Resisting temptations makes you feel more vulnerable to the next temptations that come along.

8 When situations accumulate that challenge you with temptations, it gets more and more difficult to resist the temptations.

9 If you have just resisted a strong temptation, you feel strengthened and you can withstand any new temptations.

10 It is particularly difficult to resist a temptation after resisting another temptation right before.

11 Resisting temptations activates your willpower and you become even better able to face new upcoming temptations

12 Your capacity to resist temptations is not limited.

Even after you have resisted a strong temptation you can control yourself right afterwards. 


\section{Trait Self-control Questionnaire}

Using the scale provided, please indicate how much each of the following statements reflects how you typically are.

\begin{tabular}{llcccc}
\hline \multicolumn{2}{l}{$\begin{array}{c}\text { Not at } \\
\text { all like } \\
\text { me }\end{array}$} & $\begin{array}{c}\text { Unlike } \\
\text { me }\end{array}$ & $\begin{array}{c}\text { Sometimes } \\
\text { like me }\end{array}$ & $\begin{array}{c}\text { Like } \\
\text { me }\end{array}$ & $\begin{array}{c}\text { Very } \\
\text { much }\end{array}$ \\
like me
\end{tabular}




\section{Appendix B}

Experience Sampling Measures- Desire and Resistance Success

1. Please provide your name. This will only going to be used to link your responses. What is your first name?

What is your last name?

2. Are you experiencing or have you experienced a desire in the last 30 minutes?

Yes

No

3. What type of desire is it?

Food

Nonalcoholic drinks

Alcohol

Coffee

Tobacco

Other substances

Sex

Social Media use (e.g., Instagram, Facebook, etc)

Internet surfing

Gaming (video games, internet games, cell phone games, etc)

Watching movies, TV shows

Spending

Work

Social contact

Sports participation

Leisure

Sleep

Hygiene

Other:

4. How long did you experience the desire?

$0-5$ minutes

6-10 minutes

11-20 minutes

21-30 minutes

31-60 minutes

$1-2$ hours

2-5 hours

$5+$ hours 
5. How strong was the desire?
0 -not at all
1
2
3
4
5
6-irresistable

6. Have you tried to resist the desire?

Yes

No

7. How successful were you at resisting the desire?

Not at all- I gave in to the desire fully

Slightly successful

Moderately successful- I gave in to the desire a little

Very successful

Entirely-I did NOT give in to the desire

8. Briefly, why did you try to resist? (What goal do you have that conflicts with this desire?)

9. How important is this goal?

Not at all important

Somewhat important

Very important

Extremely important 


\section{Appendix C}

\section{Follow-up Measures}

1. During the 7 days that survey links were text messaged to you, were there any surveys you did not answer?

Yes

No

2. How many of the text messaged surveys do you think you missed? Please give your estimate in percentages, from $0 \%$ ( 0 surveys unanswered) to $100 \%$ (all surveys unanswered).

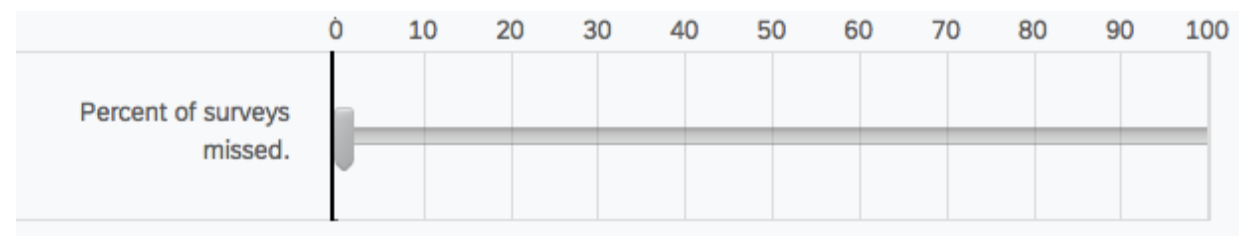

3. If yes, why did you not respond? Select all that apply.

Was unable to respond at the time it was sent.

At work/job/internship during reporting period.

In class during reporting period.

Lost phone during reporting period.

Phone had a dead battery during reporting period.

Did not realize I was sent a text message until reporting period ended.

The survey did not load properly on the phone, so it could not be filled out.

Did not want to respond at that time.

Did not like answering the surveys.

Other:

4. What was the MOST COMMON reason you did not respond to the texted surveys?

Select ONLY 1 option.

Was unable to respond at the time it was sent.

At work/job/internship during reporting period.

In class during reporting period.

Lost phone during reporting period.

Phone had a dead battery during reporting period.

Did not realize I was sent a text message until reporting period ended.

The survey did not load properly on the phone, so it could not be filled out.

Did not want to respond at that time.

Did not like answering the surveys.

Other: 
5. How annoying or disruptive of your daily life were the texted surveys?

Not at all

Slightly

Somewhat

Very

Extremely

6. What overall comments do you have about participating in the text messaged surveys?

7. What overall comments do you have about participating in the whole study? The whole study included the first hour long survey on SONA, texted surveys, and this current survey.

8. Would you consider participating in more studies like this?

Yes

No 


\section{Implicit Theories of Self-control Questionnaire}

This questionnaire has been designed to investigate your ideas about willpower. Willpower is what you use to resist temptations, to stick to your intentions, and to remain in strenuous mental activity.

There are no right or wrong answers. We are interested in your ideas. Using the scale below, please indicate how much you agree or disagree with each of the following statements.

\begin{tabular}{cccccc}
\hline Strongly & Moderately & Slightly & Slightly & Moderately & Strongly \\
Disagree & Disagree & Disagree & Agree & Agree & Agree \\
1 & 2 & 3 & 4 & 5 & 6 \\
\hline
\end{tabular}

$\begin{array}{lllllll}\text { Strenuous mental activity } & 1 & 2 & 3 & 4 & 5 & 6\end{array}$

1 Strenuous mental activity exhausts your resources, which you need to refuel afterwards

(e.g. through taking breaks, doing nothing, watching television, eating snacks).

2 After a strenuous mental activity, your energy is depleted and you must rest to get it refueled again.

3 When you have been working on a strenuous mental task, you feel energized and you are able to immediately start with another demanding activity.

4 Your mental stamina fuels itself. Even after strenuous mental exertion, you can continue doing more of it.

5 When you have completed a strenuous mental activity, you cannot start another activity immediately with the same concentration because you have to recover your mental energy again

6 After a strenuous mental activity, you feel energized for further challenging activities.

\section{Resisting Temptations}

7 Resisting temptations makes you feel more vulnerable to the next temptations that come along.

8 When situations accumulate that challenge you with temptations, it gets more and more difficult to resist the temptations.

9 If you have just resisted a strong temptation, you feel strengthened and you can withstand any new temptations.

10 It is particularly difficult to resist a temptation after resisting another temptation right before.

11 Resisting temptations activates your willpower and you become even better able to face new upcoming temptations

12 Your capacity to resist temptations is not limited.

Even after you have resisted a strong temptation you can control yourself right afterwards. 


\section{Trait Self-control Questionnaire}

Using the scale provided, please indicate how much each of the following statements reflects how you typically are.

\begin{tabular}{|c|c|c|c|c|c|c|}
\hline & & $\begin{array}{c}\text { Not at } \\
\text { all like } \\
\text { me } \\
1\end{array}$ & $\begin{array}{c}\text { Unlike } \\
\text { me } \\
2\end{array}$ & $\begin{array}{c}\text { Sometimes } \\
\text { like me } \\
3\end{array}$ & $\begin{array}{c}\text { Like } \\
\text { me } \\
4\end{array}$ & $\begin{array}{c}\text { Very } \\
\text { much } \\
\text { like me } \\
5\end{array}$ \\
\hline 1 & I have a hard time breaking bad habits. & $\square$ & $\square$ & $\square$ & $\square$ & $\square$ \\
\hline 2 & I am lazy. & $\square$ & $\square$ & $\square$ & $\square$ & $\square$ \\
\hline 3 & I say inappropriate things. & $\square$ & $\square$ & $\square$ & $\square$ & $\square$ \\
\hline 4 & $\begin{array}{l}\text { I do certain things that are bad for me, if } \\
\text { they are fun. }\end{array}$ & $\square$ & $\square$ & $\square$ & $\square$ & $\square$ \\
\hline 5 & I refuse things that are bad for me. & $\square$ & $\square$ & $\square$ & $\square$ & $\square$ \\
\hline 6 & I wish I had more self-discipline. & $\square$ & $\square$ & $\square$ & $\square$ & $\square$ \\
\hline 7 & I am good at resisting temptation. & $\square$ & $\square$ & $\square$ & $\square$ & $\square$ \\
\hline 8 & $\begin{array}{l}\text { People would say that I have iron self- } \\
\text { discipline. }\end{array}$ & $\square$ & $\square$ & $\square$ & $\square$ & $\square$ \\
\hline 9 & $\begin{array}{l}\text { Pleasure and fun sometimes keep me } \\
\text { from getting work done. }\end{array}$ & $\square$ & $\square$ & $\square$ & $\square$ & $\square$ \\
\hline 10 & I have trouble concentrating. & $\square$ & $\square$ & $\square$ & $\square$ & $\square$ \\
\hline 11 & $\begin{array}{l}\text { I am able to work effectively toward } \\
\text { long-term goals }\end{array}$ & $\square$ & $\square$ & $\square$ & $\square$ & $\square$ \\
\hline 12 & $\begin{array}{l}\text { Sometimes I can't stop myself from doing } \\
\text { something, even if I know it is wrong. }\end{array}$ & $\square$ & $\square$ & $\square$ & $\square$ & $\square$ \\
\hline 13 & $\begin{array}{l}\text { I often act without thinking through all } \\
\text { the alternatives }\end{array}$ & $\square$ & $\square$ & $\square$ & $\square$ & $\square$ \\
\hline
\end{tabular}




\section{Appendix D}

Additional Baseline Descriptive Analyses

Table 8

Frequencies of People with Each Type of Risk

\begin{tabular}{|c|c|c|c|}
\hline Type of Risk Factor & $\begin{array}{l}\text { Frequency of } \\
\text { Risk Present }\end{array}$ & 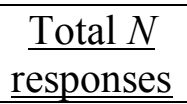 & \% Risk Present \\
\hline Education Caregiver 1 & 60 & 214 & 28.0 \\
\hline Education Caregiver 2 & 58 & 187 & 31.2 \\
\hline SES Ladder & 17 & 214 & 7.9 \\
\hline Difficulty Paying Bills & 117 & 213 & 54.9 \\
\hline Home Chaos & 40 & 214 & 18.7 \\
\hline Caregiver 1 insecure & 39 & 213 & 18.3 \\
\hline Anxious & 22 & 213 & 10.3 \\
\hline Avoidant & 31 & 213 & 14.5 \\
\hline Caregiver 2 insecure & 48 & 187 & 25.7 \\
\hline Anxious & 29 & 187 & 13.6 \\
\hline Avoidant & 40 & 187 & 18.7 \\
\hline
\end{tabular}

Note. Caregiver Insecure cells denote if a participant indicates they have at least 1 insecure attachment pattern (avoidant, anxious, or both) to that caregiver. 
Table 9

Frequencies of Participants’ Non-College Living Arrangements by Caregiver

\begin{tabular}{|c|c|c|}
\hline $\begin{array}{l}\text { Caregiver participant goes home to when not at } \\
\text { school (selected all that applied) }\end{array}$ & $\underline{n}$ & $\%$ of $N=214$ \\
\hline Biological Mother & 190 & 88.8 \\
\hline Biological Father & 161 & 75.2 \\
\hline Step-Mother & 11 & 5.1 \\
\hline Step-Father & 20 & 9.3 \\
\hline Any other Mother-Figure Guardian & 4 & 1.9 \\
\hline Any other Father-Figure Guardian & 4 & 1.9 \\
\hline Custodial Grandparents & 4 & 1.9 \\
\hline No Caregiver & 6 & 2.8 \\
\hline Other & 6 & 2.8 \\
\hline Types of two-caregiver homes & $\underline{n}$ & $\%$ out of 214 \\
\hline Biological Parents & 144 & 67.3 \\
\hline Biological mother \& Step- Father & 17 & 7.9 \\
\hline Biological Father \& Step-Mother & 8 & 3.7 \\
\hline Both combos of Biological parent \& step-Parent & 3 & 1.4 \\
\hline Total Number of Caregivers While Growing Up & $\underline{n}$ & $\%$ out of 210 \\
\hline One Caregivers & 14 & 6.5 \\
\hline Two Caregivers & 182 & 86.0 \\
\hline Three Caregivers & 9 & 4.2 \\
\hline Four + Caregivers & 7 & 3.3 \\
\hline $\begin{array}{l}\text { Total Number of People In Home While } \\
\text { Growing Up }\end{array}$ & $\underline{n}$ & $\%$ out of 214 \\
\hline 2 & 7 & 3.3 \\
\hline 3 & 20 & 9.4 \\
\hline 4 & 103 & 48.4 \\
\hline 5 & 57 & 26.8 \\
\hline $6-7$ & 19 & 8.9 \\
\hline $8+$ & 6 & 2.8 \\
\hline
\end{tabular}

Note. Participants were asked to select all that apply to separate caregiver options (biological mother, biological father, etc.) for who they go home to when not at college. Responses were recoded to account for types of two parent families. Participants were also asked to describe how many caregivers they had while growing up. Some described changing numbers (e.g., lived with 2 parents until 1 moved away for a job). So, the total number represents how many caregivers each subject had at all while growing up. 
Table 10

Frequencies of Participants' Number of Times They Had Moved Residences

\begin{tabular}{lcc}
\hline$\underline{\text { Total Number of Moves }}$ & $\underline{n}$ & $\frac{\text { \% out of }}{214}$ \\
\hline Never changed residences & 85 & 40.3 \\
One time & 54 & 25.6 \\
Two times & 16 & 7.6 \\
Three times & 23 & 10.9 \\
Four times & 7 & 3.3 \\
Five times & 9 & 4.3 \\
Six or more times & 17 & 7.9 \\
\hline
\end{tabular}


Table 11

Descriptives of Additional Risk Indices

\begin{tabular}{|c|c|c|c|c|c|}
\hline Variables & $\frac{\text { Mean (SD) or }}{\underline{\%}}$ & $\underline{\underline{\text { Min }}} \underline{\underline{\text { Possible }}}$ & $\underline{\text { Max }} \underline{\underline{\text { Possible }}}$ & $\underline{\text { Skew (SE) }}$ & Kurtosis (SE) \\
\hline $\begin{array}{l}\text { Time family had } \\
\text { difficulty paying bills }\end{array}$ & $1.90(.94)$ & 1 & 4 & $.71(.17)$ & $-.54(.33)$ \\
\hline $\begin{array}{l}\text { Time home } \\
\text { environment was full of } \\
\text { confusion, noise, and } \\
\text { high energy }\end{array}$ & $2.20(.49)$ & 1 & 4 & $.49(.17)$ & $-.73(.33)$ \\
\hline $\begin{array}{l}\text { SES Ladder Variability } \\
\text { highest-lowest SES } \\
\text { status }\end{array}$ & $1.82(1.72)$ & 1 & 9 & $.63(.19)$ & $-.30(.37)$ \\
\hline
\end{tabular}

Note. Higher values indicate more time living with risk factor. 
Table 12

Frequencies of Participants' SES Ladder Variability.

\begin{tabular}{lccc}
\hline Change in Highest and & $\underline{n}$ & $\underline{\text { \%out of }}$ \\
\hline Lowest SES status & 58 & 34.7 \\
Never changed & 54 & 32.3 \\
One - two steps & 45 & 26.9 \\
Three-four steps & 8 & 4.8 \\
Five -six steps & 2 & 1.2 \\
Seven - eight steps & & \\
\hline
\end{tabular}

Note. Higher values indicate the participant reported a greater difference between their highest and lowest SES ladder 'steps'. 
Table 13

Unstandardized Coefficients and Standard Errors for Regression Models Predicting Baseline Trait Self-control from Separate Risk Factors

\begin{tabular}{|c|c|c|c|c|c|}
\hline Predictors & & beta (se) & $\mathrm{F}(\mathrm{df})$ & p-value & $\mathrm{R}^{2}$ \\
\hline \multirow[t]{3}{*}{ Caregiver 1} & Edu & $-.003(.02)$ & $F(3,209)=26.73$ & $p<.001$ & $R^{2}=.32$ \\
\hline & Belief & $.47 * * *(.06)$ & & & \\
\hline & Edu x Belief & $.002(.03)$ & & & \\
\hline \multirow[t]{3}{*}{ Caregiver 2} & Edu & $.03(.02)$ & $F(3,181)=25.29$ & $p<.001$ & $R^{2}=.30$ \\
\hline & Belief & $.44 * * *(.06)$ & & & \\
\hline & Edu x Belief & $-.06(.04)$ & & & \\
\hline \multirow[t]{3}{*}{ SES } & Ladder & $.04(.02)$ & $F(3,209)=23.96$ & $p<.001$ & $R^{2}=.33$ \\
\hline & Belief & $.46 * * *(.06)$ & & & \\
\hline & Ladder x Belief & $-.002(.04)$ & & & \\
\hline \multirow[t]{6}{*}{ Difficulty Paying } & Bills & $-.07(.04)$ & $F(3,208)=26.72$ & $p<.001$ & $R^{2}=.33$ \\
\hline & Belief & $.46 * * *(.05)$ & & & \\
\hline & Bills x Belief & $-.001(.05)$ & & & \\
\hline & Chaos & $-.03 * *(.01)$ & $F(3,209)=41.21$ & $p<.001$ & $R^{2}=.37$ \\
\hline & Belief & $.43 * * *(.05)$ & & & \\
\hline & Chaos $\mathrm{x}$ Belief & $-.01(.01)$ & & & \\
\hline & Avoidance & $-.07 *(.03)$ & $F(3,208)=27.68$ & $p<.001$ & $R^{2}=.35$ \\
\hline \multirow[t]{2}{*}{ Attachment } & Belief & $.44 * * *(.05)$ & & & \\
\hline & $\begin{array}{l}\text { Avoidance } \mathrm{x} \\
\text { Belief }\end{array}$ & $.05(.05)$ & & & \\
\hline Caregiver 1 & Anxious & $-.01(.03)$ & $F(3,208)=24.49$ & $p<.001$ & $R^{2}=.32$ \\
\hline \multirow[t]{2}{*}{ Attachment } & Belief & $.47 * * *(.06)$ & & & \\
\hline & $\begin{array}{l}\text { Anxious x } \\
\text { Belief }\end{array}$ & $-.01(.04)$ & & & \\
\hline Caregiver 2 & Avoidance & $-.07 *(.03)$ & $F(3,182)=33.36$ & $p<.001$ & $R^{2}=.34$ \\
\hline \multirow[t]{2}{*}{ Attachment } & Belief & $.41 * * *(.07)$ & & & \\
\hline & $\begin{array}{l}\text { Avoidance } \mathrm{x} \\
\text { Belief }\end{array}$ & $.04(.04)$ & & & \\
\hline Caregiver 2 & Anxious & $-.05(.04)$ & $F(3,182)=21.47$ & $p<.001$ & $R^{2}=.34$ \\
\hline \multirow[t]{2}{*}{ Attachment } & Belief & $.42 * * *(.06)$ & & & \\
\hline & $\begin{array}{l}\text { Anxious x } \\
\text { Belief }\end{array}$ & $.07(.05)$ & & & \\
\hline
\end{tabular}

Note. Models were computed using Hayes PROCESS. Edu = education level. Belief = Implicit belief, higher scores indicate stronger belief in nonlimited resource. Bills = Difficulty Paying Bills. Chaos $=$ home environment chaos. Insecurity $=$ attachment insecurity with caregivers. $* p<.05 . * * p<.01 . * * * p<.001$. 
Table 14

Unstandardized Coefficients and Standard Errors for Regression Models Predicting Daily Success Resisting Desires from Separate Risk Factors

$\underline{\text { Random Intercept Models Including Level } 1 \text { and Level } 2 \text { Predictors - }}$ separated risk factors

\begin{tabular}{|c|c|c|c|c|c|c|c|c|c|}
\hline & $\underline{\text { Edu } 1}$ & $\underline{\text { Edu } 2}$ & $\underline{\text { SES }}$ & $\underline{\text { Bills }}$ & $\begin{array}{l}\text { Home } \\
\text { Chaos } \\
\end{array}$ & Avd. 1 & Anx. 1 & Avd. 2 & Anx. 2 \\
\hline & $\begin{array}{l}\text { beta } \\
(\mathrm{se})\end{array}$ & $\begin{array}{l}\text { beta } \\
\text { (se) }\end{array}$ & $\begin{array}{l}\text { beta } \\
\text { (se) }\end{array}$ & $\begin{array}{l}\text { beta } \\
(\mathrm{se})\end{array}$ & $\begin{array}{l}\text { beta } \\
(\mathrm{se})\end{array}$ & $\begin{array}{l}\text { beta } \\
(\mathrm{se})\end{array}$ & $\begin{array}{l}\text { beta } \\
\text { (se) }\end{array}$ & $\begin{array}{l}\text { beta } \\
\text { (se) }\end{array}$ & $\begin{array}{l}\text { beta } \\
(\mathrm{se})\end{array}$ \\
\hline $\begin{array}{l}\text { Desire } \\
\text { strength }\end{array}$ & $\begin{array}{c}-.30 * * * \\
(.04)\end{array}$ & $\begin{array}{c}-.29 * * * \\
(.05)\end{array}$ & $\begin{array}{c}-.30 * * * \\
(.04)\end{array}$ & $\begin{array}{c}-.30 * * * \\
(.04)\end{array}$ & $\begin{array}{c}-.30 * * * \\
(.04)\end{array}$ & $\begin{array}{c}-.30 * * * \\
(.04)\end{array}$ & $\begin{array}{c}-.30 * * * \\
(.04)\end{array}$ & $\begin{array}{c}-.29 * * * \\
(.04)\end{array}$ & $\begin{array}{c}-.29 * * * \\
(.04)\end{array}$ \\
\hline Goal & $\begin{array}{c}.20 * * * \\
(.06)\end{array}$ & $\begin{array}{c}.21 * * * \\
(.06)\end{array}$ & $\begin{array}{c}.20 * * * \\
(.06)\end{array}$ & $\begin{array}{c}.20 * * * \\
(.06)\end{array}$ & $\begin{array}{c}.20 * * * \\
(.06)\end{array}$ & $\begin{array}{c}.20 * * * \\
(.06)\end{array}$ & $\begin{array}{c}.20 * * * \\
(.06)\end{array}$ & $\begin{array}{c}.20 * * * \\
(.06)\end{array}$ & $\begin{array}{c}.20 * * * \\
(.06)\end{array}$ \\
\hline Implicit & $.14^{*}$ & .11 & $.13^{+}$ & .13 & .08 & .12 & .12 & $.14^{+}$ & .12 \\
\hline Belief & $(.07)$ & $(.08)$ & $(.07)$ & $(.08)$ & $(.17)$ & $(.07)$ & $(.07)$ & $(.08)$ & $(.08)$ \\
\hline Risk & .01 & $.08^{*}$ & .03 & -.09 & -.09 & -.05 & -.06 & .04 & -.02 \\
\hline Factor & $(.03)$ & $(.03)$ & $(.07)$ & $(.06)$ & $(.06)$ & $(.04)$ & $(.04)$ & $(.04)$ & $(.04)$ \\
\hline Risk x & .04 & .03 & .04 & -.02 & -.02 & .03 & -.06 & -.05 & -.01 \\
\hline Belief & $(.04)$ & $(.04)$ & $(.30)$ & $(.07)$ & $(.07)$ & $(.06)$ & $(.08)$ & $(.05)$ & $(.05)$ \\
\hline $\begin{array}{l}\text { Residual } \\
\text { variance }\end{array}$ & $84.26 \%$ & $84.73 \%$ & $84.37 \%$ & $84.54 \%$ & $84.54 \%$ & $85.00 \%$ & $84.48 \%$ & $84.56 \%$ & $84.31 \%$ \\
\hline
\end{tabular}

Note. ${ }^{+} p<.075 .{ }^{*} p<.05 .{ }^{*} p<.01 . * * * p<.001$. Models were computed using Hayes PROCESS. Edu = education level. Belief = Implicit belief, higher scores indicate stronger belief in nonlimited resource. Bills = difficulty paying bills, higher values indicate more difficulty. Chaos $=$ home environment chaos, higher values indicate more chaos at home. Goal $=$ goal importance, higher values indicate more importance. Avd. $=$ attachment avoidance. Anx. $=$ attachment anxiety. 


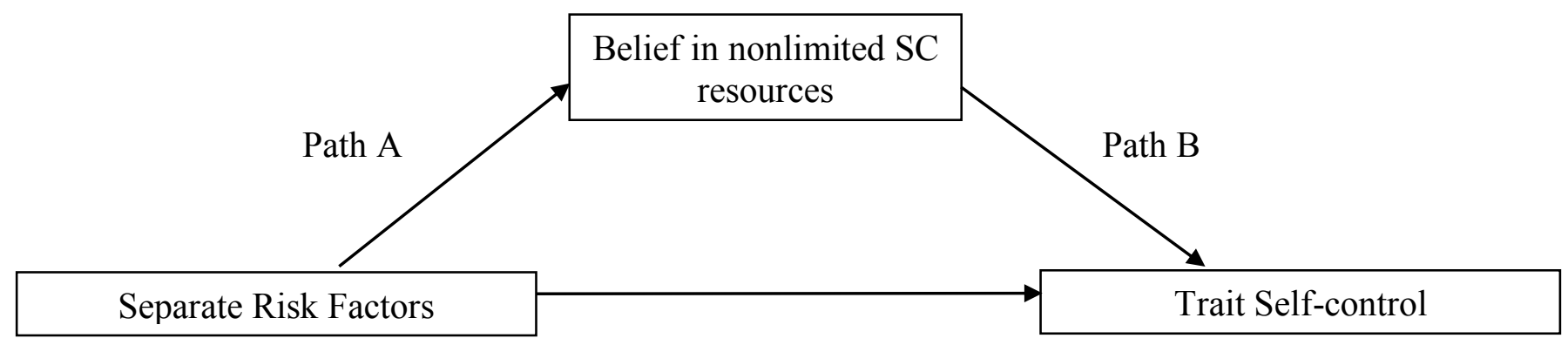

Direct Effect

Indirect Effect

Table 14

Unstandardized Coefficients and Standard Errors for Mediation Models of Separate Risk Factors, Beliefs, and Trait Self-Control

\begin{tabular}{|c|c|c|c|c|c|c|}
\hline & $\underline{\text { Path A }}$ & $\underline{\text { Path B }}$ & \multicolumn{2}{|c|}{ Direct effect } & \multicolumn{2}{|c|}{$\underline{\text { Indirect effect }}$} \\
\hline $\begin{array}{l}\text { Model with } \\
\text { each risk }\end{array}$ & $\mathrm{b}(\mathrm{se})$ & $\mathrm{b}(\mathrm{se})$ & $\mathrm{b}(\mathrm{se})$ & $\begin{array}{l}\text { LLCI, } \\
\text { ULCI }\end{array}$ & $\mathrm{b}(\mathrm{se})$ & $\begin{array}{l}\text { LLCI, } \\
\text { ULCI }\end{array}$ \\
\hline $\begin{array}{l}\text { Caregiver } 1 \\
\text { Edu }\end{array}$ & $.004(.23)$ & $.47 * * *(.05)$ & $-.002(.02)$ & $-.04, .04$ & $.001(.01)$ & $-.03, .03$ \\
\hline $\begin{array}{l}\text { Caregiver } 2 \\
\text { Edu }\end{array}$ & $.004(.03)$ & $.45^{* * *}(.05)$ & $.02(.02)$ & $-.02,-.07$ & $.002(.01)$ & $-.03, .03$ \\
\hline SES ladder & $.07 *(.03)$ & $.46^{* * *}(.05)$ & $.04(.02)$ & $-.01, .08$ & $.03(.02)$ & $.01, .07$ \\
\hline $\begin{array}{l}\text { Difficulty } \\
\text { Paying Bills }\end{array}$ & $-.09(.05)$ & $.46 * * *(.05)$ & $-.07(.04)$ & $-.14, .01$ & $-.04(.03)$ & $-.10, .01$ \\
\hline $\begin{array}{l}\text { Home } \\
\text { Chaos }\end{array}$ & $-.05 * * *(.01)$ & $.43 * * *(.05)$ & $-.03 * *(.01)$ & $-.05,-.01$ & $-.02(.01)$ & $-.03,-.01$ \\
\hline $\begin{array}{l}\text { Caregiver } 1 \\
\text { Avoidance }\end{array}$ & $-.16^{* * *}(.04)$ & $.43 * * *(.04)$ & $-.08 * *(.03)$ & $-.13,-.02$ & $-.07(.02)$ & $-.11,-.04$ \\
\hline $\begin{array}{l}\text { Caregiver } 1 \\
\text { Anxious }\end{array}$ & $-.13 * *(.05)$ & $.47 * * *(.05)$ & $-.005(.03)$ & $-.07, .06$ & $-.06(.03)$ & $-.12,-.02$ \\
\hline $\begin{array}{l}\text { Caregiver } 2 \\
\text { Avoidance }\end{array}$ & $-.11 * *(.03)$ & $.41^{* * *}(.05)$ & $-.07 * *(.02)$ & $-.12,-.03$ & $-.05(.01)$ & $-.08,-.02$ \\
\hline $\begin{array}{l}\text { Caregiver } 2 \\
\text { Anxious }\end{array}$ & $-.08 *(.04)$ & $.43 * * *(.05)$ & $-.06^{*}(.03)$ & $-.12,-.01$ & $-.03(.02)$ & $-.08, .004$ \\
\hline
\end{tabular}

Note. $* p<.05 . * * p<.01 . * * * p<.001$. Mediational models with each early risk factor, implicit belief about SC (higher values indicate stronger nonlimited belief), and Trait Self-control. Models were run separately, such that each early risk factor was tested as a predictor of the proposed path. The confidence intervals of the indirect effects were denote which paths are significant (does not include 0 in interval). Bolded font in indirect effect columns indicate significance. 


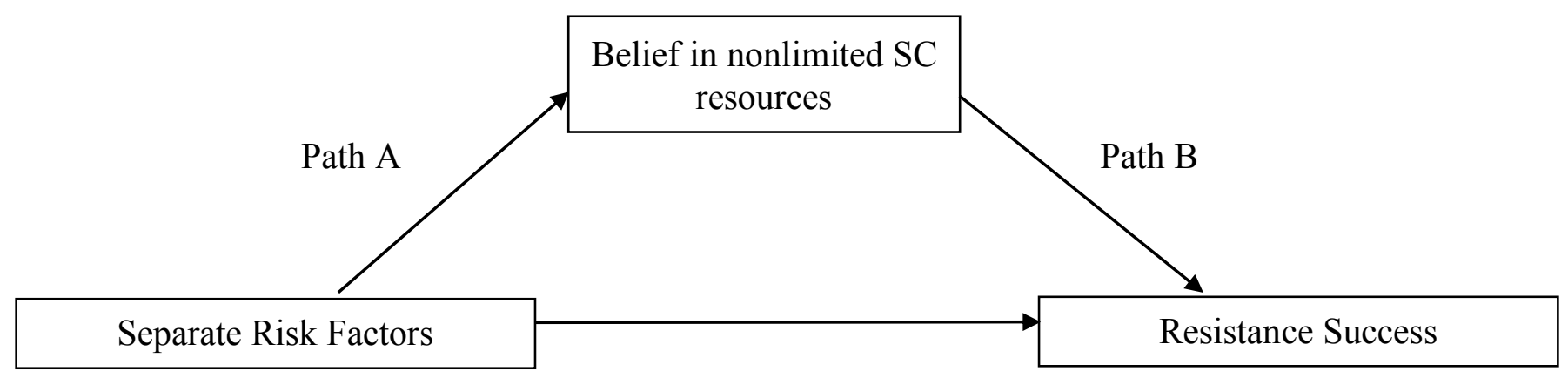

Direct Effect

Indirect Effect

Table 15

Unstandardized Coefficients and Standard Errors for Mediation Models Of Separate Risk Factors, Beliefs, And Momentary Self-Control

\begin{tabular}{|c|c|c|c|c|c|c|}
\hline & $\underline{\text { Path A }}$ & $\underline{\text { Path B }}$ & \multicolumn{2}{|c|}{$\underline{\text { Direct effect }}$} & \multicolumn{2}{|c|}{ Indirect effect } \\
\hline $\begin{array}{l}\text { Model with } \\
\text { each risk }\end{array}$ & $\underline{b(s e)}$ & $\underline{b(s e)}$ & $\underline{b(s e)}$ & $\begin{array}{l}\text { LLCI, } \\
\underline{\mathrm{ULCI}} \\
\end{array}$ & $\underline{b(s e)}$ & $\begin{array}{l}\text { LLCI, } \\
\underline{\text { ULCI }}\end{array}$ \\
\hline $\begin{array}{l}\text { Caregiver } 1 \\
\text { Edu }\end{array}$ & $.004(.03)$ & $.13^{+}(.07)$ & $.01(.03)$ & $-.17, .24$ & $.001(.004)$ & $-.03, .03$ \\
\hline $\begin{array}{l}\text { Caregiver } 2 \\
\text { Edu }\end{array}$ & $.01(.04)$ & $.11(.08)$ & $.08 *(.03)$ & $.01, .14$ & $.001(.004)$ & $-.01, .01$ \\
\hline SES ladder & $.08 *(.04)$ & $.14(.07)$ & $.03(.04)$ & $-.04, .10$ & $.01(.01)$ & $-.004, .02$ \\
\hline $\begin{array}{l}\text { Difficulty } \\
\text { Paying Bills }\end{array}$ & $-.08(.06)$ & $.12(.07)$ & $-.08(.06)$ & $-.19, .03$ & $-.01(.01)$ & $-.03, .01$ \\
\hline $\begin{array}{l}\text { Home } \\
\text { Chaos }\end{array}$ & $-.05 * * *(.01)$ & $.11(.07)$ & $-.02(.01)$ & $-.04, .01$ & $-.01(.004)$ & $-.01, .003$ \\
\hline $\begin{array}{l}\text { Caregiver } 1 \\
\text { Avoidance }\end{array}$ & $-.17 * * *(.04)$ & $.11(.07)$ & $-.05(.04)$ & $-.13, .03$ & $-.02(.01)$ & $-.05, .01$ \\
\hline $\begin{array}{l}\text { Caregiver } 1 \\
\text { Anxious }\end{array}$ & $-.14 *(.06)$ & $.13^{+}(.07)$ & $-.05(.04)$ & $-.12, .03$ & $-.02(.01)$ & $-.04, .01$ \\
\hline $\begin{array}{l}\text { Caregiver } 2 \\
\text { Avoidance }\end{array}$ & $-.12 * *(.04)$ & $.14(.08)$ & $.04(.04)$ & $-.03, .11$ & $-.02(.01)$ & $-.04, .01$ \\
\hline $\begin{array}{l}\text { Caregiver } 2 \\
\text { Anxious }\end{array}$ & $-.08^{+}(.04)$ & $.11(.08)$ & $-.02(.04)$ & $-.10, .05$ & $-.01(.01)$ & $-.03, .01$ \\
\hline
\end{tabular}

Note. ${ }^{+} p<.075 * p<.05 .{ }^{* *} p<.01$. Mediational models with each early risk factor, implicit belief about SC (higher values indicate stronger nonlimited belief), and desire resistance success. Models were run separately, such that each early risk factor was tested as a predictor of the proposed path. The confidence intervals of the indirect effects denote which paths are significant (does not include 0 in interval). All models also include level one variables which were consistently significantly associated with resistance success (desire strength, $b=-.30$, se $=.04, p$ $<.001$, CI [-0.38, -0.22], and goal importance, $b=.20$, se $=.06, p<.001$, CI [0.10, 0.31]). 


\section{Appendix E}

Additional Experience Sampling Descriptive Analyses

Table 16

Descriptives of Success Resisting Desires by Desire Type

\begin{tabular}{|c|c|c|c|c|c|}
\hline & $\frac{N \text { of each }}{\text { desire }}$ & $\frac{\frac{N \text { of }}{\text { attempts to }}}{\frac{\text { resist each }}{\underline{\text { desire }}}}$ & $\frac{\frac{\% \text { of }}{\text { attempts to }}}{\frac{\text { resist each }}{\underline{\text { desire }}}}$ & $\begin{array}{c}\frac{\underline{\text { Average }}}{\text { resistance success }} \\
\underline{\text { by desire }} \\
\frac{\text { (confirmed }}{\text { resistance }} \\
\underline{\text { attempted })}\end{array}$ & $\begin{array}{c}\frac{1 \text { Average }}{\text { resistance }} \\
\underline{\text { success (all) }}\end{array}$ \\
\hline & $N=2221$ & $N=2221$ & $N=2221$ & $N=991$ & $N=2221$ \\
\hline Desire type & $\underline{n}$ & $\underline{n}$ & $\underline{0}$ & $M(S D)$ & $M(S D)$ \\
\hline Food & 741 & 266 & 35.6 & $3.61(1.37)$ & $1.29(1.92)$ \\
\hline Non-alcoholic drinks & 51 & 15 & 29.4 & $3.53(1.60)$ & $1.04(1.83)$ \\
\hline Alcohol & 73 & 30 & 42.5 & $4.33(1.18)$ & $1.78(2.27)$ \\
\hline Coffee & 121 & 50 & 41.3 & $3.92(1.34)$ & $1.62(2.12)$ \\
\hline Tobacco & 41 & 21 & 51.2 & $3.33(1.49)$ & $1.71(1.99)$ \\
\hline Other substances & 50 & 21 & 42.0 & $3.29(1.62)$ & $1.38(1.94)$ \\
\hline Sex & 95 & 64 & 67.4 & $4.28(1.15)$ & $2.88(2.23)$ \\
\hline Social media & 89 & 39 & 43.8 & $3.21(1.17)$ & $1.40(1.78)$ \\
\hline Internet surfing & 25 & 9 & 40.0 & $3.11(1.36)$ & $1.12(1.72)$ \\
\hline Gaming & 43 & 9 & 20.9 & $3.67(1.41)$ & $.77(1.63)$ \\
\hline $\begin{array}{l}\text { Watching } \\
\text { TV/movies }\end{array}$ & 116 & 39 & 33.6 & $3.67(1.36)$ & $1.23(1.91)$ \\
\hline Spending money & 53 & 38 & 71.7 & $3.68(1.40)$ & $2.64(2.05)$ \\
\hline Work & 34 & 4 & 11.8 & $4.00(1.41)$ & $.47(1.38)$ \\
\hline Social contact & 73 & 29 & 39.7 & $3.66(1.14)$ & $1.45(1.94)$ \\
\hline Sports participation & 26 & 2 & 7.7 & $5.00(.00)$ & $.38(1.36)$ \\
\hline Leisure & 105 & 60 & 57.1 & $3.77(1.18)$ & $2.15(2.07)$ \\
\hline Sleep & 356 & 252 & 70.5 & $3.92(1.19)$ & $2.76(2.05)$ \\
\hline Hygiene & 25 & 3 & 12.0 & $5.00(.00)$ & $.60(1.66)$ \\
\hline Other & 104 & 40 & 38.5 & $3.48(1.41)$ & $1.34(1.34)$ \\
\hline
\end{tabular}

Note. Higher values on resistance success indicate more success $(\min =1, \max =5)$. In general, when people attempted to resist the desire, they were moderately successful. Average resistance success $($ all $)=$ includes resist attempts recoded as 0 (lowest success resisting) if they said "No" to attempting any resistance. 


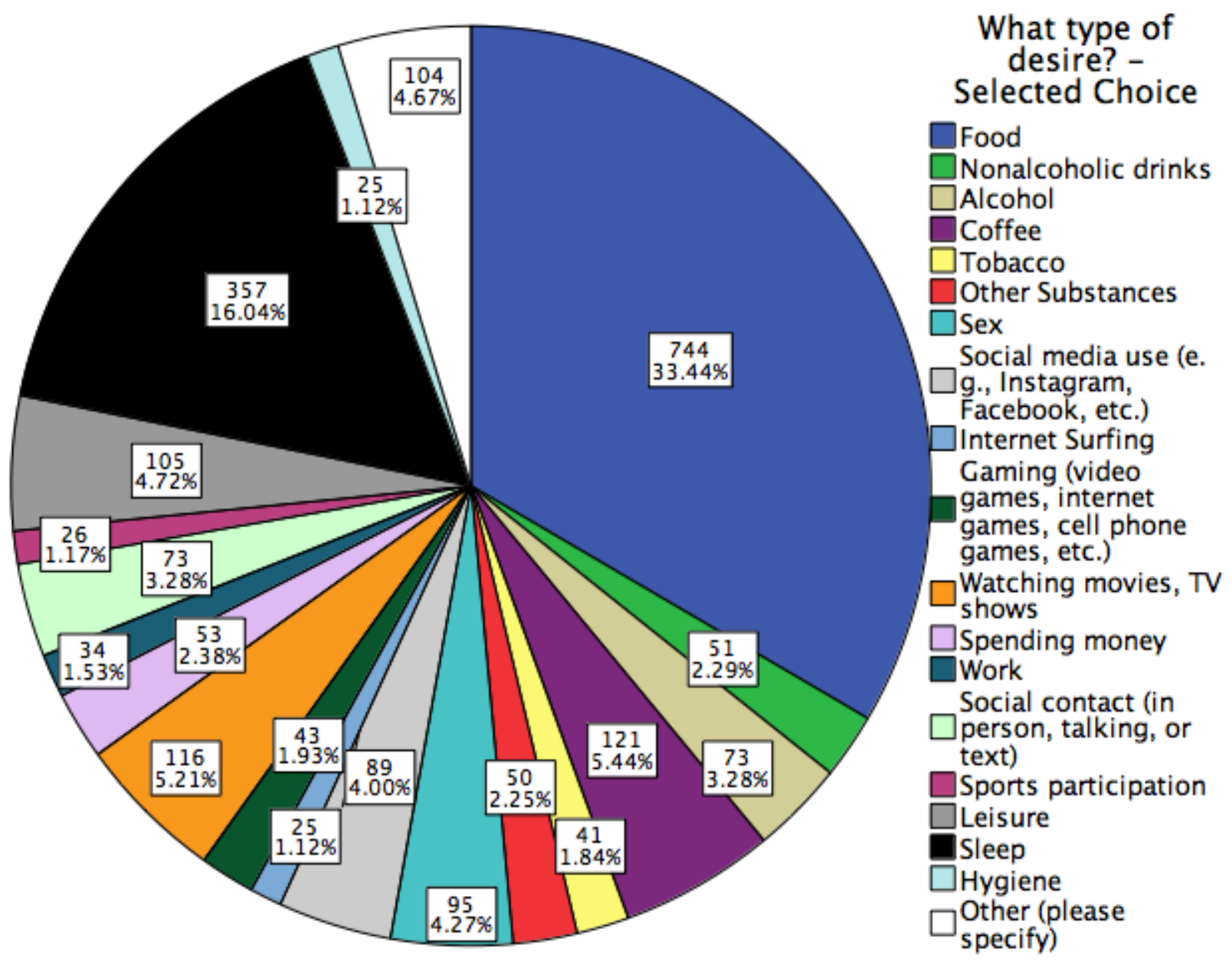

Figure 7. Frequencies of each desire type across a week. 


\section{Appendix F}

Analyses with Follow-up Assessment

Table 17

Mean Differences and Correlations Between Baseline and Follow-Up Assessment on Trait SelfControl and Implicit Beliefs

\begin{tabular}{llcccc} 
& & $\underline{\mathrm{N}}$ & $\underline{\text { Mean }(\mathrm{SD})}$ & $\underline{t \text {-test }}$ & $\underline{\text { Correlation }}$ \\
\hline Trait Self-control & Baseline & 177 & $3.16(.60)$ & $t(176)=-3.72^{* * *}$ & $r=.85^{* * *}$ \\
& Follow-up & 177 & $3.25(.61)$ & & \\
\hline Implicit Beliefs & Baseline & 176 & $3.56(.74)$ & $t(175)=.30$ & $r=.56^{* * *}$ \\
& Follow-up & 176 & $3.55(.68)$ & & \\
\hline
\end{tabular}

Note. ${ }^{*} p<.05 . * * p<.01 . * * * p<.001$.

Table 18

Unstandardized Coefficients and Standard Deviations for Regression Models Predicting FollowUp Assessments

\begin{tabular}{lcc}
\hline & Trait SC follow-up & $\underline{\text { Implicit beliefs at follow-up }}$ \\
\hline Model summary & $F(2,173)=229.63, p<.001$ & $F(2,173)=40.71, p<.001$ \\
& $R^{2}=.73$ & $R^{2}=.32$ \\
\hline Implicit belief at baseline & beta (se) & beta (se) \\
Trait self-control baseline & $.09(.04)^{*}$ & $.49(.07)^{* * *}$ \\
\hline
\end{tabular}

Note. $* p<.05$. $* * p<.01 . * * * p<.001$. 
Table 19

Frequencies of Number of Reasons for Missing Surveys of $N=126$

\begin{tabular}{lcc}
\hline Number of Reasons Missed Surveys & $\underline{n}$ & $\underline{\%}$ \\
\hline One & 36 & 28.6 \\
Two & 34 & 27.0 \\
Three & 31 & 24.6 \\
Four & 18 & 14.3 \\
Five & 5 & 4.0 \\
Six & 2 & 1.6 \\
\hline
\end{tabular}


Table 20

Frequencies of Each Reason for Missing Surveys

\begin{tabular}{|c|c|c|}
\hline & $\frac{\text { Frequencies }}{\underline{N=126}}$ & $\frac{\text { Percent of participants who }}{\text { selected each reason }}$ \\
\hline Reason for missing survey & $\underline{n}$ & $\underline{\%}$ \\
\hline $\begin{array}{l}\text { Was unable to respond at time it was } \\
\text { sent }\end{array}$ & 99 & 46.3 \\
\hline $\begin{array}{l}\text { At work/ job/ internship during } \\
\text { reporting period }\end{array}$ & 40 & 18.7 \\
\hline In class during reporting period & 54 & 25.2 \\
\hline Lost phone during reporting period & 2 & .9 \\
\hline $\begin{array}{l}\text { Phone had dead battery during } \\
\text { reporting period }\end{array}$ & 17 & 7.9 \\
\hline $\begin{array}{l}\text { Did not realize I was sent a text } \\
\text { message until reporting period ended }\end{array}$ & 63 & 29.4 \\
\hline $\begin{array}{l}\text { The survey did not load properly on my } \\
\text { phone, so it could not be filled out }\end{array}$ & 9 & 4.2 \\
\hline Did not want to respond at that time & 12 & 5.6 \\
\hline Did not like answering surveys & 3 & 1.4 \\
\hline Other & 7 & 3.3 \\
\hline
\end{tabular}


Table 21

Correlations or T-Tests Between Percent of Texted Surveys Completed and Key Study Variables

\begin{tabular}{lc} 
Demographics & Correlations or t-tests \\
\hline Age & $-.13^{+}$ \\
College year & -.08 \\
Gender (male vs female) & $t(211)=.71, p=.48$ \\
Race (White vs non-White) & $t(212)=.04, p=.97$ \\
\hline Key Predictors & \% Surveys Completed \\
\hline Total Risk & $-.14^{*}$ \\
Implicit Belief & $.15^{*}$ \\
Trait SC & $.13^{+}$ \\
\hline Separate risks & \% Surveys Completed \\
\hline Edu Caregiver 1 & .05 \\
Edu Caregiver 2 & .09 \\
SES ladder & .01 \\
Difficulty paying bills & -.03 \\
Chaos & $-.15^{*}$ \\
Avoidant Caregiver 1 & $-.19^{* *}$ \\
Anxious Caregiver 1 & $-.17^{*}$ \\
Avoidant caregiver 2 & -.05 \\
Anxious caregiver 2 & .01 \\
\hline
\end{tabular}

Note. $p<.07^{+} . p<.05^{*}, p<.01^{* *}, \mathrm{p}<.001^{* * *}$. Total risk is $\log$ transformed. SC $=$ Self-control. 


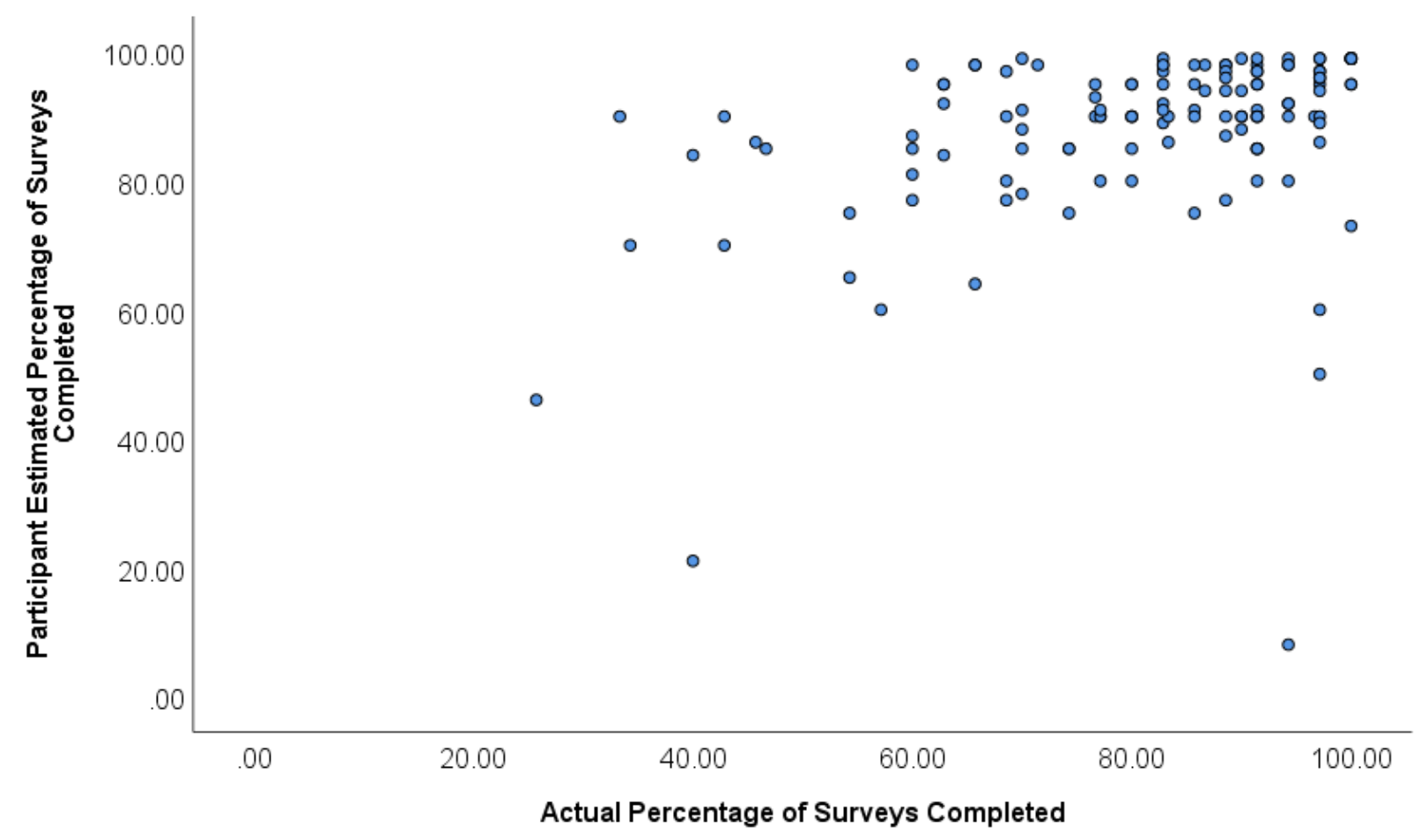

Figure 8. Scatterplot showing positive correlation $(r=.36, p<.001, n=126)$ between participant estimated percentage of texted surveys completed and tracked percentage of surveys completed. 


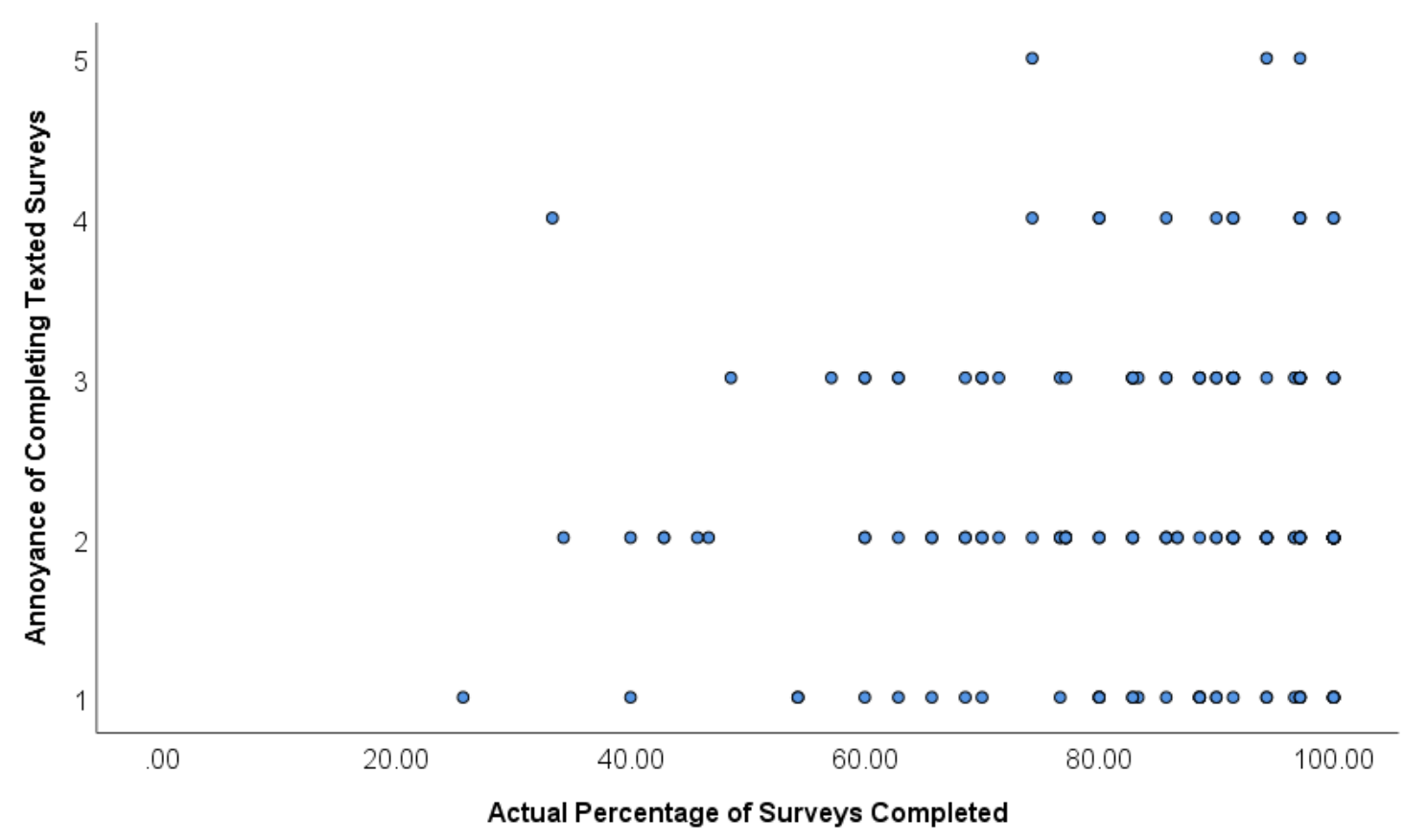

Figure 9. Scatterplot showing relationship between tracked percentage of surveys completed and how annoying or disruptive answering the texted surveys was for participants $(1=$ not at all to 5 = extremely annoying or disruptive. 


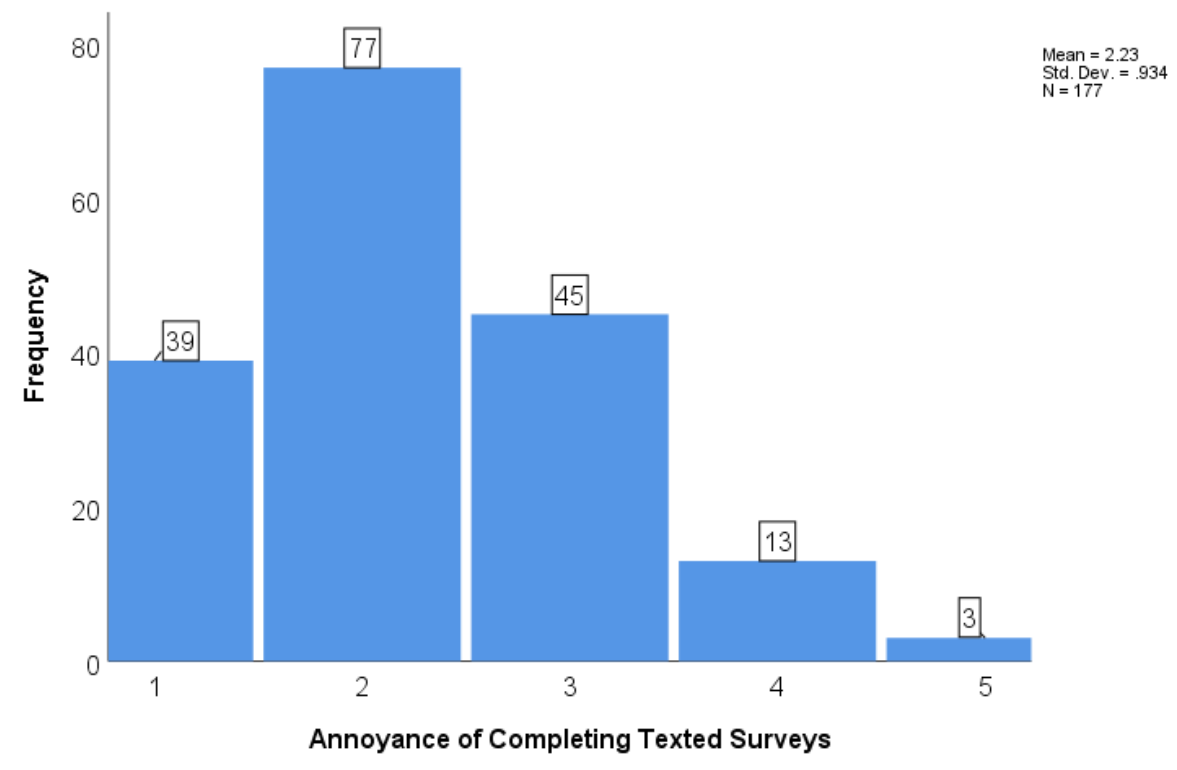

Figure 10. Frequency of participants who reported each level of annoyance in answering texted surveys. 


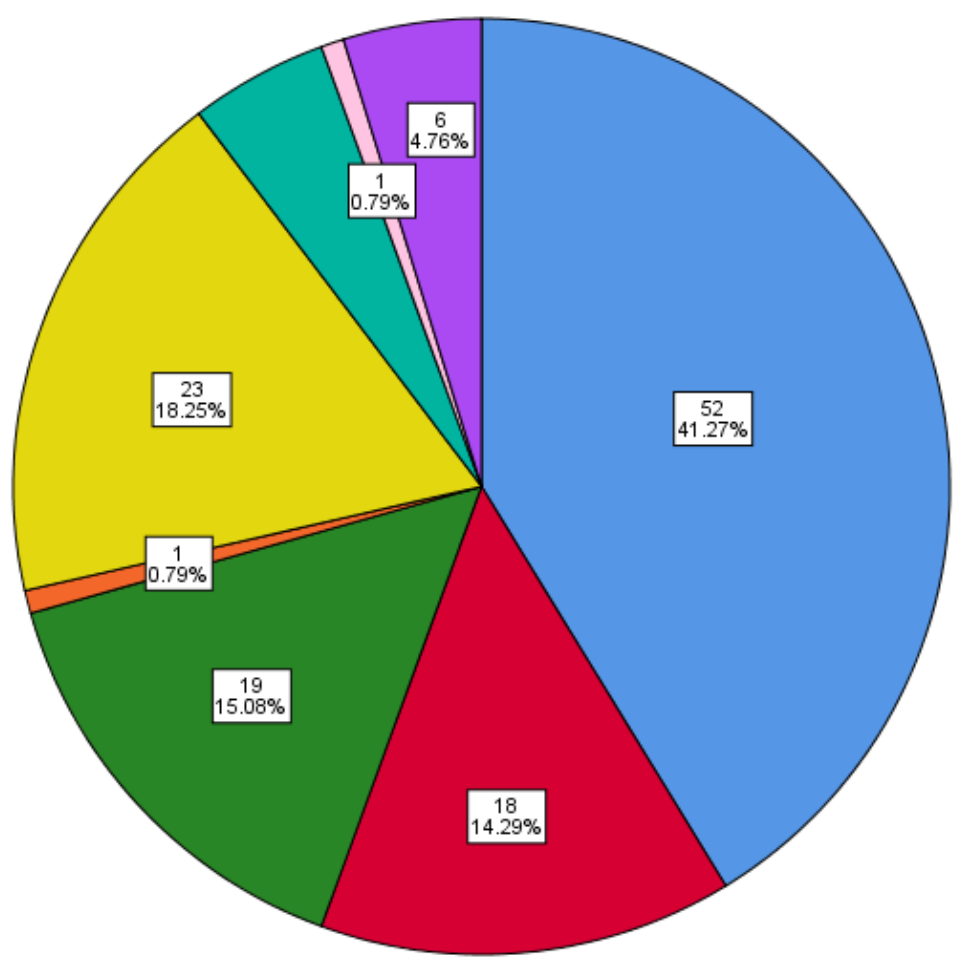

Reasons for Not Answering Texted Surveys

$\square$ Was unable to respond at the time it was sent.

At work/job/internship during reporting period.

$\square$ In class during reporting period.

$\square$ Phone had a dead battery during reporting period

Did not realize I was sent a $\square$ text message until reporting period ended.

$\square$ Did not want to respond at that time.

$\square$ Did not like answering the surveys.

$\square$ other?

Figure 11. Frequency of participants who reported each reason as their most common reason for missing surveys. 


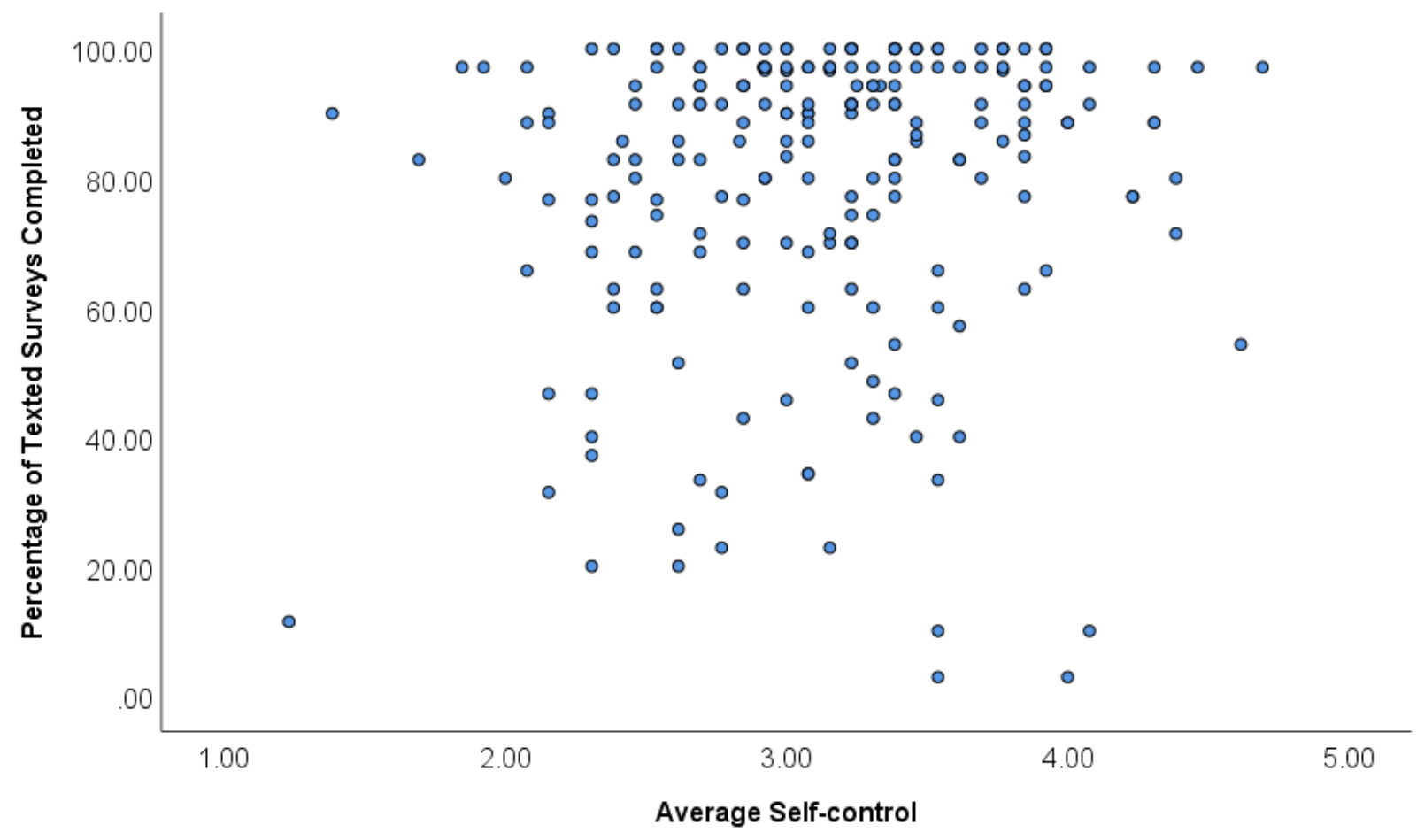

Figure 12. Scatterplot showing the relationship $(r=.16, p=.069, n=214)$ between self-control and tracked percentage of texted surveys completed. 
Table 22. Participant open-ended responses to "What overall comments do you have about

participating in the text messaged surveys?"

\begin{tabular}{|c|c|c|}
\hline Posi & Mixed & ents \\
\hline $\begin{array}{l}\text { Lots of fun, very self } \\
\text { reflective } \\
\text { The surveys were easy to } \\
\text { finish } \\
\text { Quick and Easy } \\
\text { They were kinda fun. They } \\
\text { made me realize the good } \\
\text { things that happened in my } \\
\text { days. } \\
\text { I thought they were } \\
\text { interesting. } \\
\text { It made me think of my self } \\
\text { control more than I typically } \\
\text { would } \\
\text { It was a good experience and } \\
\text { helpful for my psychology } \\
\text { class requirements } \\
\text { Was interesting evaluating } \\
\text { my cravings } \\
\text { They were creative and made } \\
\text { me think of my day to day life } \\
\text { in a different and more } \\
\text { analytic way } \\
\text { It really made me think about } \\
\text { what I was desiring and how I } \\
\text { would resist the temptation. } \\
\text { They didn't get in the way of } \\
\text { my daily routine or activities } \\
\text { at all. They were short and } \\
\text { easy } \\
\text { it made me aware of myself } \\
\text { They were over all very easy } \\
\text { and not very time consuming } \\
\text { Great incite on being in touch } \\
\text { with how I felt every day } \\
\text { Made me stop and think about } \\
\text { - }\end{array}$ & $\begin{array}{l}\text { It was an annoyance at } \\
\text { times, but for the most } \\
\text { part they happened at } \\
\text { times when I wasn't } \\
\text { super busy. Because I } \\
\text { knew I was gaining } \\
\text { extra credit I was less } \\
\text { of an annoyance. } \\
\text { They were a minor } \\
\text { inconvenience but they } \\
\text { felt really annoying. I } \\
\text { was bored of taking } \\
\text { them, and I wanted to } \\
\text { answer about multiple } \\
\text { desires sometimes, but } \\
\text { I couldn't. Also, they } \\
\text { made me realize that } \\
\text { I'm actually hungry all } \\
\text { the time. I had to } \\
\text { acknowledge my own } \\
\text { actions. } \\
\text { I thought they were } \\
\text { effective but } \\
\text { sometimes annoying } \\
\text { and hard to answer at } \\
\text { some points } \\
\text { I enjoyed it, but after a } \\
\text { few days the surveys } \\
\text { became tedious. } \\
\text { I enjoyed participating } \\
\text { in the text messages } \\
\text { surveys, although it } \\
\text { was sometimes } \\
\text { difficult to gauge what } \\
\text { time period to base the } \\
\text { responses on }\end{array}$ & $\begin{array}{l}\text { - Too many surveys } \\
\text { throughout the day } \\
\text { - } \text { Came at inconvenient times } \\
\text { Don't repetitively make } \\
\text { people answer so many } \\
\text { emotions everyday. } \\
\text { the amount of surveys i had } \\
\text { to take was HORRIBLE } \\
\text { The texted surveys were } \\
\text { very repetitive. } \\
\text { Not as many in one day } \\
\text { I think participants should } \\
\text { be able to choose more } \\
\text { than one desire they're } \\
\text { having at that time when } \\
\text { texted. } \\
\text { I did not experience the } \\
\text { desires that tend to get me } \\
\text { into trouble during the text } \\
\text { messaging period but after } \\
\text { participating I believe I am } \\
\text { more willing and able to } \\
\text { resist these desires } \\
\text { The surveys were a little } \\
\text { difficult to complete on a } \\
\text { smart phone. } \\
\text { The text messages would } \\
\text { first, but got very old quick } \\
\text { was in class and I couldn't } \\
\text { answer them or they were } \\
\text { sent at a busy time of day. } \\
\text { It would have been nicer to } \\
\text { get a warning of when the } \\
\text { text message would be sent } \\
\text { co it wouldn't interfere with } \\
\text { - }\end{array}$ \\
\hline
\end{tabular}




\section{Appendix G}

\section{Exploratory Comparisons Among Final Sample and Sub-samples}

Table 23

Chi-Square Tests Comparing People Who Reported Any Desires During the Week of Texted Surveys Versus Excluded Participants that Reported 0 Desires

\begin{tabular}{|c|c|c|c|c|}
\hline & & $\frac{\frac{\text { Participants that }}{\text { had 0 desires }}}{\frac{\text { reported }}{N(\%)}}$ & $\begin{array}{l}\frac{\frac{\text { Participants that }}{\text { reported at least } 1}}{\underline{\text { desire }}} \\
\underline{N(\%)}\end{array}$ & $\underline{\text { Total N of }}$ \\
\hline \multirow[t]{3}{*}{ Gender } & Chi-square & $.17, d f=1, p=.14$ & & 238 \\
\hline & Male & $2(4.4 \%)$ & $43(95.6 \%)$ & 45 \\
\hline & Female & $23(11.9 \%)$ & $170(88.1 \%)$ & 193 \\
\hline \multirow[t]{3}{*}{ Race/Ethnicity } & Chi-square & $30, d f=1, p=.58$ & & 239 \\
\hline & White & $21(10.0 \%)$ & $188(90.0 \%)$ & 209 \\
\hline & Non-White & $4(13.3 \%)$ & $26(86.7 \%)$ & 30 \\
\hline
\end{tabular}


Table 24

Comparisons of Participants Who Reported Any Desires During the Week of Texted Surveys Versus Excluded Participants that Reported 0 Desires

\begin{tabular}{|c|c|c|c|c|c|}
\hline Variables & & $\underline{\mathrm{N}}$ & Mean (SD) & $\mathrm{t}(\mathrm{df})=$ & p-value \\
\hline Age & 0 desires & $\overline{25}$ & $19.16(1.03)$ & $t(236)=.21$ & $p=.83$ \\
\hline & At least 1 desire & 213 & $19.11(1.17)$ & & \\
\hline College Year & 0 desires & 25 & $1.96(.93)$ & $t(237)=.84$ & $p=.40$ \\
\hline & At least 1 desire & 214 & $1.79(.93)$ & & \\
\hline Total early risk & 0 desires & 25 & $1.76(1.54)$ & $t(237)=-.04$ & $p=.97$ \\
\hline & At least 1 desire & 214 & $1.77(1.45)$ & & \\
\hline Beliefs & 0 desires & 25 & $3.62(.48)$ & $\mathrm{t}(236)=.75$ & $p=.45$ \\
\hline & At least 1 desire & 213 & $3.51(.74)$ & & \\
\hline Self-control & 0 desires & 25 & $3.22(.49)$ & $\mathrm{t}(237)=.77$ & $p=.44$ \\
\hline & At least 1 desire & 214 & $3.12(.61)$ & & \\
\hline Edu1 & 0 desires & 25 & $8.00(1.56)$ & $\mathrm{t}(237)=.59$ & $p=.55$ \\
\hline & At least 1 desire & 214 & $7.79(1.73)$ & & \\
\hline Edu2 & 0 desires & 21 & $7.14(2.10)$ & $\mathrm{t}(205)=-1.50$ & $p=.14$ \\
\hline & At least 1 desire & 186 & $7.74(1.69)$ & & \\
\hline SES ladder & 0 desires & 25 & $7.36(1.85)$ & $\mathrm{t}(237)=1.80$ & $p=.07$ \\
\hline & At least 1 desire & 214 & $6.79(1.47)$ & & \\
\hline Difficulty & 0 desires & 25 & $1.84(1.11)$ & $\mathrm{t}(236)=-.14$ & $p=.89$ \\
\hline & At least 1 desire & 213 & $1.87(.92)$ & & \\
\hline Chaos & 0 desires & 25 & $5.04(3.56)$ & $\mathrm{t}(237)=.59$ & $p=.56$ \\
\hline & At least 1 desire & 214 & $4.55(4.02)$ & & \\
\hline Avoidance 1 & 0 desires & 25 & $2.27(1.23)$ & $\mathrm{t}(236)=-.76$ & $p=.50$ \\
\hline & At least 1 desire & 213 & $2.47(1.29)$ & & \\
\hline Anxious 1 & 0 desires & 25 & $1.71(1.06)$ & $\mathrm{t}(236)=.99$ & $p=.33$ \\
\hline & At least 1 desire & 213 & $1.49(1.05)$ & & \\
\hline Avoidance 2 & 0 desires & 21 & $3.02(1.57)$ & $t(206)=-.82$ & $p=.42$ \\
\hline & At least 1 desire & 187 & $3.31(1.59)$ & & \\
\hline Anxious 2 & 0 desires & 21 & $1.90(1.60)$ & $\mathrm{t}(206)=.41$ & $p=.68$ \\
\hline & At least 1 desire & 187 & $1.77(1.41)$ & & \\
\hline
\end{tabular}

Note. All independent t-tests comparing means on variables of those who reported 0 desires to rest of sample are non-significant. 
Table 25

Chi-Square Tests Comparing Final Sample Versus Excluded Participants That Only Completed the Baseline Survey

\begin{tabular}{|c|c|c|c|c|}
\hline & & $\frac{\text { Final Sample }}{\underline{N(\%)}}$ & $\begin{array}{c}\text { Baseline Survey } \\
\underline{\text { Only }} \\
\underline{N(\%)}\end{array}$ & $\underline{\text { Total N of }}$ \\
\hline \multirow[t]{3}{*}{ Gender } & Chi-square & $d f=1, p=.64$ & & 364 \\
\hline & Male & $48(4.4 \%)$ & $24(95.6 \%)$ & 72 \\
\hline & Female & $203(11.9 \%)$ & $89(88.1 \%)$ & 292 \\
\hline \multirow[t]{3}{*}{ Race/Ethnicity } & Chi-square & $, d f=1, p=.58$ & & 367 \\
\hline & White & $221(10.0 \%)$ & $100(90.0 \%)$ & 321 \\
\hline & Non-White & $32(13.3 \%)$ & $14(86.7 \%)$ & 46 \\
\hline
\end{tabular}


Table 26

T-test Comparisons of Final Sample Versus Excluded Participants That Only Completed the Baseline Survey

\begin{tabular}{|c|c|c|c|c|c|}
\hline \multicolumn{2}{|l|}{ Variables } & \multirow{2}{*}{$\frac{\mathrm{N}}{252}$} & \multirow{2}{*}{$\frac{\text { Mean }(\mathrm{SD})}{19.12(1.14)}$} & $\underline{\mathrm{t}(\mathrm{df})=}$ & p-value \\
\hline \multirow[t]{2}{*}{ Age } & Final Sample & & & $\mathrm{t}(363)=-.98$ & $p=.33$ \\
\hline & Baseline Only & 113 & $19.25(1.33)$ & & \\
\hline \multirow[t]{2}{*}{ College Year } & Final Sample & 253 & $1.81(.93)$ & $\mathrm{t}(365)=.20$ & $p=.85$ \\
\hline & Baseline Only & 114 & $1.79(.97)$ & & \\
\hline \multirow[t]{2}{*}{ Total early risk } & Final Sample & 253 & $1.79(1.45)$ & $\mathrm{t}(365)=-.11$ & $p=.91$ \\
\hline & Baseline Only & 114 & $1.82(1.30)$ & & \\
\hline \multirow[t]{2}{*}{ Beliefs } & Final Sample & 252 & $3.51(.72)$ & $\mathrm{t}(364)=-.02$ & $p=.98$ \\
\hline & Baseline Only & 114 & $3.51(.67)$ & & \\
\hline \multirow[t]{2}{*}{ Self-control } & Final Sample & 253 & $3.11(.61)$ & $t(237)=-.65$ & $p=.51$ \\
\hline & Baseline Only & 114 & $3.16(.64)$ & & \\
\hline \multirow[t]{2}{*}{ Edu1 } & Final Sample & 253 & $7.81(1.70)$ & $\mathrm{t}(364)=1.40$ & $p=.16$ \\
\hline & Baseline Only & 213 & $7.54(1.82)$ & & \\
\hline \multirow[t]{2}{*}{ Edu2 } & Final Sample & 219 & $7.63(1.77)$ & $\mathrm{t}(309)=1.37$ & $p=.17$ \\
\hline & Baseline Only & 92 & $7.32(2.02)$ & & \\
\hline \multirow[t]{2}{*}{ SES ladder } & Final Sample & 253 & $6.87(1.85)$ & $\mathrm{t}(365)=.44$ & $p=.67$ \\
\hline & Baseline Only & 114 & $6.80(1.47)$ & & \\
\hline \multirow{2}{*}{$\begin{array}{l}\text { Difficulty } \\
\text { paying bills }\end{array}$} & Final Sample & 252 & $1.85(.93)$ & $\mathrm{t}(364)=-.39$ & $p=.70$ \\
\hline & Baseline Only & 214 & $1.89(.92)$ & & \\
\hline \multirow[t]{2}{*}{ Chaos } & Final Sample & 253 & $4.62(3.93)$ & $\mathrm{t}(365)=.58$ & $p=.56$ \\
\hline & Baseline Only & 114 & $4.38(3.15)$ & & \\
\hline \multirow[t]{2}{*}{ Avoidance 1} & Final Sample & 252 & $2.49(1.31)$ & $\mathrm{t}(363)=-.71$ & $p=.48$ \\
\hline & Baseline Only & 113 & $2.59(1.41)$ & & \\
\hline \multirow[t]{2}{*}{ Anxious 1} & Final Sample & 252 & $1.54(1.07)$ & $\mathrm{t}(363)=-1.25$ & $p=.21$ \\
\hline & Baseline Only & 113 & $1.70(1.38)$ & & \\
\hline \multirow[t]{2}{*}{ Avoidance 2} & Final Sample & 220 & $3.29(1.57)$ & $\mathrm{t}(308)=1.35$ & $p=.21$ \\
\hline & Baseline Only & 90 & $3.05(1.51)$ & & \\
\hline \multirow[t]{2}{*}{ Anxious 2} & Final Sample & 220 & $1.81(1.44)$ & $\mathrm{t}(308)=-.76$ & $p=.45$ \\
\hline & Baseline Only & 90 & $1.96(1.70)$ & & \\
\hline
\end{tabular}

Note. All independent t-tests comparing means on variables of participants in the final saple compared to the larger baseline sample are non-significant. 


\section{Appendix $\mathrm{H}$}

Primary Analyses with Original Resistance Success Measure

Table 27

Unstandardized Coefficients and Standard Errors for Regression Models of Level 1 and Level 2 Predictors on Original Momentary Self-Control

\begin{tabular}{|c|c|c|c|c|c|}
\hline \multirow[t]{2}{*}{$\underline{\text { Variables }}$} & \multirow[t]{2}{*}{$\underline{\text { Mull }}$} & $\frac{\frac{\text { Random }}{\text { Intercept }}}{\frac{\text { Model with }}{\text { Level 1 }}}$ & \multicolumn{3}{|c|}{$\frac{\text { Random Intercept Models Including Level } 1}{\text { and Level } 2 \text { Predictors }}$} \\
\hline & & beta (se) & beta (se) & beta (se) & beta (se) \\
\hline Desire strength & -- & $-.31 * * *(.04)$ & $-.31 * * *(.04)$ & $-.31 * * *(.04)$ & $-.31 * * *(.04)$ \\
\hline $\begin{array}{l}\text { Goal } \\
\text { importance }\end{array}$ & -- & $.21 * * *(.05)$ & $.21 * * *(.05)$ & $.21 * * *(.05)$ & $.21 * * *(.05)$ \\
\hline Early risk & -- & -- & $-.52 *(.22)$ & -- & $-.44^{+}(.23)$ \\
\hline Implicit Belief & -- & -- & -- & $.13^{+}(.07)$ & $.11(.08)$ \\
\hline Risk x Belief & -- & - & -- & -- & $-.25(.30)$ \\
\hline $\begin{array}{c}\text { Residual } \\
\text { variance } \\
\text { (unexplained) }\end{array}$ & $85.65 \%$ & $83.26 \%$ & $83.61 \%$ & $83.77 \%$ & $83.59 \%$ \\
\hline
\end{tabular}

Note. ${ }^{+} p=.06 . * p<.05 . * * p<.01 . * * * p<.001$. 


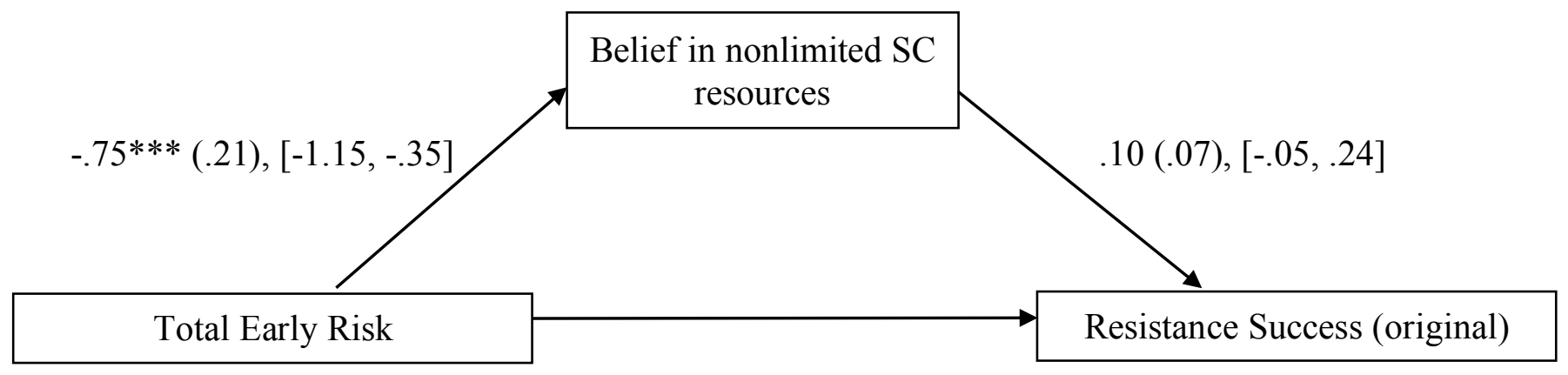

Direct Effect: $-.45 *(.21),[-.86,-.04]$

Indirect Effect: $.07(.06),[-.19, .04]$

Figure 13. Mediational model with total early risks, implicit belief about SC (higher values indicate stronger nonlimited belief), and resistance success (higher values indicate greater success resisting desires). Model includes level one variables predicting resistance success (desire strength, $b=-.31$, se $=.04, p<.001$, CI [-0.39, -0.23], and goal importance, $b=.21$, se $=$ $.06, p<.001, \mathrm{CI}[0.10,0.31])$. The confidence interval values of the indirect effect include zero, indicating that the indirect effect is non-significant.

Note. $* p<.05 . * * p<.01$. 